\title{
Journeys into Teaching: Pathways Created by Overseas-Trained Teachers into a Career Secondary School Teaching in New Zealand
}

\author{
Celia Elaine Stanyon \\ A four paper thesis submitted in \\ partial fulfilment of the \\ requirements of the \\ Master of Education \\ Victoria University of Wellington \\ 22 August 2013
}




\section{Abstract}

New Zealand-trained teachers have good reasons to teach abroad, change careers or retire and there are sound reasons to hire overseas-trained teachers (OTTs) to fill vacancies. Securing work in a new country can be difficult and it makes social and economic sense to facilitate this process. This thesis reports on the journeys of six OTTs documenting the individual pathways navigated; from teaching in their country of origin to securing a permanent placement as a secondary school teacher in New Zealand.

This study explores the pathways OTTs navigated in order to teach in New Zealand. It investigates the challenges they faced, the supports they encountered and the suggestions they had to offer others in a similar situation. The participants were OTTs at secondary schools in the Wellington region of New Zealand and most had emigrated from the United Kingdom. Participants taught different subjects and had varying lengths of teaching experience. They had immigrated to and successfully found a post in New Zealand between January 2006 and January 2012.

The interpretive paradigm was used as the theoretical grounding for this research as this places importance on the subjective experiences of those interviewed. Qualitative data were collected using semi-structured interviews as part of a collective, case study design. A thematic approach to data analysis was used and the data were compared and contrasted under the themes of challenges, supports and suggestions.

Findings that concurred with previous research were that OTTs faced challenges from bureaucracy, culture shock and financial stress; and that networking, professional development, luck and maintaining a positive attitude were supportive. Participants suggested preparation, networking, interagency co-operation, a positive attitude and relief teaching could assist other OTTs. The findings were used to formulate a suggested pathway that might facilitate the journeys of future OTTs. 


\section{Acknowledgements}

This thesis could not have been completed without a network of very special people whom I have the privilege of knowing.

First, I would like to thank my primary supervisor, Anne Yates, for her kind, considerate and thoughtful guidance through the writing process. I am immensely fortunate and grateful to have been given the opportunity to work with her. Second, I would like to thank my secondary supervisor, Professor Dugald Scott. I would like to thank him for his input into this thesis. Third, thanks to Deborah Laurs at Student Learning Support for encouraging me to find my "voice" and use it.

I owe the participants a debt of gratitude for their willingness to share their stories with me. It was interesting and enjoyable listening to their narratives about forging a teaching career in their country of choice.

I would like to thank my friends. Thanks to, Lawrence Viljoen, whose common sense approach helped me to write more accessibly. Thank you to, Nicola Hare, for her careful, considered and invaluable input. Thanks to, Tanya Matthews, for providing immense help with grammar and punctuation. Thank you to, Linda Porter, for sharing hints and tips about desktop publishing that helped to shape this thesis into a presentable format.

To my beloved husband, Charles Young, thank you for your support. Thank you for the time and space to think and write, and for the laughter and dinner dates that encouraged me through these past two years. I would like to thank my wonderful family for their encouragement and their steadfast belief that I could complete this thesis.

To my friends and colleagues, thank you for your support. 


\section{Contents}

Abstract

Acknowledgements

Contents

Abbreviations

Definition of terms

\section{Chapter 1: Introduction}

1.1 Introduction

1.2 Background: locating oneself in the study

1.3 Context 3

Why the education sector loses teachers 3

Employing OTTs is a solution.

Immigration at a glance.

Pathways

Barriers to OTTs securing employment

1.4 Rationale

1.5 Research topic

1.6 Overview of thesis.

\section{Chapter 2: Literature Review}

2.1 Introduction

2.2 International perspectives on the recruitment of OTTs

2.3 Challenges

Bureaucracy

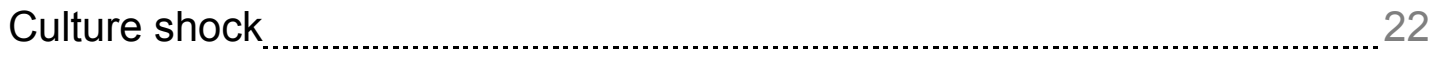

2.4 Supports

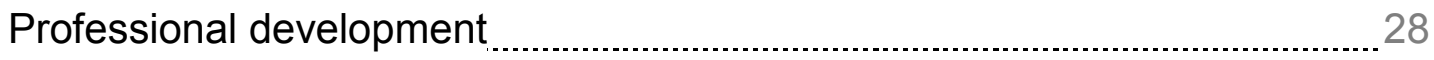

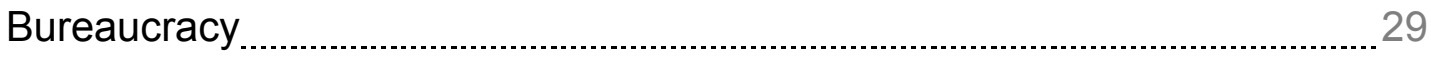


Networks

2.5 Conclusion

\section{Chapter 3: Method}

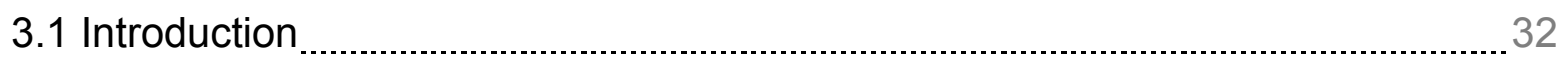

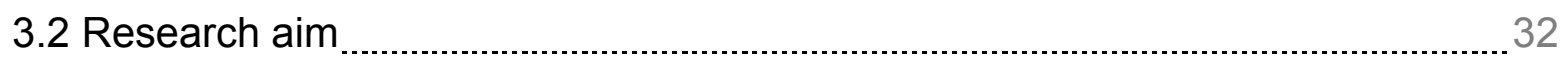

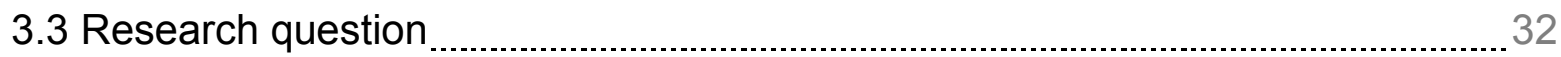

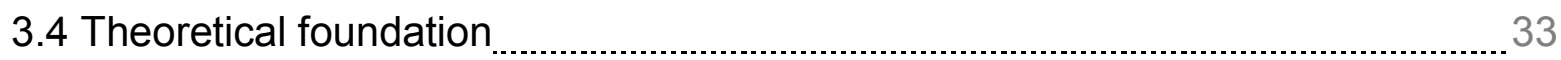

3.5 Research design

3.6 Selection of participants

3.7 Limitations

3.8 Ethical considerations $\ldots$

3.9 Data gathering

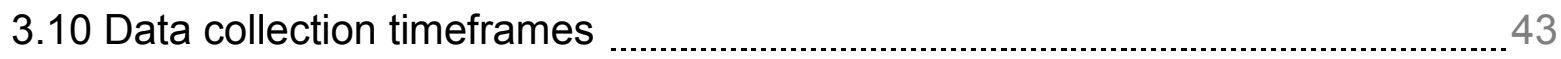

3.11 Managing and recording data

3.12 Analysis of data

3.13 Comparing and contrasting data

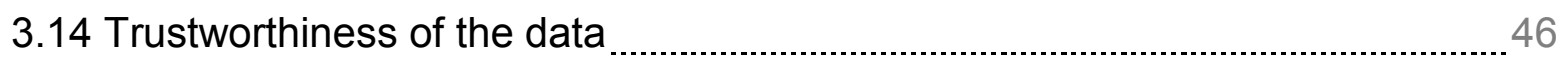

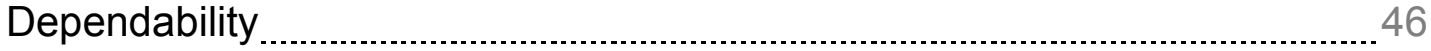

Trustworthiness

3.15 Summary $\quad 48$

\section{Chapter 4: Findings}

4.1 Introduction

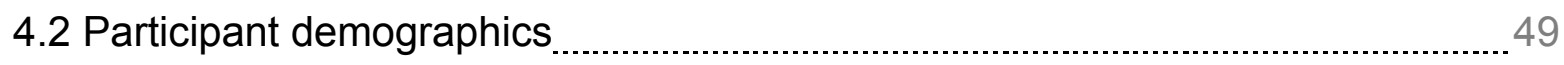

4.3 Tom"s journey

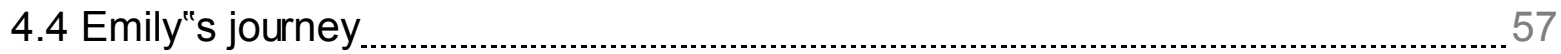

4.5 Alabama"s journey

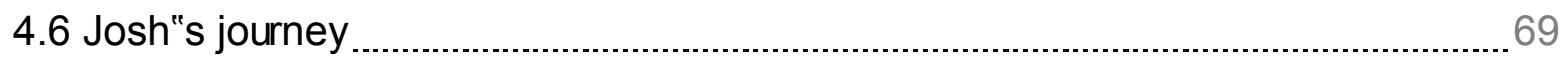

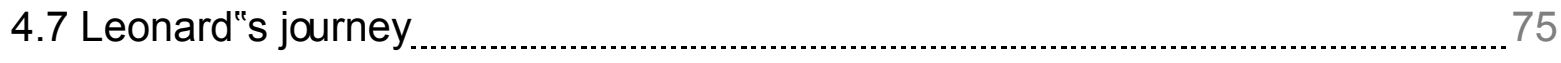


4.8 Doug"s journey

4.9 Pathways

4.10 Themes

4.11 Challenges

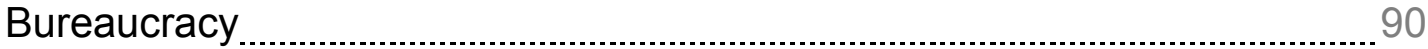

Culture shock

Finance

Lack of subject experience $\ldots$

4.12 Supports $\quad 94$

Networks

Preparation $\ldots$

Luck

Teaching subjects

Natural environment

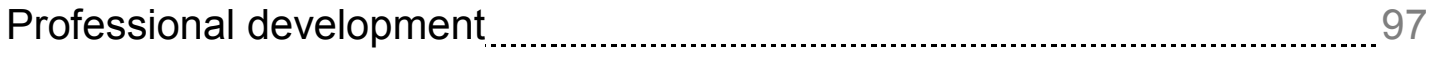

4.13 Suggestions

Preparation _ $\quad 98$

Networks

Interagency co-operation ..................................................................................... 100

Positive attitude

Relief teach

4.14 Conclusion

\section{Chapter 5: Discussion}

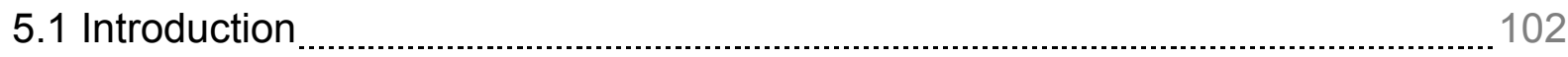

5.2 Challenges

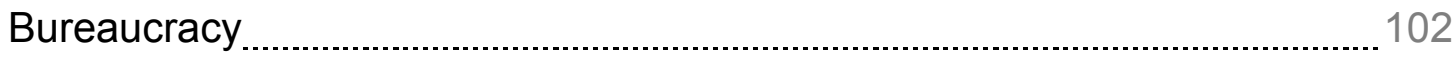

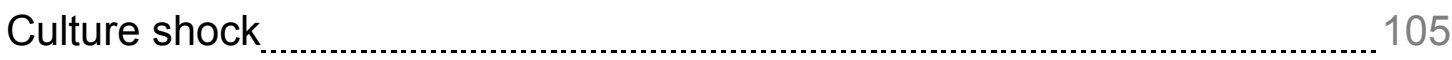

Finance

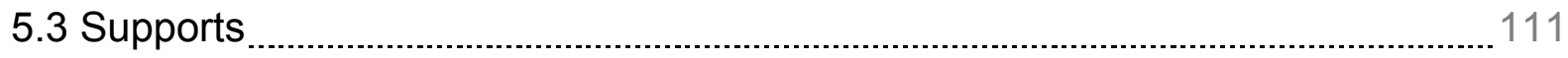

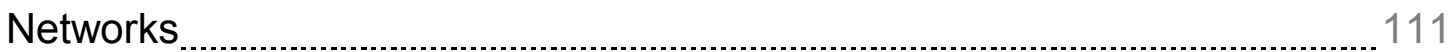

Contents $\quad$ v | Page


Preparation

Teaching subject

Luck and a positive attitude.

Natural environment

Professional development

5.4 Suggested pathway

5.5 Conclusion

\section{Chapter 6: Conclusion}

6.1 Summary

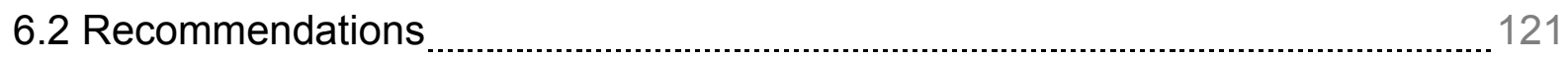

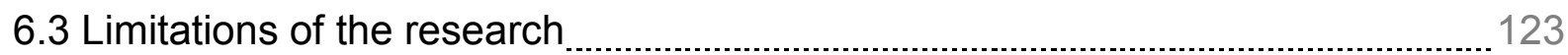

6.4 Future research $\quad 124$

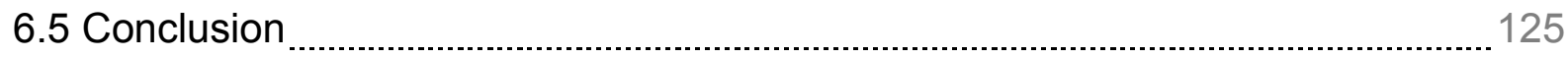

\section{References}

\section{Appendices}

Appendix A: Information sheet for participants

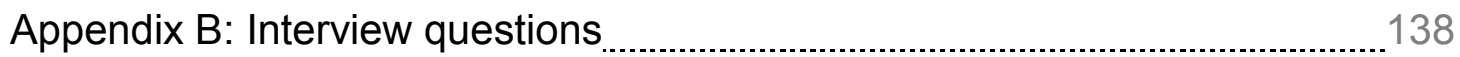

Appendix C: Consent form ................................................................................. 140

Appendix D: Data collection calendar ................................................................ 142

Appendix E: Research journal - entry 1 ........................................................... 143 


\section{List of tables}

Table 1: Participant demographics

Table 2: Themes

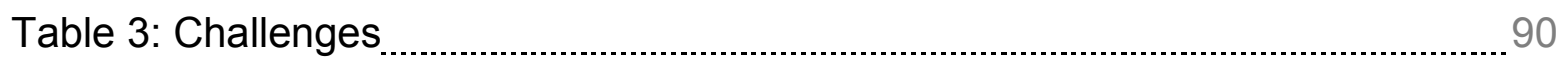

Table 4: Supports

Table 5: Suggestions

\section{List of figures}

Figure 1: Three-step pathway

Figure 2: Five-step pathway

Figure 3: Gateways and pathways

Figure 4: Tom"s pathway

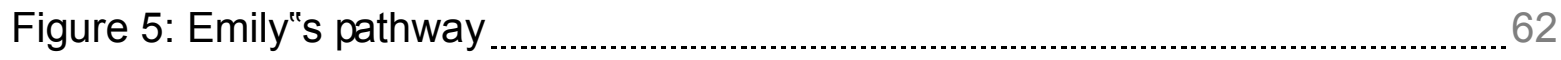

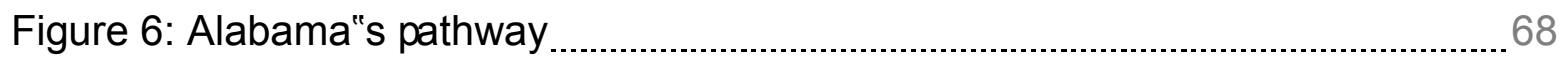

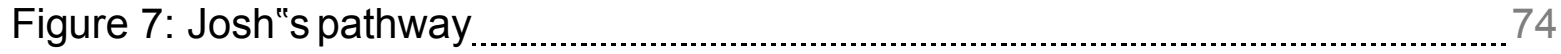

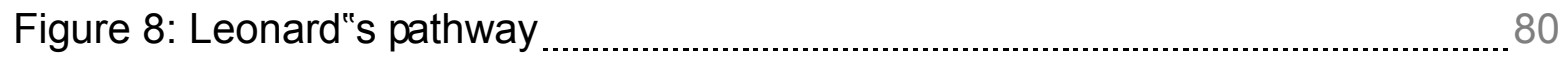

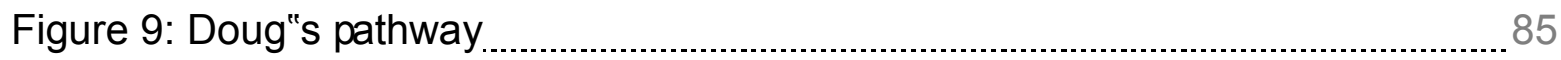

Figure 10: Pathways

Figure 11: Suggested pathway ............................................................................... 118 


\section{Abbreviations}

CV Curriculum vitae

EEO Equal Employment Opportunity

Eol Expression of Interest

INZ Immigration New Zealand

IRD Inland Revenue Department

IRG International Relocation Grant

MoE Ministry of Education

NCEA National Certificates of Educational Achievement

NUT National Union of Teachers

NZQA New Zealand Qualifications Authority

NZTC New Zealand Teachers Council

OTT Overseas-Trained Teacher

PCC Police Clearance Certificate

PRV Permanent Resident Visa

PTR Provisional Teacher Registration

SAU Salary Assessment Unit 


\section{Definition of Terms}

\section{Bureaucracy}

The meaning of the word, bureaucracy, in this context is administration involved in the immigration, registration and recruitment process for OTTs.

\section{Capital}

In this context the word, capital, is used in the Bourdieusian sense as a metaphor taken from economics to indicate value or wealth. This value is not in monetary terms but wealth in cultural and social terms; and these forms of capital have value through the perceptions of others (Grenfell, 2009).

\section{Commonwealth Teacher Recruitment Protocol}

The Commonwealth Teacher Recruitment Protocol calls for the rights of the recruiting country to be balanced against the rights of the source country and those of the OTT (Miller, Ochs \& Mulvaney, 2008).

\section{Cultural responsiveness}

Johnson (2003) explains that cultural responsiveness is underpinned by the principle, "that diverse ways of understanding and interpreting the world are an asset and a resource, not a liability; and that it is in the best interest of all learners to build on the strengths and experiences that children collectively bring to the classroom" (p. 24).

\section{Culture shock}

The term culture shock refers to difficulties an OTT faces as a consequence of a move to their country of choice. 


\section{National Certificates of Educational Achievement}

NCEA are national, standards-based qualifications in New Zealand for senior secondary school students (Shulruf, Hattie \& Tumen, 2008).

\section{Overseas-trained teacher}

For the purposes of this study an OTT is defined as a secondary school teacher who obtained their qualifications and taught for the duration of one year or more in a country other than New Zealand.

\section{Qualifications Assessment}

Applicants intending to teach are required to submit a Qualifications Assessment that has been completed by the New Zealand Qualifications Authority (NZQA), which establishes the level of their qualification as compared to qualifications obtained in $\mathrm{New}$ Zealand (INZ, 2012c).

\section{Salary Assessment}

In order to receive an appropriate salary an OTT applies for a Salary Assessment from the Salary Assessment Unit (SAU). This assessment reviews a teacher"s qualifications and experience and, based on these, determines their rate of pay (Novopay, n.d.).

\section{Transition process}

Transition is understood in this context as a move from one state to another and, in terms of immigration, this means a move from one country to another; thus, the term "transition process" is used here to incorporate OTTs" immigration, employment and integration. 


\section{Chapter 1: Introduction}

\subsection{Introduction}

We live in an age where people increasingly cross borders carrying useful skills. Diverse school populations mirror this crossing of borders. New Zealand teachers have good reason to want to teach overseas and there are good reasons for overseastrained teachers to want to teach in New Zealand. It makes both social and economic sense to have efficient systems in place to allow OTTs to find appropriate work in New Zealand. For the purposes of this study an overseas-trained teacher (OTT) is defined as a secondary school teacher who obtained their qualifications and taught for the duration of one year or more in a country other than New Zealand.

\subsection{Background: locating oneself in the study}

My husband and I immigrated to New Zealand in February 2007. I was the primary applicant on our application for Permanent Resident Visas (PRV) because my teaching qualification and experience earned our application bonus points. Having received a PRV and gained Provisional Teacher Registration (PTR), I started applying for teaching posts in the Education Gazette online six months prior to arriving in New Zealand; and I continued to apply once we had arrived in this country. I supplied my curriculum vitae (CV) to local schools and visited several principals so that they might put a face to my CV and perhaps call me for relief teaching. I started a Master"s degree in Education perceiving that a local qualification listed on my $\mathrm{CV}$ might assist in gaining an interview for a teaching post. In a tutorial I asked for some guidance applying for teaching work. A lecturer supplied me with a flyer indicating steps for a newly qualified teacher to follow in order to gain employment. I was given de-identified CVs by a fellow student to assist in the rewriting of my $\mathrm{CV}$ for the New Zealand context. I rewrote my CV and gained two 
interviews in September 2009. I was unsuccessful at securing either post due to my lack of New Zealand teaching experience.

A friend with whom I attended university immigrated to New Zealand in January 2010. She was the primary applicant on an application for PRV that she and her husband submitted because her teaching qualification and experience earned their application bonus points. I supplied her with the flyer and de-identified CVs that I had been given and she rewrote her CV. She started applying for teaching posts listed in the Education Gazette online prior to arriving in New Zealand and continued applying subsequent to her arrival in this country. One of her husband"s colleagues supplied the contact details of a retired principal with whom she met. This retired principal assisted her with further editing of her CV. Subsequent to reviewing her CV she was invited for two interviews at two different schools and was awarded a part-time, fixed-term teaching position at one of those schools. This placement came after three months of living in New Zealand. The same school that awarded her a part-time position offered her a full-time, permanent teaching position after she had taught at the school for one year.

The differences in our experiences led me to think about how other OTTs" experiences might differ and how they had found their way, from arriving in New Zealand with the right to live and work in this country, to gaining full-time, permanent employment as a teacher. 


\subsection{Context}

The education sector loses teachers for various reasons and hiring OTTs is a solution to resulting vacancies but barriers are encountered when OTTs seek work. In order to provide context for this study, some of the reasons why local teachers leave are discussed. This is followed by information about employing OTTs as a solution to teacher shortages. A summary of the immigration process is presented and a description of problems OTTs encounter when seeking work is provided.

\section{Why the education sector loses teachers}

The education sector loses teachers due to emigration, retirement and changes in profession and each of these will be discussed in turn.

Occupational mobility has increased and this time in human history has been described in international literature both as an age of globalisation (Cushner \& Mahon, 2002; Reimers, 2006; Zhao, 2009) and as a period of migration of people as they cross national borders (Olmeda \& Harbon, 2010). Worldwide, the education sector is affected by migration to the extent where teachers are described in academic literature as a mobile workforce (Appleton, Sives \& Morgan, 2006; Hess, 2009; McNamara, Lewis \& Howson, 2004).

New Zealand-trained teachers leave to teach abroad (Fisher, 2011) with a large proportion travelling to gain overseas experience. A quarter return after one year (Cameron, Baker \& Lovett, 2006) and some leave to teach abroad permanently. This trend has increased and Fisher reported in 2011 that the Post Primary Teachers Association data had shown the greatest volume of resignations for the purposes of relocating to teach overseas since 2001 when records began.

Emigration is one reason why teachers leave the teaching profession in New Zealand and retirement is another. Publications written in New Zealand and internationally report 
that the general population of this country will age over the next fifty years (Anderton, Maharey, Wilson, Dalziel \& Hobbs, 2003; Creedy, Enright, Gemmell \& Mellish, 2009; Guest, Bryant \& Scobie, 2003) and the teaching cohort is also described in international literature as an aging population (Cameron et al., 2006; Harker \& Chapman, 2006; Lonsdale \& Ingvarson, 2003; Voigt Graf, Iredale \& Khoo, 2009). The ongoing global economic crisis and the recession in New Zealand (Jones, 2009) were reported locally to have encouraged teachers close to retirement age to continue teaching (Lewis, 2010). However, as the economic climate normalises, retirements from teaching are projected to rise in this country (Lewis, 2010) and literature, written in New Zealand and internationally, concurs that the current number of student teachers enrolled is unlikely to be adequate (Anand \& Dewar, 2004; Harker \& Chapman, 2006; Lonsdale \& Ingvarson, 2003).

Emigration and retirement lead to attrition in teacher numbers, and a further contributing factor is changes in profession. There is a high turnover in the teaching profession in New Zealand (Barnes, Crowe \& Schaefer, 2007; Lonsdale \& Ingvarson, 2003; Kain, 2011). Teachers leave to gain more time with their families, and because of the volume of paperwork and assessments associated with this profession (Kersaint, Lewis, Potter \& Meisels, 2005). Some leave for financial benefits or because they receive little administrative support (Fisher, 2011), while others leave due to family responsibilities (Stinebrickner, 2002).

Above are three reasons why teachers leave the teaching profession in New Zealand and addressing those losses is made challenging because, in this country, the Education sector also faces difficulties attracting new teachers. These difficulties are because of the comparatively low remuneration teachers receive here (Education Counts, 2010; Hall \& Langton, 2006; Howard, 2009; Kane \& Mallon, 2006), due to the low status of local teacher education programmes (Cameron \& Baker, 2004) and of teaching as a profession in this country (Howard, 2009; Kane \& Mallon, 2006), and because of the high workload of teachers (Hall \& Langton, 2006; Howard, 2009; Kane \& Mallon, 2006). 
There is a loss of teachers but attracting new teacher candidates to address this is problematic. What follows is a discussion about employing OTTs as a solution to counter those losses.

\section{Employing OTTs is a solution}

The supply of teachers for New Zealand schools is dependent on a number of sources and one of those sources is OTTs (Ng, 2006). The Ministry of Education"s 2006 survey indicated that, each year, OTTs filled a third of the teaching vacancies in New Zealand ( $\mathrm{Ng}, 2006)$.

In Christchurch, the Aranui High School Principal was reported by Booker (2004) as saying that he was receiving few applications from New Zealand teachers and many from OTTs. The Mairehau High School principal indicated the likelihood that more OTTs would be employed in the future due to the lack of New Zealand-trained teachers available to fill vacancies (Brooker, 2004).

In Auckland the situation is similar. Auckland is the city with the largest population in New Zealand (De Wit, Loman, Faithfull \& Hinckson, 2012) and filling teaching positions in schools located in its Southern neighbourhoods, where there is a perception that difficult behaviour is widespread, can be especially problematic (Laxon, 2012). The short supply of New Zealand-trained teachers for some placements at South Auckland schools and the growing secondary school population has created a necessity for employing OTTs (Biggs, 2010).

Employing OTTs is not only useful to fill personnel gaps, as indicated above, it can also be beneficial for students from a social perspective; because the population of New Zealand is increasingly culturally diverse (Statistics New Zealand, 2002; Ward \& Masgoret, 2008) and international research indicates that there is a need for the teaching cohort of a country to reflect the diversity of its student population (Branch \& 
Kritsonis, 2006; Dei, 2002; Fenwick, 2001; Gifford, 2007). The benefits include that children from minority cultures have an opportunity to see themselves reflected in their teachers (Schmidt \& Block, 2010), and staff and students gain exposure to the diverse knowledge, experience and languages OTTs bring with them (Hartsuyker, 2007; Schmidt \& Block, 2010). Biggs (2010) reported that in New Zealand, "leaders were unanimous in their belief that OTTs added value to their schools" (p. 86).

There are shortfalls in teaching personnel and one way of addressing these is to hire OTTs. Hiring OTTs allows New Zealand students and teachers the benefit of exposure to new knowledge and experience. In order for OTTs to live and work in New Zealand there is an immigration process they are required to complete.

\section{Immigration at a glance}

Bedford (2003, p.66) explains that,

A „points system" similar to the ones implemented by Australia and Canada, was introduced in New Zealand in 1991. This system assesses and ranks prospective migrants on the basis of their qualifications, work experience, age, ability to settle, and English language ability.

OTTs interested in coming to New Zealand complete a self-assessment provided on Immigration New Zealand"s (INZ) website to ascertain whether they obtain sufficient points to qualify for selection to gain entry into this country (INZ, 2012a); and subsequently submit an Expression of Interest (Eol) to INZ. INZ selects some Eols and invites those applicants to submit an application for a Permanent Resident Visa (PRV). An application for a PRV requires submission of supporting documentation such as a birth certificate, passport and Police Clearance Certificate (PCC) (INZ, 2012b).

Applicants intending to teach are also required to submit a Qualifications Assessment that has been completed by the New Zealand Qualifications Authority (NZQA), which 
establishes the level of their qualification as compared to qualifications obtained in New Zealand (INZ, 2012c). OTTs are also required to obtain Teacher Registration from the New Zealand Teachers Council (NZTC), the professional, regulatory body for teachers in this country. There are three categories of teacher registration: Provisional, Subject to Confirmation and Full Registration. OTTs are often awarded registration in either of the first two categories that require oversight in a teaching environment for a couple of years before an application for Full Registration can be made.

OTTs can apply for teaching positions before, during or after submitting visa, qualifications and registration applications. Having a job offer before submitting an Eol attracts points in support of that application. However, if an offer of employment is received before receipt of a PRV, Qualifications Assessment and Teacher Registration that offer will be conditional on obtaining these, as it is illegal to work in New Zealand without these.

In order to receive an appropriate salary, an OTT applies for a Salary Assessment from the Salary Assessment Unit (SAU). This assessment reviews a teacher"s qualifications and experience and, based on these, determines their rate of pay (Novopay, n.d.). An Inland Revenue Department (IRD) number is advisable for OTTs receiving a salary in New Zealand so that the appropriate tax rate is payable. An IRD number is important because those without one pay a higher, no-declaration tax rate. An IRD number can be applied for once an OTT has a PRV (IRD, 2013).

OTTs can apply for the right to live and work in New Zealand by applying for a PRV, Qualifications Assessment and Teacher Registration. 


\section{Pathways}

OTTs are teachers in their country of origin and they choose to relocate to another country. Depicting the basic elements of this process means that it can be viewed as a simple, three-step pathway reflected in Figure 1: Three-step pathway.

Figure 1: Three-step pathway
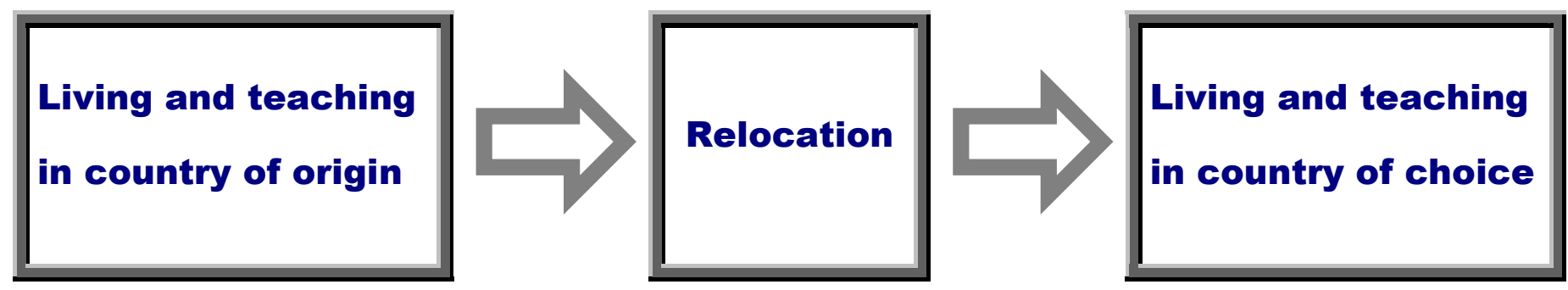

In New Zealand there is an immigration process governing entry into this country and INZ is the administrative institution that manages this process. There is a teacher registration process managing access to teaching and this is administratively managed by NZTC. These two processes add two further steps to the three step pathway reflected above and these added steps are represented in Figure 2: Five-step pathway.

Figure 2: Five-step pathway

\begin{tabular}{|c|c|c|c|c|}
\hline $\begin{array}{l}\text { Living and } \\
\text { teaching in } \\
\text { country of } \\
\text { origin }\end{array}$ & $\begin{array}{c}\text { Immigration } \\
\text { Process }\end{array}$ & Relocation & $\begin{array}{c}\text { Teacher } \\
\text { Registration }\end{array}$ & $\begin{array}{l}\text { Living and } \\
\text { teaching in } \\
\text { country of } \\
\text { choice }\end{array}$ \\
\hline
\end{tabular}

Complexities arise for OTTs because progress from one step to another is not guaranteed and the immigration process can be viewed more as a gateway than a step; because if an OTT does not secure a visa she is not permitted access to New Zealand. Teacher registration is another gateway, rather than a step that takes teachers directly into teaching in New Zealand. An OTT may thus not be permitted to enter the full-time, permanent teaching workforce. If immigration and teacher registration are gateways 
then Figure 2: Five step pathway is not an accurate reflection of the pathway; and that situation would be a more accurately represented as follows:

Figure 3: Pathways and gateways

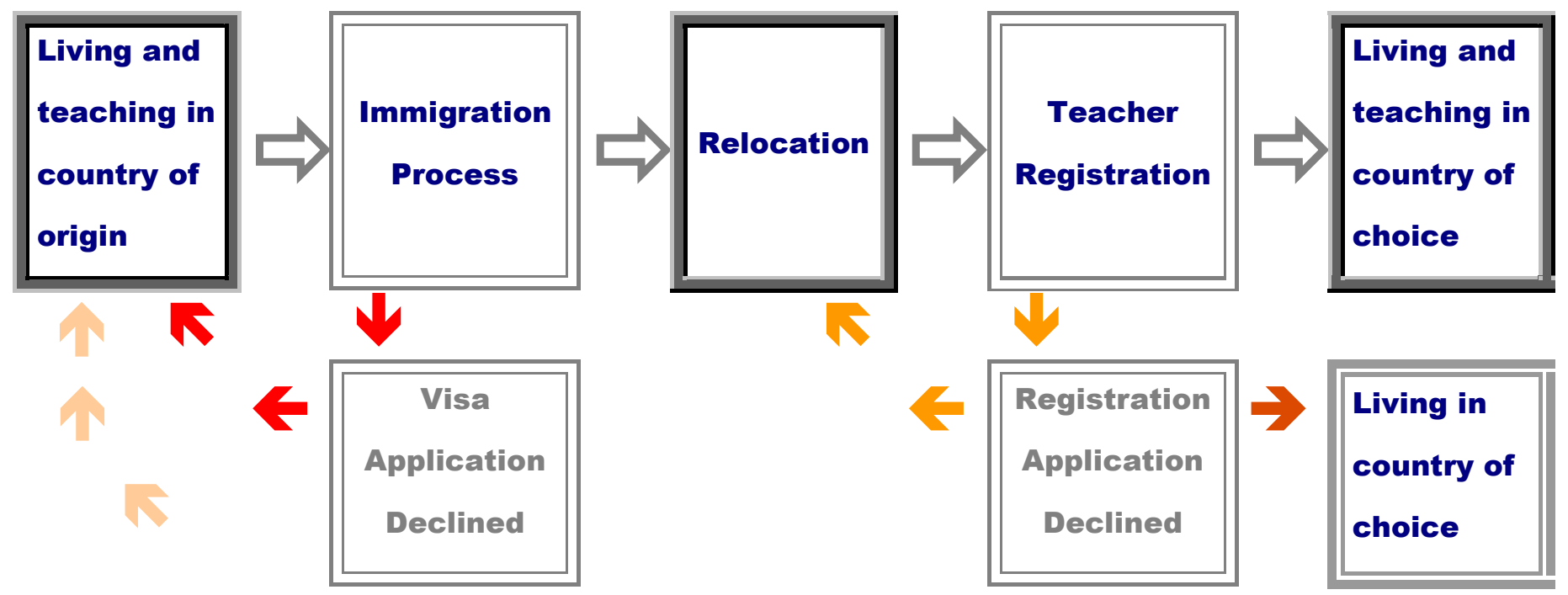

There are other gateways that can be added and, as more and more are included, the initial three-step pathway becomes more convoluted; because with each addition there are more possible alternatives to that three step pathway. It is the process of OTTS encountering gateways and either navigating those successfully or not that leads to the creation of a multitude of individual pathways. 


\section{Barriers to OTTs securing employment}

Teachers from other countries immigrate to New Zealand to teach (Voigt Graf et al., 2009) and in 2011 secondary school principals reported employing 235 OTTs who had entered the teaching profession in New Zealand recently (Lee, 2011). However, OTTs are met with barriers when seeking work; such as a lack of connection between immigration and employment, hesitancy of principals to employ them and difficulty navigating a pathway into teaching.

INZ listed secondary school teachers on its ,Long Term Skill Shortage List" from 2003 (Barback, 2013) until 2012 (Ministry of Education, 2012) and an implication of this was that if a teacher with appropriate qualifications applied for a PRV, that teacher received bonus points for their application (Firkin, Dupuis \& Meares, 2004). Bonus points assisted teachers to gain the total points necessary for a successful application for a PRV. The receipt of this visa permitted an individual to live and work in New Zealand but did not guarantee employment as a teacher. An OTT could potentially arrive in New Zealand with the right to live and work but seek and not secure a teaching post. There was no mechanism in place to make a connection between successful applications to INZ and vacant teaching positions.

During a search for work OTTs may encounter a barrier because some principals perceive that OTTs require greater assistance than schools are in a position to provide. Woulfe reported in 2008 that, although there were many proficient OTTs, all teachers who were new to the education system in New Zealand required a lot of on-the-job training. Woulfe quoted the 2008 president of the Secondary Principals Association as stating, "I'll put it kindly, they need a lot more support provided" (p. 1). Some principals are cautious about hiring OTTs and this can be a barrier because there is no centralised, school-hiring authority and schools hire staff independently. Applications are thus made directly to schools in New Zealand (NZTC, n.d.a; TeachNZ, n.d.). Principals are involved in the recruitment of teachers and their perceptions about OTTs can dictate whether or not they are hired. 
Employment applications can be made to schools before, during or after applying for a visa and this means that there is no single pathway to follow in order to gain employment as a teacher in New Zealand. Consequently, individual pathways are created as OTTs navigate their way into teaching positions. Those OTTs who arrive in this country can be a valuable addition to the education sector. OTTs have been educated and taught overseas and arrive with knowledge, skills and experience that have been verified by NZQA and the NZTC as part of the immigration process. It makes economic and social sense to facilitate OTTs" navigation of barriers by suggesting a pathway in order that these individuals might be employed as teachers.

\subsection{Rationale}

OTTs enter New Zealand to teach but finding work in a new country can be difficult. The problem is that there is no designated pathway into a teaching career. The situation is that OTTs create pathways for themselves and this research explored individual pathways six OTTs had forged. Facilitating the process of OTTs" immigration and employment through development of a suggested pathway is important in order to improve efficiency when filling teaching posts vacated by New Zealand-trained teachers who choose to teach overseas, change professions, or retire. It is also important because it can support teachers from a diversity of cultures to find teaching positions in order for the teaching cohort to reflect the diversity of the student population; and it can assist teachers, who have arrived in the country with the legal right to live and work, to navigate their way into teaching posts.

\subsection{Research topic}

This study examines individual pathways created by OTTs from teaching in their country of origin to gaining full-time, permanent employment as secondary school teachers in New Zealand. It reports on how OTTs secured teaching work in New Zealand. It explores the journeys of six OTTs into teaching, presenting challenges and supports 
they encountered, documenting suggestions they had for others; and employing these to formulate a suggested pathway.

\subsection{Overview of thesis}

The first chapter provided an introduction to this thesis by describing the background, supplying contextual information and giving a rationale. The topic of this research is stated and is followed by an overview.

Chapter two is a literature review that examines academic journal articles from the United Kingdom, United States, Canada, Australia and New Zealand. It explores international perspective about hiring OTTs and describes challenges and supports available to them.

Chapter three describes the research method. It situates this study within a theoretical framework and details elements of the research design such as: ethical considerations, selection of participants, data gathering and its analysis, drawing of conclusions, and the process of ensuring trustworthiness of data.

Chapter four provides the findings of this study. It narrates six cases individually and, subsequently, compares and contrasts these using two themes: challenges and supports. It also documents suggestions made by participants.

Chapter five is a discussion of findings that emerged. Findings of significance form a focus and reference is made to themes that were identified in the literature review. In this chapter I suggest a pathway for future OTTs use.

Chapter six presents a summary of the thesis and indicates recommendations. It sets out limitations of this study and provides ideas about areas for future study. 


\section{Chapter 2: Literature Review}

\subsection{Introduction}

This literature review begins by exploring international perspectives on hiring OTTs. Subsequently, an argument in favour of hiring OTTs is presented and, because their employment is seen as desirable, the pathways they might navigate into teaching are reviewed. A gap in New Zealand literature is identified due to the lack of a designated pathway into teaching. The aim of this thesis is to present a pathway into teaching and thus address that gap. International literature about challenges OTTs encounter and supports they have access to is explored. This exploration identifies themes that were used during data analysis.

Academic journal articles cited in this review were published in the United Kingdom, the United States, Canada, Australia and New Zealand. Literature from these countries was chosen because of some of the similarities shared with New Zealand. These similarities are: that these countries have high human development indices (United Nations Development Programme, 2013), face ongoing teacher shortages (American Federation of Teachers, 2009; Harker \& Chapman, 2006; Lonsdale \& Ingvarson, 2003; Ross \& Hutchings, 2003) and employ OTTs as a strategy to address those shortages (Miller, Ochs, Mulvaney, 2008). This is a group of countries where English is the dominantly spoken language (Huddleston \& Pullum, 2002; Statistics New Zealand, 2006b) and is the language predominantly used to teach in schools (Education Counts, 2011).

The electronic databases used to search for literature were: the Education Research Complete, Education Resource Information Center (ERIC) via OCLC First Search, ERIC via ProQuest, Google and Google Scholar. The key terms entered in searches for literature were: foreign, international, immigrant, migrant, overseas, taught, educated, trained, qualified, teacher, teachers, educator, educators, United Kingdom, United States of America, Canada, Australia and New Zealand. 


\subsection{International perspectives on the recruitment of OTTs}

Literature is divided on the benefits of hiring OTTs. Literature that is unsupportive raises concerns about the impact on the education sector of both the hiring country and the source country, as well as negative effects on OTTs.

In the United Kingdom, vast teacher shortages were experienced during the 1990s and early 2000s (Miller, 2007). Salaries were comparatively low, the workload of teachers was high, student behaviour was problematic, the status of the teaching profession was low and turnover of teachers was high (Lonsdale \& Ingvarson, 2003). In 2003, the National Union of Teachers (NUT) warned that teacher salaries were below graduate salaries in most sectors. It indicated that salary increases would be required to retain teachers. It also stated the problem of retention, coupled with unmet targets for teacher training, would lead to a continued need to employ OTTs. This was supported by Ross and Hutchings (2003) who stated that, although recruitment of OTTs had been helpful to address shortages, it had not addressed the underlying issues of teacher recruitment and retention. Their report supported NUT"s findings that, if the problems of teacher recruitment and retention were not resolved, there would be an ongoing need to employ OTTs.

In the United Kingdom the momentum of the trend to employ OTTs increased from the 1990s onward; and Miller, Ochs and Mulvaney (2008) proposed that it would continue to do so because of the aging teaching population and consequent retirements from the profession. This paper referred to the Commonwealth Teacher Recruitment Protocol that called for the rights of the recruiting country to be balanced against the rights of the source country and those of the OTT. It indicated that, in spite of this protocol, developing countries were still losing their most qualified teachers.

Similar to the United Kingdom, the United States of America employs OTTs to fill vacancies on an ongoing basis. This trend has been in evidence for many years and recruiting has become a lucrative business. In the United States of America, teacher 
losses are reported to outpace teacher recruitment (Lonsdale \& Ingvarson, 2003). The recruitment situation appears different from the United Kingdom because there is evidence of abuse of OTTs by recruiters who overcharge and provide misinformation about what teaching overseas will be like (American Federation of Teachers, 2009). Books and De Villiers (2013) indicated that in some cases, recruiters were paid three times for recruiting OTTs. Firstly, schools paid recruiters a fee, secondly, OTTs paid a start-up fee and, thirdly, OTTs paid recruiters a portion of their monthly salary. The American Federation of Teachers published a report in 2009 and its main findings were that: abuses of OTTs were widespread, recruitment for profit was virtually unregulated, recruitment had a negative impact on source countries, the causes of teacher shortages were hidden by recruitment, and employment of OTTs was on the rise. This report indicated that immigration of nurses had started in the 1950s and progressed to a level where, today, one in three nurses was educated overseas. It cautioned that, without careful intervention, this same trend would be seen in education.

In Australia the situation is somewhat different from the United Kingdom and the United States. Retirements are indicated to be the greatest reason for teacher shortage in Australia (Lonsdale \& Ingvarson, 2003) and another reason for teachers leaving is to teach in the United Kingdom. McNamara, Lewis and Howson (2007) conducted research in the United Kingdom that found OTTs from Australia were often older than the twenty-something year old, beginning-teacher expected to be teaching overseas. This meant that Australia was losing more experienced and better qualified teachers. A negative impact was that the country suffered a capital loss after having invested in training a teacher.

In New Zealand the recruitment of OTTs has not reached the level where recruitment companies are making the amount of money that would fund offices overseas as is the case in the United Kingdom. Another difference is that the size of the general population and the education sector are smaller in New Zealand and, consequently, the number of teachers required is lower and less likely to have a significant negative impact on source countries. 
In New Zealand, employing OTTs has not led to financial abuse by recruiters as is evident in the United States of America. One reason why financial abuse is not evident in New Zealand is that there is only one teacher recruitment agency preferred by the MoE, Education Personnel (TeachNZ, n.d.), and OTTs more often find work for themselves than through an agency. Anand and Dewar (2004) reported that $87 \%$ of OTTs applied to schools directly for their first teaching position. Another reason why financial abuse is not evident in New Zealand is that schools pay recruiters a finder"s fee and OTTs do not pay recruiters, as is the case in the United States of America.

The situation in New Zealand shares similarities with Australia because retirement is a reason for attrition and New Zealand teachers leave to teach abroad (Fisher, 2011). As with Australian teachers, New Zealand-trained teachers working in the United Kingdom were found to be older and more experienced. A loss of these teachers was found to have a negative impact on the education sector, similar to that in Australia which was a capital loss (McNamara et al., 2007).

The literature referred to above would discourage hiring OTTs as doing so masks the underlying causes that lead to shortages and this practice disadvantages source countries. However, there is literature that has a counter view and is supportive of the recruitment of OTTs.

Literature supportive of hiring OTTs looks at the demographic of the student population and advocates for the diversity of that population to be mirrored by the teaching cohort. There have been, and are projected to be, increasing numbers of culturally diverse children in the United States of America (Wotherspoon, 1989) and the lack of representation of ethnic minorities in the teaching force is described as having serious educational and social implications within schools in particular, and society in general (Gifford, 2007). There are researchers who advocate for the diversity of the student body to be reflected in its teachers (Fenwick, 2001; Gifford, 2007) and hiring OTTs can achieve this aim. 
A disparity between the number of students from different cultures and teachers from different cultures is evident in Australia. Australia has a large immigrant population (Burns \& Hornel, 1989; Saha, 1985); and Santoro (2000) identified that there was greater ethnic diversity in the student population than in the teaching cohort. The study recommended that greater numbers of teachers of various ethnicities should be employed.

In Canada, a disparity between diversity in the student and teaching populations is likewise evident. Over half of Canada"s population growth comes from net immigration (Walsh \& Brigham, 2007). Faez (2010) states that, "a diverse demographic population is a fundamental characteristic of Canada" (p. 1). Immigration leads to an increase in the number of students of different cultures and Ryan, Pollock and Antonelli (2009) investigated the number of teachers of colour as compared the proportion of students of colour in Canadian schools. Findings indicated that the number of students of colour had grown but the number of teachers of colour employed in Canadian schools had not kept pace.

In New Zealand there is also a disparity between the teaching cohort and the culturally diverse student body. Howard (2009) examined the reasons why there is a disparity between the high number of Asian students and the low number of Asian teachers in New Zealand. These barriers were low salary, status and public opinion of teachers in New Zealand, high workload and entry standards for the teaching profession, poor student behaviour and different classroom management styles, racism and cultural differences, and language competence. There is evidence of similar barriers in other countries and these will be explored in detail in section, 2.4. Challenges.

Employing OTTs is important for immigrant students because, as Schmidt and Block (2010) state, "children from immigrant backgrounds need role models and advocates within the system who can speak their first language and relate to their circumstances of navigating their way in a new country, language and culture" (p. 4). OTTs may 
understand immigrant children"s lives outside of school and might empathise more readily than their locally trained colleagues (Santoro, 2007).

The benefit of employing OTTs is not limited to immigrant students. All teachers and children potentially of benefit from engaging with multicultural and multilingual OTTs because diversity is a reality of schooling (Schmidt \& Block, 2010) and of life outside of school. Santoro explains that local teachers can be assisted by OTTs because they have the, "potential to act as cross cultural mentors for their "mainstream" colleagues" (p. 81).

A further argument for hiring OTTs is that it is a waste of resources not to do so. OTTs arrive in their country of choice as qualified and experienced teachers and it makes sense to facilitate their entry into teaching. It appears improvident to allow these teachers access to a country and, subsequently, have these highly skilled immigrants work in fields for which they are often times greatly overqualified (Reitz, 2005).

Internationally, attitudes towards employing OTTs are diverse. Advocates against hiring OTTs claim that employment of them masks the underlying reasons for teacher shortages (American Federation of Teachers, 2009) and does not address those reasons (Ross \& Hutchings, 2003); and employing OTTs negatively impacts source countries (American Federation of Teachers, 2009; McNamara et al., 2007; Miller et al., 2008). Other researchers study the growing difference between the ethnicity of children and teachers in schools due to immigration (Howard, 2009; Ryan, Pollok \& Antonelli, 2009; Santoro, 2000). These researchers perceive this difference as a problem that should be addressed by employing OTTs so that immigrant children can see themselves reflected in their teachers (Schmidt \& Block, 2010). All children and teachers can benefit from exposure to diversity, and the qualifications and skills OTTs bring with them can be utilised (Reitz, 2005).

The situation is a complex one and I view hiring OTTs as desirable. This position is taken because the practice of hiring OTTs is ongoing and unlikely to stop. The reason 
why it is not likely to cease is due to the improbability that the underlying issues leading to a necessity for hiring OTTs can, or will, be addressed. This is partly because it is unlikely that the relatively low wages that teachers earn in New Zealand will be increased to match teacher salaries in other Organisation for Economic Co-operation and Development (OECD) countries. As Scott and Gini (2010) state, "In absolute terms, New Zealand teacher salaries are lower than the OECD average..." (p. 25). Low salaries for teachers make teaching abroad an attractive option for New Zealand-trained teachers.

The low regard for teaching in this country is also not likely to be addressed in the near future; and has not been helped recently by the introduction of Novopay in 2012. Novopay is a technology-based school payroll system, the implementation of which was fraught with difficulties. As is stated in the Report of the Ministerial Inquiry into the Novopay Project, "The problems with Novopay have affected public trust and confidence in the Ministry of Education, and also the wider public sector. This will take time to restore." (Jack \& Wevers, 2013, p. 1). The widely broadcasted challenges due to teachers not receiving pay from Novopay may not have made teaching an attractive option to students making decisions about their future careers.

Hiring OTTs is also seen as desirable because of the growing diversity of the student population and the benefit to learners of being exposed to culturally diverse teachers. This is an age of globalisation and people are in a position to move more freely between countries; and this situation will inevitably lead to diversity. Diversity is an expected consequence of globalisation; and hiring OTTs is valuable because it allows a diverse student group to be taught by a diverse group of teachers.

Hiring OTTs is seen as desirable and facilitating their successful entry and integration into the teaching profession in their country of choice is advisable. 


\subsection{Challenges}

Many researchers have investigated the difficulties faced by OTTs and Phillion (2003) justifies these investigations by indicating that it is important to understand the difficulties OTTs face so that targeted programmes can be developed to appropriately facilitate their entry into teaching. As is suggested by Phillion (2003), challenges are explored to gain understanding, which is used to develop a pathway to assist with OTTs" entry into teaching. This section explores challenges associated with the bureaucracy of the immigration, teacher registration and employment of OTTs, and the difficulties associated with culture shock experienced as a result of language, differently valued capital and a lack of cultural responsiveness.

\section{Bureaucracy}

The meaning of the word, bureaucracy, in this context is administration involved in the immigration, registration and recruitment process for OTTs. OTTs face many bureaucratic processes: in order to immigrate to New Zealand a visa from INZ is required; to be eligible to work as a teacher here registration with the NZTC is necessary; but secondary schools hire teachers without the assistance of a centralized hiring institution (NZTC, n.d.a.; TeachNZ, n.d.). Research, both internationally and in New Zealand, has found that on bureaucratic difficulty faced by OTTs is that they are provided with misinformation about teaching in their country of choice (De Villiers \& Books, 2009; Guo \& Singh, 2009; Pollock, 2010; Vohra, 2005).

In the United Kingdom there is evidence of misinformation being provided. The ongoing and large demand for OTTs has resulted in the recruitment of teachers becoming a highly competitive market in which there are many recruiters. Ross and Hutchings (2003) indicated there were hundreds of teacher recruitment agencies operating in the United Kingdom. De Villiers and Books (2009) studied content on the websites of fortythree teacher recruitment agencies and found that many of those agencies were presenting misinformation by giving a positive picture about what could be expected when teaching abroad; without supplying information about the difficulties that would be 
faced during immigration. According to De Villiers and Brooks, the problem with providing this optimistic information was the resulting disillusionment, because those high expectations were not met.

Similarly, Guo and Singh"s (2009) research found evidence of misinformation that was promulgated by advertisements and recruitment agencies in Australia. These indicated the country faced ongoing teacher shortages and permanent placements could readily be secured. However, OTTs found out after arriving in that country shortages were in specialist subject areas only. Pollock"s (2010) Canadian-based research had related findings because OTTs were misinformed about the extent of the teacher shortage and the ease of access to the teaching profession. In New Zealand the situation is similar and teachers do not always receive balanced information about access to employment (Vohra, 2005).

Misinformation is one challenge resulting from bureaucracy and, after making the decision to relocate and teach abroad, a further bureaucratic challenge is teacher registration. International research has identified teacher registration as a barrier (Beynon, llieva \& Dichupa, 2004; Chow, 2011; Guo \& Singh, 2009; Howard, 2009). Teacher registration is similarly problematic for OTTs in New Zealand and Biggs (2010) states that, "some OTTs arrive in New Zealand without understanding the process for registration" ( $p$. 110). OTTs have indicated it would be useful to receive more information about teacher registration in New Zealand (Anand \& Dewar, 2004).

Canadian research indicates that teacher registration is not simply difficult due to the administration involved but because it can impact OTTs" on a personal level. Beynon, llieva and Dichupa (2004) found OTTs experienced feelings of identity negation when required to complete course and practicum work (after qualifying and gaining several years of teaching experience in their countries of origin) and had to renegotiate their identity as teacher. Walsh, Brigham and Wang (2011) found that OTTs faced the need to contribute financially to the home while applying for teacher registration before having secured work. 
Once registration has been secured and work can be sought, other challenges associated with bureaucracy are faced and one of these is integration. Schmidt (2010) investigated the integration of OTTs in Canada, and found they faced systemic discrimination because they were last to be hired; in a tiered hiring process that started by hiring surplus teachers, if none were available then recent graduates were hired, followed by relief teachers, including OTTs. Schmidt suggested a paradigm shift from the viewpoint of OTTs"employment as a problem for the individual to it being a problem of the education system. Schmidt proposed an employment solution could be found through systemic advocacy.

OTTs face challenges associated with bureaucracy stemming from obtaining misinformation, from barriers created by the teacher registration process and obstacles that stand in the way of their integration. Schmidt (2010) suggests that OTTs can be supported through systemic advocacy. However, in New Zealand the education system is large, complex and includes many individuals. Consequently, changing it will take time. Suggesting a pathway could more readily facilitate OTTs entrance into teaching.

\section{Culture shock}

The term culture shock refers to difficulties an OTT faces as a consequence of a move to their country of choice. The term culture shock was first explained by Oberg (1960, $p$. 177):

Culture shock is precipitated by the anxiety that results from losing all our familiar signs, and symbols of social intercourse. These signs or cues include the thousand and one ways in which we orient ourselves to the situations of daily life: when to shake hands and what to say when we meet people...All of us depend for our peace of mind and our efficiency on hundreds of these cues, most of which we do not carry on the level of conscious awareness. Now when an individual enters a strange culture, all or most of these familiar cues are removed. 
OTTs must learn to negotiate a new society when they immigrate and the resulting unfamiliarity with social cues leads to culture shock. This can be experienced both during the immigration process and thereafter because teaching is a profession in which a multitude of human interactions takes place each day in schools.

Language barriers are facets of culture shock that can include accent and vocabulary. Language barriers can be faced from the beginning of the migration process starting with teacher registration (Beynon et al., 2004; Mawhinney \& Xu, 1997; Schmidt, 2010; Walsh, Brigham \& Wang, 2011) as understanding registration requirements is difficult even when English is the dominant language of an OTT (Mawhinney \& Xu, 1997).

Subsequent to securing teacher registration, language can also create difficulty for OTTs when they seek employment. Hawthorne (2007) indicates that in Australia, OTTs from non-English speaking backgrounds are not readily hired and only $26 \%$ of those teachers will secure teaching work within the first five years of arrival in the country. In Canada, this percentage is lower at only $16 \%$.

International literature concurs that teaching in another language is a concern to OTTS (Deters, 2006; Hwang, Baek \& Vrongistinos, 2005; Sharplin, 2009). Arva and Medgyes" (2000) Canadian-based study investigated whether language affected OTTs" behaviour in the classroom. This research found that non-native teachers were not able to emulate native teachers" English-language competence in any sphere. Internationally, it is recommended that OTTs receive mentorship and support to deal with language in their professional context (Deters, 2006; Sharplin, 2009).

The differences in teacher behaviour that Arva and Medgyes (2000) identified need not be problematic. However, international research indicates accents and vocabulary that are not local are perceived as a barrier to student learning by school-hiring staff. In contrast, findings indicate that although children may struggle initially to understand a new accent or word, but will find it easier to understand after hearing it again and then 
no longer struggle with comprehension (Sharplin, 2009; Walsh, 2008). These findings could allay the fears that students cannot learn from multilingual OTTs.

Research findings discussed indicate that language can pose initial challenges for OTTs both pre- and post-teacher registration. However, with acceptance and support those challenges can be overcome.

A lack of cultural responsiveness both within and outside of the classroom can be a further cause of culture shock. Johnson (2003) explains that cultural responsiveness is underpinned by the principle, "that diverse ways of understanding and interpreting the world are an asset and a resource, not a liability; and that it is in the best interest of all learners to build on the strengths and experiences that children collectively bring to the classroom" (p. 24). Cultural responsiveness is particularly important for OTTs because they are in a new cultural context.

Student behaviour and teacher expectations are culturally embedded. International literature indicates that differences in what is valued in the teaching and learning context (Seah \& Bishop, 2002), perceptions about teaching-subject (Seah, 2005) and expectations about behaviour in the classroom (Florence, 2010; Inglis \& Philps, 1995; Sharplin, 2009) create challenges. In order to navigate differences researchers suggest that OTTs acknowledge difference (Florence, 2010; Sharplin, 2009) and bring together previous and new expectations (Seah, 2005; Florence, 2010). A New Zealand-based study conducted by Mitchell (2010) lends support to the international research with its finding that a lack of cultural responsiveness caused difficulty for OTTs and this researcher stated, "I know of two female teachers who have recently left the profession because of their inability to adapt sufficiently to the cultural differences between themselves and their students" (p. 3). A further finding of Mitchell"s (2010) research was that cultural responsiveness was an important factor in students" perceptions about which teachers were competent. 
OTTs" lack of cultural responsiveness can lead to the experience of culture shock and affect the perceptions of their students. OTTs can benefit from being culturally responsive toward students. The discussion to follow indicates OTTs can also benefit from cultural responsiveness extended to them by their colleagues.

New Zealand (Nayar, 2009; Stewart, 2010) and international (Cho, 2010; Guo \& Singh, 2009; Miller, 2008; Miller, 2009; Subedi, 2008) literature indicates that OTTs experience a difference in value placed on the social and cultural capital they bring with them to their country of choice. The difference in value placed on this capital can lead to culture shock. In this context the word, capital, is used in the Bourdieusian sense as a metaphor taken from economics to indicate value or wealth. This value is not in monetary terms but wealth in cultural and social terms; and these forms of capital have value through the perceptions of others (Grenfell, 2009). For example, the word the Zulu people of South Africa use for teacher is umfundisi and this is also the word used for a priest or a person of great moral character. In that cultural context a teacher is given similar esteem and ascribed the moral character religious people ascribe to priests. However, in New Zealand the word "teacher" does not imply moral character; and the value placed on teachers through the perceptions of others here is not similar to the value religious individuals place on priests. OTTs entering New Zealand may find their social and cultural capital valued differently here from in their country of origin. The perceived difference in value can lead to OTTs"experience of culture shock.

New Zealand-based researcher, Stewart (2010), proposed the use of the term, professional capital, to describe all of those things that give a teacher competence as a professional in the field of education. Stewart explored the loss of professional capital experienced by OTTs when they begin working in New Zealand schools; and proposed New Zealand teachers need to value the professional capital OTTs bring with them in order to support their integration.

International literature indicates that OTTs" cultural (Cho, 2010; Miller, 2009; Subedi, 2008; Walsh et al, 2011), linguistic (Cho, 2010; Subedi, 2008) and professional (Miller, 
2008) capital is valued differently in their country of origin and country of choice. Miller (2008) attributed this to two factors: a pervading negative attitude towards difference in the United Kingdom and the use of knowledge as power to keep out those who are considered undesirable. Miller indicated that undesirables were teachers from developing countries and concluded that negativity toward difference and use of knowledge as power created two barriers that stood in the way of OTTs securing employment. The situation is similar in Canada and Ryan et al. (2009) state that, when it comes to hiring OTTs, "Canadian employers continue to be sceptical. Like the general public, they believe that immigrants from „third-world countries" hold inferior "human capital" " (p. 605).

In New Zealand, there is also evidence of a lack of value given to OTTs" professional capital (Stewart, 2010). Nayar (2009) found evidence of barriers faced by Indian immigrants in New Zealand. This study found that securing an interview was difficult, gaining a post with overseas teaching experience was a challenge, and racial discrimination was experienced around accent and use of language.

A lack of value placed on OTT"s cultural, linguistic and professional capital can make it difficult for them to access a permanent teaching position and may lead them to accept marginalised positions. In Canada, Pollock (2010) found several practices that were associated with the cycle of marginalisation: OTTs engagement in unpaid work; participation in many formal and informal learning activities; and acceptance of any relief work offered.

Obtaining a position does not end this marginalisation. Miller (2006) documented ongoing challenges for OTTs in the United Kingdom. These included being in a worse financial situation after migration and diminishing self-esteem. Reasons for these negative experiences may be explained in a study conducted by Warner (2010). This study found classroom management, curriculum complexity and lack of professional support were predominant professional difficulties for OTTs. Professional support at school, a positive personal attitude, hard work and completion of the overseas teachers 
training programme were found to be reasons for professional success. If those supports are not available, or not made use of, this may lead to the experiences Miller"s (2006) research detailed.

OTTs are settling into at least two communities at the same time (one at school and one at home) and international publications indicate this can be a complex process (Deters, 2006; Gao, 2010; Gilpin, 2005; Kitonga, 2010). Complexities arise because there are multiple interpretations of situations and behaviours in and outside of the classroom; and cultural, personal and professional identities are interwoven. OTTs can overcome these by using improvisation, through trying new strategies in their new environment, and through their own agency, by being proactive solution finders (Gao, 2010). OTTs can also be successful at settling in if they are able to bring together the different identities and ideologies from their country of origin and those from their country of choice (Kitonga, 2010).

In New Zealand, research has found further evidence of the difficulties OTTs face establishing their identity, both personal and professional (Butcher, 2012; Okumara, 2008). Similar indicators of OTTs" success were found in New Zealand as were evident in international research i.e. having good communication skills and creating strategies to cope with a changed environment, such as drawing support from networks (Okumara, 2008). A study by Butcher (2012) uncovered systemic failure to support OTTs and explored system-focused solutions, as opposed to OTT focused solutions, recommending wider research that could inform future systems and procedures in support of OTTs" socialization.

\subsection{Supports}

Supports provide ways for OTTs to navigate challenges they come across when immigrating and seeking employment. The section to follow explores supports for OTTs. Three supports are discussed and the first of these is professional development opportunities. The second support documented is assistance received from 
bureaucracy, and the third is help supplied by professional networks to which OTTs belong.

\section{Professional development}

Professional development can support OTTs through the transition of immigrating to a new country, finding work there and integrating successfully. Transition is understood in this context as a move from one state to another. In terms of immigration, this means a move from one country to another; thus, the term "transition process" is used here to span OTTs" immigration, employment and integration. Professional development opportunities are various and some provide application information, others focus on teacher education and some explore mentorship.

Sutherland and Rees (1995) reported on a course to prepare OTTs to work in Britain. That course aimed to assist them to overcome issues related to certification, the duration of time needed to gain residency, the language requirements and the equivalency of qualifications. The course was found to be of benefit to OTTs. A similar course could assist OTTs in New Zealand because Anand and Dewar (2004) indicated that teachers new to this country would have appreciated receiving more information about the registration process. However, the course Sutherland and Reese (1995) investigated may not be broad enough because its focus was on the application process and this is only one aspect of transition. The course did not provide support to OTTs for finding work and integrating successfully.

Professional development in the form of teacher education programmes has been investigated internationally (Cruickshank, 2004; Lonsdale \& Ingvarson, 2003; Schlam \& Guan, 2009; Walsh \& Brigham, 2007; Warner, 2010). These studies focus on programmes that could help OTTs to teach in their new context but do not provide support for immigration and employment.

Mentorship is advocated by international researchers as a way of facilitating OTTs" integration (Deters, 2006; Peeler \& Jane, 2005; Walsh \& Brigham, 2007). In Australia, 
Peeler and Jane (2005) found that there was a difference in the relationships and the level of help received by OTTs who developed a positive self-image and those who did not. Those with regular access to mentorship had a way of bridging the gap between their former way of teaching and current requirements. Participants in this study had engaged in an education programme obtaining information about teaching in Australia and had also had the benefit of mentorship. Providing OTTs with education programmes and mentorship may prove a way of providing more comprehensive assistance to them.

In New Zealand, Biggs" (2010) study of the induction of OTTs found that the induction programmes in place were targeted to meet the needs of beginning teachers and consequently did not meet the needs of OTTs. The conclusion of this study was that a specific needs-based induction programme should be developed. Exploring the needs of OTTs and developing a programme to meet those needs would provide appropriately targeted professional development opportunities.

The professional development opportunities explored by the above cited research did not provide comprehensive support to OTTs. As Biggs (2010) suggests, a needs-based programme should be developed. That programme could combine all of the programmes cited above by supply information about the mandatory applications for immigration, provide guidance about employment, offer teacher education and give OTTs access to a mentor would be ideal. However, a programme this extensive might

prove prohibitively difficult to research, implement, resource and maintain. In the absence of such a programme, OTTs might create a needs-based programme for themselves.

\section{Bureaucracy}

Bureaucracy can provide support to OTTs by ensuring equal employment opportunities, minimising barriers that stand in the way of hiring OTTs, and formulating policies and programmes to facilitate their transition. 
Policy can encourage equitable hiring practices. Studies conducted internationally indicate that equal employment opportunity (EEO) is a focus of policy but this does not always translate into equitable hiring processes in schools (Sharplin, 2009; Schmidt \& Block, 2010). The situation is similar in New Zealand, there is an overarching framework supportive of equity and diversity in employment but this does not translate into a school-hiring policy. Local government and public sector employers are required to implement EEO policies within their workplaces (Mintrom \& True, 2004). However, there is no centralised body that ensures these policies are implemented.

Minimising bureaucratic barriers obstructing schools from hiring OTTs can be supportive. In the United Kingdom in 2012, support for OTTs came in the form of the British government minimising teacher-training restrictions. This made it easier for OTTs from certain Commonwealth countries to be hired by schools (Department for Education, 2013).

Bureaucracy can support OTTs if it is informed by their transition experiences. International research indicates that understanding the transition of teachers is important for policy makers when developing policy and programmes to support them through the transition process (Cross, Hong \& Williams-Johnson, 2011; Phillion, 2003). New Zealand-based research concurs (Biggs, 2010; Butcher, 2012).

\section{Networks}

The formal networks that OTTs belong to can assist them with their transition. International studies indicate that if members of OTTs" professional networks value the knowledge and skills they bring with them, this assists with their transition (Deters, 2006; Cho, 2010; Walsh \& Brigham, 2007). New Zealand-based research conducted by Stewart (2010) concurs as it proposed support of OTTs" integration through locally trained colleagues valuing the professional capital that they bring with them.

OTTs" colleagues can offer further support them by recognizing their needs and efforts to integrate. This can be done in part by understanding OTTs are not simply settling into 
a new job but also a new education system and a new society. In the United States of America, Abramova"s (2011) research explored Russian OTTs" needs during their integration in schools and recommended the community recognise those needs in order to support them. Abramova"s recommendation supports a New Zealand-based study conducted by Vohra (2005) who explored the integration of Indian immigrant teachers in primary schools. This study found that OTTs" efforts at integrating would be greatly assisted by recognition of their efforts by schools and associated professional institutions.

There are also practical ways in which formal networks can support OTTs. In New Zealand, Okumara (2008) found that Japanese OTTs were assisted by the New Zealand Japanese Language Network which helped OTTs to learn local teaching methods and provided opportunities for classroom observations. These are two practical suggestions as to how colleagues can support OTTs.

\subsection{Conclusion}

In this literature review I have argued that hiring OTTs is desirable and because of that desirability, it is useful to facilitate their entry into teaching by providing an effective pathway. I went on to discuss literature regarding challenges OTTs encounter and support they have access to. Common difficulties faced are to do with bureaucracy and culture shock. Supports proposed by researchers were professional development, bureaucracy and networks. No pathway is evident in New Zealand literature to date and this is a gap in that literature which I seek to address by exploring the views of participants before suggesting a pathway. 


\section{Chapter 3: Method}

\subsection{Introduction}

This chapter begins by describing the research aim, question and sub-questions. The theoretical foundation of this research and its design are explained. The process of participant selection is described, followed by an outline of the limitations of the sample. Ethical considerations of this study are presented and explained. The process of data gathering is described and data collection timeframes are provided. Details of the management and recording of data are provided, and data analysis is discussed. The process of comparing and contrasting data is described and the trustworthiness of data is discussed.

\subsection{Research aim}

The aim of this study was to develop a suggested pathway for OTTs by investigating multiple, individual pathways navigated by OTTs into a career teaching in New Zealand, presenting challenges and supports that they encountered, and providing their suggestions.

\subsection{Research question}

The overarching research question was:

What individual pathways did OTTs follow from teaching in their country of origin to finding full-time, permanent work as a secondary school teacher in New Zealand?

With the aim of also finding out:

- What challenges did participants face to securing permanent employment as secondary school teachers? 
- What supports assisted participants?

- What suggestions did participants have for others in the same situation?

\subsection{Theoretical foundation}

The theoretical foundation for a study is a set of ideas about the world that guide the process of the research and this set of ideas is referred to as the research paradigm. There are two broad research paradigms, the positivist and the interpretive paradigm. The positivist research paradigm could be described as scientific and often makes use of an unnatural, laboratory environment to investigate a phenomenon, generating numbers as data sets and aiming to obtain research findings that can be generalised (Kaboub, 2008). Gallagher (2006) explains this paradigm by stating that, "Reality exists outside of our interpretations of it, and an accurate depiction of reality (objective knowledge) is achieved through careful and systematic observation and experiment using the scientific method and neutral procedures" (p. 96). Bunniss and Kelly agree (2010) indicating that positivist research methods, "tend to be quantitative methods, often including statistical testing of hypotheses (e.g. randomised controlled trials, questionnaires)" (p. 361).

The interpretive paradigm is different and values subjectivity and research that takes place in natural settings. It makes use of words and images as data, with the aim of capturing multiple interpretations of reality. Gallagher (2006, p. 204) explains this paradigm stating that:

Ultimately, because we cannot attain absolute objectivity, and because we have no means to make subjective/objective distinctions, we are inevitably confronted with the understanding that knowledge is not discovered but rather is constructed. What we know about the social world is not the social world itself, but what we make of it. 
This thesis reports OTTs" personal descriptions about how they found work in New Zealand and each OTT created his or her own pathway. These personal descriptions and individual pathways were investigated employing the interpretive paradigm. This paradigm is appropriate because participants" reports about their experiences were central.

Bunniss and Kelly (2010) explain that interpretive research, "Tends to use qualitative methods to capture various interpretations of a phenomenon (e.g. naturalistic observation, interviews, use of narrative)" (p. 361). Participants were interviewed about their experience. This method of data gathering was appropriate because individual pathways were under investigation and through interviews participants" personal interpretations of their unique pathways into teaching were obtained.

The researcher has an integral role in this type of research and Terre Blanche and Durrheim (2002) state that, "in qualitative research the researcher is the instrument of observation" (p. 46). Due to the constructed nature of knowledge in this paradigm the researcher is not objective and uninvolved but rather assists in creating meaning. The role of the researcher is as one of the research instruments. The reason this role was appropriate for this study was because I am an OTT and have personal experience to bring to my role as the researcher and that experience is framed as valuable for the making of meaning within this research paradigm.

Data gathered from interviews was descriptive because it obtained detailed accounts of each participant"s experience in their own words. Atieno (2009) explains that, "Qualitative research is descriptive in that the researcher is interested in process, meaning and understanding gained through words" (p. 14). This research made use of participants" descriptions to investigate the process of immigration and employment for teachers.

The choice of qualitative data for this research is supported by Richards and Morse (2007) who state that qualitative methods are best, "If the purpose is to understand an 
area where little is known..." (p. 29). The field of this research is not new; there is a lot of research about immigration in general and about specific aspects of finding teaching work in a new country (e.g. registration, loss of status and language barriers). However, there is little research about pathways beginning with OTTs working in their country of origin and ending with finding work in their country of choice.

\subsection{Research design}

Eisenhardt (1989) states that, "The case study is a research strategy which focuses on understanding the dynamics present within single settings" (p. 534). The single setting under study was OTTs" move from teaching in their country of origin to securing teaching work in New Zealand. The dynamics studied were challenges and supports OTTs experienced in that setting and this study looks at a collection of cases. This research can be described as a collective case study (Stake, 1995) and this collection of cases allowed for comparison and contrast.

Lunenburg (2011) explains the usefulness of a case study design stating that, "It is extremely valuable in answering exploratory questions" (p. 5). This study, although it does not look at a new field of research because there is extensive research about OTTs, does ask a new or exploratory question within that established field.

Qualitative data were collected using semi-structured interviews because Boeije (2010), states that, "Qualitative methods offer the opportunity for participants to describe the subject of study in their own words and to do so largely on their own conditions" (p. 32). A preliminary list of interview questions was developed and appears as Appendix B. These questions were open-ended to encourage participants to share as much information as they chose.

Semi-structured interviews provided participants an opportunity to share their personal descriptions about finding work in their new country of residence. The semi-structured 
nature of questions allowed the researcher to add questions or adapt these as new information arose during interviews.

The use of semi-structured interviews is supported by Richards and Morse (2007) who state that semi-structured interviews should be used when, "the researcher knows enough about the phenomenon or the domain of inquiry to develop questions about the topic in advance of interviewing but not enough to be able to anticipate the answers" ( $p$. 114). This approach was selected because I had been through the process of immigrating to, and applying for teaching work in, New Zealand. I could thus ask questions about an experience that I had in common with participants.

\subsection{Selection of participants}

Participants for this study were selected using „snowball sampling" (Barbour, 2008, p. 52) which is a method of sampling that makes use of the participants" personal networks. The word snowball is a metaphor using the process of a snowball rolling down a hill and becoming larger as it picks up more snow on its way down that hill. Similarly, this research involved contacting a few potential participants initially, who provided contact details for other individuals, who in turn provided contact details for more individuals.

Four OTTs in the Wellington region were contacted initially and informed about this study and characteristics of the participants being sought. Of those OTTs, two agreed to be participants and provided contact details for other OTTs who in turn provided the contact details for further OTTs. This process yielded five participants. A sixth participant was gained by e-mailing deputy principals an explanation of this study and a request for this information to be forwarded onto OTTs.

The criteria for selection of participants were that they were secondary school teachers based in the Wellington Region who had arrived in New Zealand between January 2006 
and 2012. They held Permanent Resident Visas (PRVs) and were registered with the NZTC. Reasons for the choice of these criteria are explained below.

As stated, the participants were immigrant, secondary school teachers in the Wellington region of New Zealand. The choice of secondary school teachers was because there are few secondary school specific recruitment companies in New Zealand, creating a situation where secondary school teachers often find work without assistance (Anand \& Dewar, 2004). This choice was also made because of my interest as a trained secondary school teacher. I live in the Wellington region and this region was selected due to familiarity as well as considerations of practicality regarding travel-time and cost.

At the time of these interviews participants held PRVs for New Zealand. This visa type was used as a prerequisite for this research because the alternative of a Work Visa was for a particular duration only; and did not indicate whether a teacher intended to live and work in this country indefinitely. Work Visas range in duration and can be granted for a maximum stay of three years (INZ; n.d.a) while PRVs are granted to individuals who apply successfully to live and work in New Zealand permanently (INZ; n.d.b).

Participants arrived in New Zealand between January 2006 and January 2012. The reason for this time period was to focus on the process of finding teaching work. This time limit negated the influence of historical occurrences such as a drive to recruit teachers from other countries to work in New Zealand that took place in the 1990s (Sarney, 1996).

In order to teach in New Zealand all teachers must have teacher registration with the NZTC (NZTC; n.d.b). The participants were initially granted teacher registration either in the category of Provisional or Subject to Confirmation by the NZTC. Some participants had obtained Full Teacher Registration subsequent to teaching in New Zealand for some years. However, for the purposes of this study, it was their category of teacher registration upon entry into this country that was used as a characteristic for selection. 
Participants" country of origin, teaching qualifications, teaching subjects and teaching experience were enquired about at the interview stage but not made use of as selection criteria for participation because New Zealand does not select immigrants based on country of origin. Qualifications and experience were not used as criteria because these are included in the requirements for teacher registration; and teacher registration was a selection criterion.

\subsection{Limitations}

There were limitations which included a small group of participants who were geographic localisation to the Wellington Region, participant self-selection, more British participants than participants from other countries, and a greater number of male than female participants.

The small number of participants created challenges because it was uncertain whether findings were particular to the participants or whether other OTTs might experience similar challenges and supports when seeking employment. A small number of participants produced less data and therefore, difficulty establishing themes and patterns from the data collected.

The participants were geographically localised to the Wellington Region and localisation to this region could be problematic because it is atypical containing the country"s capital city, Wellington. The capital city is cosmopolitan because, being the seat of government, it attracts people from many countries. A group of participants that included OTTs from across this country could negate possible effects on demographics of particular regions; in which certain areas could contain greater numbers of immigrants from particular countries of origin.

Participants self-selected by volunteering to participate and this could indicate that they were in some way different from those OTTs who were informed about the study and chose not to participate. As Katzer, Cook and Crough (1998) state, "volunteers are 
different from those who do not volunteer" (p. 168). A randomly selected group of participants may have better reflected the population of OTTs. However, this method of selection was not possible because its organisation would not have fitted within the timeframe, scope and financial constraints of this study.

The group was United Kingdom-centric with five participants originating from that country and one participant originating from another country. This large proportion of British OTTs could mean that there were cultural influences affecting the experiences of those five participants.

More men than women agreed to participate in this study but there are more female than male teachers at secondary schools in New Zealand (Ministry of Education, 2005). This may have affected the male OTTs" experience if, due to a predominance of female teachers on staff, schools sought to hire male teachers and this facilitated male participants" access to teaching positions.

These limitations mean that findings are not generalisable but this does not negate the worth of this study because interpretive research is not intended for generalisation. Interpretive research is the study of particular people at a particular time and in a particular place (Patton, 2002) and the limitations listed above place this study in that category.

\subsection{Ethical considerations}

An application for ethical approval was lodged with the Faculty of Education Ethics Committee of Victoria University of Wellington. This Committee uses the Ethical Guidelines of the New Zealand Association for Research in Education (NZARE) as its default set of guidelines. This study complied with the NZARE Ethical Guidelines 2010 by gaining informed consent from participants. Informed consent was acquired through providing interested individuals with three documents. The first of these was an "Information Sheet for Participants" (Appendix A) and it presented a summary of this 
study. The second was a copy of the interview questions (Appendix $B$ ) and the third a consent form (Appendix $\mathrm{C}$ ). The description of this research and provision of interview questions were thought to allow potential participants to make an informed decision about whether they would consent to be interviewed.

Subsequent to interviews, these were transcribed and participants were given a copy of the interview transcript so that clarification and feedback could be provided. The purpose of this was to ensure a transcript was accurate and that what was said during an interview reflected the message participants wished to convey.

Participants were able to withdraw from the study until May 2012 at which time findings would be written. Participants were provided with a copy of the section of this thesis documenting their journey so that further clarification and feedback could be provided. This was done in order to ascertain that interpretation of what was said during the interview stage was an accurate reflection of the meaning they wished to convey.

Confidentiality was assured by personally transcribing interviews and altering details that might compromise it; such as the participants" names, schools and locations. Participants were given the option of selecting a pseudonym for use in this thesis.

Participants were able to indicate, using a check box on the consent form, whether or not they wanted to receive a copy of the completed thesis. All chose to check this box and will be provided printed copies.

Participants were informed about where information would be located and who it would be accessible to at each stage of the thesis. They were informed that data gathered during the course of the research would be saved on a home computer, viewed only by me and my supervisors, and destroyed at the conclusion of the study. They were also informed that the thesis resulting from this research would be entered into the Victoria University library and would be accessible to staff, students and other stakeholders. 


\subsection{Data gathering}

Data collected was qualitative in nature and was collected using semi-structured interviews. Halcon (2011) explains that semi-structured interviews are, "an example of a qualitative research method used in the social sciences that allows a focused, yet conversational and flexible dialogue between the interviewer and the interviewee" ( $p$. $3)$.

These interviews were part of a collective case study design and Tellis (1997) describes interviews as, "one of the most important sources of case study information" (p. 1). Creswell (2003) indicates that interviews can be advantageous because they allow a researcher an amount of control over the line of questioning. Creswell cautions that interviews also have limitations. Firstly, an interview is an indirect reporting tool filtered through the views of interviewees who articulate and perceive in different ways. Secondly, interviews take place away from a natural field setting, which may disconcert interviewees. Finally, responses are possibly biased due to a researcher"s presence. These limitations were not seen as problematic in the case of this study for three reasons: the first of these was because the personal perceptions of participants were given value by the interpretive paradigm situating the research. The second was that participants chose the location for interviews to take place; and this meant that the setting of interviews was familiar to them; and the third was that I am a fellow OTT with whom participants could share a common experience.

Dependent upon their method of first contact with me, participants were phoned, text messaged or e-mailed to arrange an interview. Interviews were convenient to a participant and ranged in duration from half an hour to one hour. The length of each interview was determined by participants because some wanted to communicate every detail that they could recall about their experience and others chose to provide concise responses to questions. 
During interviews a printed copy of the interview questions (Appendix B), which had been supplied to participants previously, was placed in a location where it could be read. This was done so that participants could refer to questions as frequently as they wanted to, allowing them to be reminded of the question they were answering at that time, providing the comfort of knowing what question was to follow, and how many questions were going to be asked.

During the interview, when issues arose that were not initially included in the questions, new questions were added as suggested by Barbour (2008). This process of including relevant questions that arose during the course of this study is explained by Richards and Morse (2007) who state that, when designing a qualitative study, "...because the goals of the project include learning inductively from the data, instruments designed in advance will rarely support an entire project" (p. 78).

The semi-structured interviews were recorded using a voice recorder, which allowed me to listen actively to participants" answers without distracting them or interrupting the flow of their communication by stopping to take notes. Another reason why voice recordings were used is because these are a more reliable means of recording interviews. Silverman (2000) suggests the use of voice recordings because, "...it is simply impossible to remember (or even to note at the time) such matters as pauses, overlaps, inbreaths and the like" (p. 149).

I transcribed audio files in order to become immersed in the data. Verbatim transcripts were used because, as stated by Barbour (2008), they form a, "...useful resource that allows the researcher to return to the data at a later stage to carry out further analysis" (p. 192). Subsequent to transcription, participants were sent copies of these transcripts so they could provide clarification and feedback, helping to ensure the accuracy of data sources. 


\subsection{Data collection timeframes}

I sought participants subsequent to receipt of Ethical Approval in October 2011. I started data collection thereafter and collection concluded in April 2012. Interviews were conducted at times convenient to participants and because of this these did not occur on predetermined dates. Interviews were held between November 2011 and April 2012; and transcribed between January and April 2012. Confirmation of the content of transcripts was obtained at participants" convenience and was received between February and April 2012. A data collection calendar appears as Appendix D.

\subsection{Managing and recording data}

A digital voice recorder was used to record face-to-face interviews and recordings were downloaded to a password-protected, personal computer and deleted from that recorder. Audio recordings were transcribed and transcripts were saved in Word document format.

Transcripts were e-mailed to participants welcoming their feedback about whether content conveyed the meaning they intended or whether updates were required. The offer was made to meet with participants to discuss the content of transcripts. Participants chose to read transcripts and respond via e-mail and one participant, Alabama, provided some changes to the transcript of her interview. Those changes included grammatical updates and the deletion of a city name.

Data analysis was begun subsequent to all participants providing approval of the content of their transcripts. Recordings of interviews and transcripts will be deleted subsequent to receipt of a result for this thesis. 


\subsection{Analysis of data}

Creswell (2003, pp. 191-195) suggests the use of six generic steps for qualitative data analysis:

$\begin{array}{ll}\text { Step } 1 & \text { Organise and prepare the data for analysis. } \\ \text { Step 2 } & \text { Read through all the data. } \\ \text { Step } 3 & \text { Begin data analysis with a coding process. } \\ \text { Step } 4 & \begin{array}{l}\text { Use the coding process to generate a description of the } \\ \text { setting or people as well as categories or themes for } \\ \text { analysis. }\end{array} \\ & \begin{array}{l}\text { Advance how the description and themes will be represented } \\ \text { in the qualitative narrative. }\end{array} \\ \text { Step 5 } & \text { A final step in data analysis involves making an interpretation or } \\ \text { meaning of the data. }\end{array}$

Data were organised and prepared for analysis by printing transcripts and placing them in chronological order based on when interviews were conducted. All of the transcripts were read in order to gain an idea of the whole.

Data analysis was begun with a coding process that was simple, using the concepts positive and negative i.e. those things that helped OTTs were entered into a column titled "positive" and those that were unhelpful were put in a column titled "negative". This supported the use of two themes identified in literature: challenges faced by, and supports for, OTTs. These two major themes replaced the category titles „positive" and "negative". "Challenges" and "supports" were categories into which minor themes were entered because the process of analysis uncovered that all themes could be defined as either challenges or supports. Later, a third category was introduced, titled "suggestions". 
Due to the focus of the research being pathways I had considered theming data based on the time at which it appeared in a pathway by, for example, using the three themes before arrival in New Zealand, upon arrival and settling in. I decided against this because the various nature of the pathways meant that data evident before arrival in New Zealand in one case might appear in the settling in phase of another case. This could potentially make it difficult to perform cross case analysis. Whereas, the themes challenges and supports could be identified at any point along a pathway and thus more readily allow for comparison and contrast across cases.

A coding process was used because interview transcripts amounted to a large volume of information and this needed to be reduced to themes. The term, theme, is defined by Richards and Morse (2007) as, "a common thread that runs through the data" (p. 135). The coding process was thus used to generate descriptions of themes.

During data analysis each case was studied as an independent unit in the first instance with challenges and supports employed as headings and those that each OTT had experienced being listed under the relevant heading. After analysing each case individually, all cases were compared to ascertain similarities and differences, following an approach advocated by Patton (2002, p. 450) who states that:

At a later point in analysis, it is possible to compare and contrast cases, but initially each case must be represented and understood as an idiosyncratic manifestation of the phenomenon of interest.

Ideas were generated about how the description and themes would be represented in the qualitative narrative. The decision was made that the description would follow the course of analysis, i.e. narrating each case individually and subsequently comparing all six by relaying information within the categories: challenges, supports and suggestions. The reason for this decision was that the individual stories were engaging and could potentially resonate with future OTTs providing experiences of individuals from which to obtain information and be successful in securing work as a teacher in New Zealand. 


\subsection{Comparing and contrasting data}

The data amounted to a large volume of text in the form of interview transcripts and, in order to begin to make sense of it, tables were created. These tables organised the information in an easy-to-read format. There were six tables initially and this was because each interview was represented as a separate case on an individual table. These tables included the categories: challenges, supports and suggestions. Within these three categories themes were indicated. To begin with those themes identified in the literature review were used and they included: bureaucracy, culture shock, professional development and networks. Later themes that emerged from this study were added. Once all data had been included in those individual tables, a single table was created and this compiled all information in order to allow for comparison and contrast of data across cases.

\subsection{Trustworthiness of the data}

\section{Dependability}

Reliability can be understood as how dependable a study is (Johnson \& Christensen, 2008). The dependability of this research was ensured in four steps. Firstly, by transcribing interviews ensuring that the content was captured verbatim. Secondly, by sending interview transcripts to participants for clarification and feedback allowing them to check the transcripts captured the meaning they endeavoured to convey during the interviews. Thirdly, through returning to transcripts on a regular basis during analysis and writing encouraged accuracy by ensuring a continued focus on the data. Finally, by checking the accuracy of the descriptions that had been written with participants.

\section{Trustworthiness}

Validity is referred to in literature on qualitative research as the "trustworthiness" of a study (Barbour, 2008; Johnson \& Christensen, 2008; Shenton, 2004). Trustworthiness refers to the authenticity of the data collected and this can be compromised in a number 
of ways including: researcher bias, inaccurate description, erroneous interpretation and incorrect generalisation.

Researcher bias is evident when a researcher is intent on arriving at particular findings and does so without taking care to examine whether data has led to those findings or whether she has taken a particular view of that data and led herself to the findings she aimed to obtain (Johnson \& Christensen, 2008). In this study researcher bias was guarded against using reflexivity, which is a process in which the researcher maintains constant awareness of and frequently questions her biases (Johnson \& Christensen, 2008). Reflexivity was achieved by maintaining a research journal to which the first entry was my answers to the interview questions about my experience as an OTT. This journal entry appears as Appendix E.

Descriptive validity refers to the correct description of what occurred during the study (Terre Blanche \& Durrheim, 2002) and this was aided by transcribing interviews verbatim and providing transcripts to participants for their feedback and clarification. Cranton (2001) explains, "...the trustworthiness of communicative knowledge is established through discourse and consensus among informed people" (p. 14). Returning regularly to the transcripts for clarification and gaining verification from participants enhanced descriptive validity.

Interpretive validity is the accurate interpretation of data (Johnson \& Christensen, 2008) and this was ensured by supplying participants with copies of the findings pertaining to their own experience in draft format and gaining feedback on the accuracy of interpretation.

Boejie (2010) states that, "external validity or generalisability pertains to whether the results of a study can be generalised beyond the specific research context" (p.180). External validity can be a challenge for qualitative researchers because it is difficult to control the research environment and participants. However, generalisability is not an aim of an interpretive research paradigm. As Patton (2002) explains, interpretive 
research is, "more interested in deeply understanding specific cases within a particular context than in hypothesizing about generalisations and causes across time and space" (p. 546). It is not an intention for the findings of this study to be generalisable but rather to provide useful information to other OTTs who aim to enter the New Zealand teaching workforce.

\subsection{Summary}

This chapter has documented the research aim and question, which were to investigate pathways OTTs followed into teaching in order to formulate a suggested pathway. Research was carried out in an interpretive paradigm using a qualitative design. The study was a collective case study of six OTTs and their experiences of finding a teaching position in New Zealand. Data were collected through semi-structured, face-toface interviews and analysed through Creswell"s (2003) six generic steps, which allowed two major themes, challenges and supports, to emerge. Trustworthiness was ensured through an interpretive process of continually referring to transcripts and through discourse with participants. Ethical considerations during the planning and implementation of this research were detailed: including gaining informed consent, using pseudonyms to assure participant confidentiality and safely storing data. The chapter to follow documents the findings of this research. 


\section{Chapter 4: Findings}

\subsection{Introduction}

This chapter presents the findings of this study beginning with demographic and teaching information provided by the six participants. The case of each participant is presented individually and is organized following the course of the narrative as it was told by a participant. Personal quotations are included to provide rich information by supplying participants" descriptions of their experiences. A diagram representing pathways into teaching is provided for each case. The six cases are subsequently compared and contrasted, and participants" suggestions are documented.

\subsection{Participant demographics}

There were more male than female participants; four men took part in this study and two women. Five OTTs came to New Zealand from the United Kingdom and one arrived from South Africa. All who took part spoke English as a first language, half spoke a second language and one participant spoke a third language. Participants held a tertiary qualification and most had obtained postgraduate qualifications. Two had been granted Work Visas initially; and all held Permanent Resident Visas at the time they were interviewed. Four had received Provisional Teacher Registration and two had registration, Subject to Confirmation, upon first application to the NZTC. The duration of overseas teaching experience varied from two-and-a-half to 18 years. Participants" teaching subjects represented a wide array including languages, sciences and business. Table 1 sets out demographic information. 
Table 1: Participant demographics

\begin{tabular}{|c|c|c|c|c|c|c|}
\hline Participant & Tom & Emily & Alabama & Josh & Leonard & Doug \\
\hline Gender & Male & Female & Female & Male & Male & Male \\
\hline $\begin{array}{l}\text { Country } \\
\text { of origin }\end{array}$ & $\begin{array}{l}\text { United } \\
\text { Kingdom }\end{array}$ & South Africa & $\begin{array}{l}\text { United } \\
\text { Kingdom }\end{array}$ & $\begin{array}{l}\text { United } \\
\text { Kingdom }\end{array}$ & $\begin{array}{l}\text { United } \\
\text { Kingdom }\end{array}$ & $\begin{array}{l}\text { United } \\
\text { Kingdom }\end{array}$ \\
\hline $\begin{array}{l}\text { First } \\
\text { language }\end{array}$ & English & English & English & English & English & English \\
\hline \multirow[t]{2}{*}{$\begin{array}{l}\text { Other } \\
\text { languages }\end{array}$} & Arabic & Afrikaans & French & & & \\
\hline & & Xhosa & & & & \\
\hline \multirow[t]{4}{*}{ Qualifications } & $\begin{array}{l}\text { Bachelor of } \\
\text { Arts } \\
\text { (Honours) }\end{array}$ & $\begin{array}{l}\text { Bachelor of } \\
\text { Arts } \\
\text { (Honours) }\end{array}$ & $\begin{array}{l}\text { Bachelor of } \\
\text { Science }\end{array}$ & $\begin{array}{l}\text { Bachelor of } \\
\text { Mathematics }\end{array}$ & $\begin{array}{l}\text { Bachelor of } \\
\text { Science } \\
\text { (Honours) }\end{array}$ & $\begin{array}{l}\text { Bachelor of } \\
\text { Arts } \\
\text { (Honours) }\end{array}$ \\
\hline & $\begin{array}{l}\text { Post } \\
\text { Graduate } \\
\text { Certificate in } \\
\text { Education }\end{array}$ & $\begin{array}{l}\text { Post } \\
\text { Graduate } \\
\text { Certificate in } \\
\text { Education }\end{array}$ & $\begin{array}{l}\text { Post } \\
\text { Graduate } \\
\text { Certificate in } \\
\text { Education }\end{array}$ & $\begin{array}{l}\text { Post } \\
\text { Graduate } \\
\text { Certificate in } \\
\text { Education }\end{array}$ & $\begin{array}{l}\text { Post } \\
\text { Graduate } \\
\text { Certificate in } \\
\text { Education }\end{array}$ & $\begin{array}{l}\text { Post } \\
\text { Graduate } \\
\text { Certificate in } \\
\text { Education }\end{array}$ \\
\hline & & $\begin{array}{l}\text { Master of } \\
\text { Arts }\end{array}$ & $\begin{array}{l}\text { Post } \\
\text { Graduate } \\
\text { Diploma in } \\
\text { Education } \\
\text { and } \\
\text { Professional } \\
\text { Development }\end{array}$ & & & $\begin{array}{l}\text { Licentiate of } \\
\text { Trinity } \\
\text { College } \\
\text { London }\end{array}$ \\
\hline & & & & & & $\begin{array}{l}\text { National } \\
\text { Professional } \\
\text { Qualification } \\
\text { for Headship } \\
\end{array}$ \\
\hline Initial visa & Work & $\begin{array}{l}\text { Permanent } \\
\text { Resident }\end{array}$ & Work & $\begin{array}{l}\text { Permanent } \\
\text { Resident }\end{array}$ & $\begin{array}{l}\text { Permanent } \\
\text { Resident }\end{array}$ & $\begin{array}{l}\text { Permanent } \\
\text { Resident }\end{array}$ \\
\hline $\begin{array}{l}\text { Visa at time } \\
\text { of interview }\end{array}$ & $\begin{array}{l}\text { Permanent } \\
\text { Resident }\end{array}$ & $\begin{array}{l}\text { Permanent } \\
\text { Resident }\end{array}$ & $\begin{array}{l}\text { Permanent } \\
\text { Resident }\end{array}$ & $\begin{array}{l}\text { Permanent } \\
\text { Resident }\end{array}$ & $\begin{array}{l}\text { Permanent } \\
\text { Resident }\end{array}$ & $\begin{array}{l}\text { Permanent } \\
\text { Resident }\end{array}$ \\
\hline $\begin{array}{l}\text { Initial NZTC } \\
\text { registration }\end{array}$ & Provisional & Provisional & Provisional & $\begin{array}{l}\text { Subject to } \\
\text { Confirmation }\end{array}$ & Provisional & $\begin{array}{l}\text { Subject to } \\
\text { Confirmation }\end{array}$ \\
\hline $\begin{array}{l}\text { NZTC } \\
\text { registration } \\
\text { at interview }\end{array}$ & Full & Provisional & Full & $\begin{array}{l}\text { Subject to } \\
\text { Confirmation }\end{array}$ & Provisional & Full \\
\hline $\begin{array}{l}\text { Overseas } \\
\text { teaching } \\
\text { experience }\end{array}$ & $5 \frac{1}{2}$ & 13 & $21 / 2$ & 7 & 4 & 18 \\
\hline \multirow[t]{5}{*}{$\begin{array}{l}\text { Teaching } \\
\text { subjects }\end{array}$} & Business & English & Electronics & Mathematics & Electronics & Music \\
\hline & Economics & Xhosa & Mathematics & & Mathematics & \\
\hline & & & Physics & & Physics & \\
\hline & & & Science & & Science & \\
\hline & & & Social Studies & & & \\
\hline
\end{tabular}




\subsection{Tom's journey}

Tom was a teacher from the United Kingdom who completed a Bachelor of Arts with Honours during undergraduate study and a Postgraduate Certificate in Education. He spoke English as a first language and Arabic as a second. His teaching subjects were Business and Economics and he had been teaching for five and half years prior to arriving in New Zealand. He entered New Zealand on a Work Visa and had Provisional Teacher Registration (PTR).

Janine, Tom"s partner, was from New Zealand and was living in the United Kingdom. Janine made contact with a former teacher of hers and this contact led serendipitously to work for her and Tom. Tom had the following to say:

My partner is a teacher and she completed her course and wrote a little letter to her old teacher in New Zealand to say that she had completed her training and intended to pursue a teaching career. That little piece of paper got passed onto the principal of the school who called up and offered her a job. She explained that her partner was a teacher from the United Kingdom and the principal offered to give me a job, too.

An associate of the school who was living in the United Kingdom interviewed Tom and he was formally offered a teaching position. He perceived that the school had been searching for an individual who could work comfortably with staff and students. He felt lucky having received work in this manner. He recognised the gamble the school had taken employing an OTT who was offshore and said:

The school management did not know who I was and they took a chance.

Upon arrival in New Zealand, Tom started teaching. He arrived with a Work Visa and was told that the visa would automatically be renewed for a further two years. However, 
upon application to INZ for a renewal, he was informed this was not the case. He had the following to say:

I had a two-year Work Visa and thought I could get another two year Work Visa readily. That's what I perceived. I had been told that and when I got there to claim a Work Visa they said, "You should be leaving the country actually. We can't be giving you another one but because you seem to have been given false information in the past, we'll give you an extension and, you need to get an application for PRV lodged as soon as possible. You will have to leave the country otherwise."

He made an application for a Permanent Resident Visa (PRV) which took time, effort and money. It was difficult to make this application because, at that time, he was adjusting to a new school and adapting to life in New Zealand. He now has a PRV.

In a short space of time of working at the school, Tom knew he had made a connection with staff and students but indicated that it took a number of years to come to the decision he would like to teach at that school indefinitely. He explained the situation by saying that:

It's taken me a bit of time. I found I knew very quickly that I was connected to my colleagues and I knew very quickly that I was connected to the students but I didn't know very quickly that I was connected to the school and it's taken me about two or three years to actually pin my colours upon the school and say, "Right, I'm staying for the duration."

Student behaviour was different in New Zealand from what Tom had encountered in the United Kingdom and when comparing the behaviour of New Zealand secondary school students to students in England. He said: 
I found New Zealand students, coming from the UK, either exceedingly laid back or exceedingly in your face. I found these two sides. I didn't find this middle ground, average student.

The strongly bicultural nature of the New Zealand environment was one that he found different from the multicultural environment in which he had previously taught. He suggested OTTs attend professional development courses and gain information in order to better understand this unique environment saying:

Coming from a multicultural country, and coming to this very clear biculturalism it's really strong. I would love to put some time into working that out, really going into that in some depth. There should almost be a requirement that teachers do a course in Māori before they can become a teacher in New Zealand. You know? Māori verse, Māori sounds and that should include a marae visit.

Documentation was perplexing to Tom because he perceived there to be an excessive demand for paperwork. For instance, he had gathered reference letters throughout his career. He explained that:

The main thing was that I came across expecting to need references and l've travelled a lot in my life and collected reference letters all my life, rather than needing to continuously update referees' addresses on my CV. So I have a number of letters and these were not eligible in New Zealand.

Those references were not useful and he was required to provide letters from previous employers specifying whether he had worked full or part-time, how many hours each role had included and detailing the duties of that position. This was a challenge that he was still facing at the time of our interview because he had to gain evidence from each of his past employers in support of his application for Salary Assessment and it was difficult to gain such evidence from the United Kingdom while located in New Zealand. He said: 
My teaching jobs were taken at one hundred percent of their time, for every year teaching a year of experience was taken into account in the salary assessment. It's the other working activities, N.G.O.s and aid organisations, that have not fallen as clearly and cleanly into categories and, because those are transitory industries, it isn't easy to gather that information from here.

After having successfully made many other applications (e.g. Visa, Teacher Registration and Qualifications Assessment) he no longer had the motivation to contact his previous employers and he expressed that by saying:

The system has almost burnt me down.

Having been worn down by bureaucracy Tom was unmotivated to gain required information to be paid the salary that he estimated he would be entitled to. This added financial complexity to the issues faced upon arrival in a new country such as, paying a deposit for accommodation and setting up house. He had a positive way of viewing this situation stating:

I think I'm being paid under what I should be paid and on good days I take that as an interesting savings scheme.

Tom expressed a great appreciation for the natural environment and spoke positively about teaching Geography in this country saying:

A major benefit is access to nature and what this adds to the realities of teaching Geography. It's a geologist's dream, this place! It's great being able to do a lot more. Being less connected to the book and the picture, and more connected to the land itself. I think it's a real gift and something that New Zealand should be publicising and putting out there - making it a key factor for its students. 
Tom spoke about the difference in the pace and focus of life in New Zealand, indicating that OTTs should make certain this lifestyle was right for them, explaining:

I think a strong meditative life is necessary. I think there needs to be a calmness or a change in pace. Why do people come to New Zealand? I think people need to really think about that. I think it's quite a slow pace of life or something altered. What it's sold as is this outdoors, beauty and nature place. As long as you make sure you participate in that and it becomes your life then it's got everything but if that isn't your life, if it's just a nice add on, then I think you need to develop something else.

Tom"s pathway into teaching is depicted in the form of a diagram on the following page, Figure 4: Tom"s Pathway. His supports, challenges and suggestions are listed beside that diagram. 
Figure 4: Tom's pathway

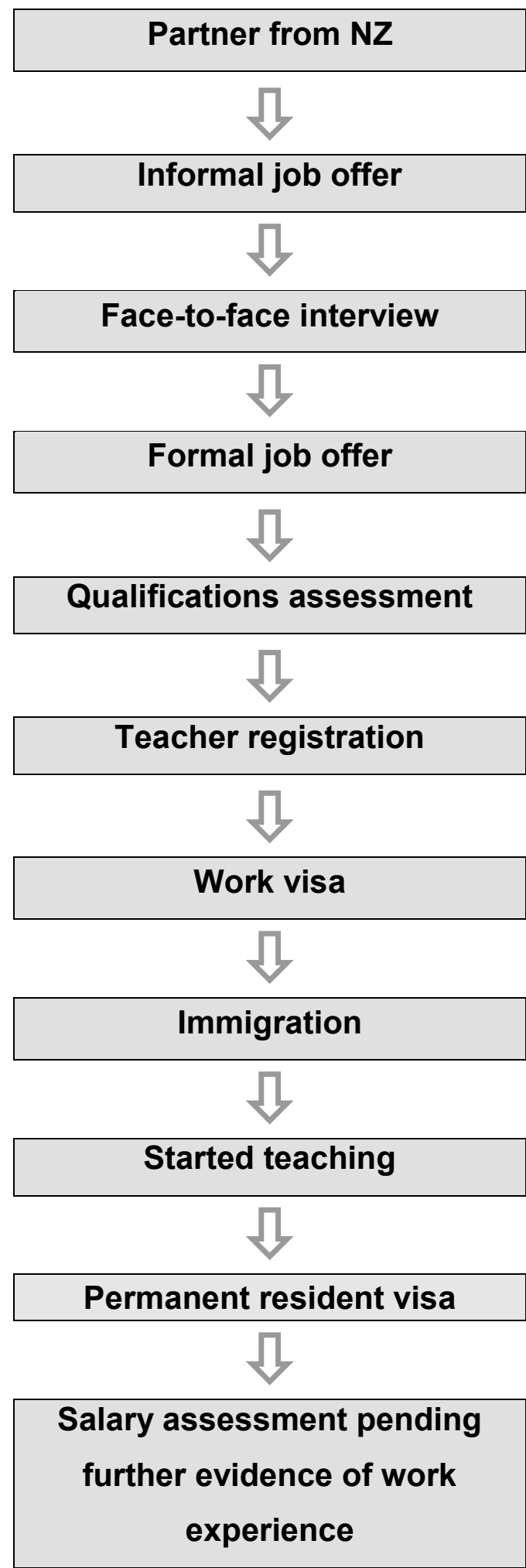

\begin{tabular}{|l|}
\hline \multicolumn{1}{|c|}{ Supports } \\
\hline - Luck \\
- Natural environment \\
- Networks
\end{tabular}

\begin{tabular}{|l|}
\hline \multicolumn{1}{|c|}{ Challenges } \\
\hline - Bureaucracy \\
- Culture shock \\
\hline
\end{tabular}

\section{Suggestions}

- Preparation

- Professional development 


\subsection{Emily's journey}

Emily was a South African teacher who had completed a Bachelor of Arts with Honours, a Postgraduate Certificate in Education and a Master of Arts. Her first language was English, her second language Afrikaans and her third language Xhosa. Her teaching subjects were English and Xhosa and she had been teaching for thirteen years before deciding to immigrate to New Zealand. She had a Permanent Resident Visa and Provisional Teacher Registration when she immigrated.

Emily and her husband had been considering a move from South Africa to New Zealand for a couple of years. The number of vacant teaching posts advertised in the Education Gazette online appeared to indicate that there was no shortage of teaching jobs and the immigration points that her teaching qualifications and experience attracted made it appear that she would secure work easily. She started applying for positions advertised in the Education Gazette online. She had a friend living in New Zealand who indicated that it was unlikely she would secure a job while offshore and, because of this, she was unconcerned that the job applications she was lodging online were not receiving positive responses. Upon arrival in New Zealand, this trend continued and she became concerned because, having the necessary qualifications and thirteen years of teaching experience, she had never struggled to find work in the past. She explained the situation saying:

I heard that, if I was not in the country, getting a job was very unlikely. So I wasn't that bothered by the fact that I wasn't getting any positive response for the jobs I was applying for. When we were in South Africa, I got no response to my applications, either no response or, "No, thanks". When we got here I had a continuation of that which I found quite stressful.

Emily widened this job search and every job that had the word "English" in the title was applied for. She did some relief teaching, which was becoming more frequent, when she applied for and was awarded a part-time, fixed-term teaching position. She said: 
I got lucky, I saw an ad for a job teaching the senior class of a school and I thought there was no way because why would you let a foreign teacher loose on your senior class?

That position was for two days a week and compromised her ability to fill other relief teaching positions because these tended to be for a full week. She found a job doing three days part-time administrative work that fitted around her teaching. A year later, that school offered her a full-time, permanent teaching position and she was certain she would have left teaching had this not occurred. She described the situation saying:

I ended up at the school, I think because they have a history or a practice of employing foreign teachers. They have a lot of foreign students. They're New Zealand students but their parents are originally from Europe. So there is a history of that. I think that's why I got work there in the first place.

The behaviour of the students was different from student behaviour Emily had encountered while teaching in South Africa and in Ireland. She had the following to say:

Maybe this is really obvious but teaching is different here to South Africa, which is different again to my experience teaching in Ireland. You come with different expectations and experiences of different conduct and what a South African child would or wouldn't do is different compared to a New Zealand child. Sometimes I wasn't sure whether a child was being rude or different, culturally different.

When asked about parts of the process she had found challenging, Emily referred to her application for Teacher Registration from the NZTC. That application was made before arriving in this country and she said that:

The paperwork required by the NZTC was long and complicated. 
Another challenge was that extra points awarded by INZ to Emily"s application for Permanent Residence, and a large number of teaching vacancies on the Education Gazette online, appeared to indicate that English teachers were in demand. This differed from her experience. She said:

I found a disconnection between INZ's perception that teachers are required here and that teachers with my subject were in demand, because that's the information I was getting. The Education Gazette was suggesting that teachers like me were needed and my experience on the ground didn't support that. I was not in demand and that was not matching with the stated fact that teachers were in demand and that teachers with experience were needed.

After arriving in this country there appeared to be an idea in the minds of potential employers that Emily"s overseas qualifications and experiences were not valid. This had a negative impact and she described the situation and its affect by stating:

There's almost an institutional knowledge that was suggesting my experiences were not valid because I was being told that teachers were needed but I wasn't getting interviews or jobs. I felt inadequate because people didn't want to interview me.

Emily referred to a natural aversion by employers to hiring OTTs because of a perception that they might find it more difficult to integrate. She expressed her thoughts by saying:

I think that there is, it's not quite xenophobia, but there's certainly a resistance from many New Zealanders, from employers. It's, I think, a natural avoidance of people who are from other cultures because it's more difficult for them to integrate and it's important for children to have teachers who are comfortable in their world, so the fact that I was South African and from a different culture was problematic for people. 
When asked about her advice to OTTs, Emily indicated they should meet with someone and gain guidance about the style and layout of their CV. CV requirements were different in New Zealand from those in South Africa with a need for more personal information than she was used to providing. She had the following to say:

Try and get to know someone in the industry and have them help you look at your CV. I had a friend who was already here help me with my CV and then I ended up having a chat with a retired principal and she refined it just that little bit more.

Emily suggested meeting with a representative of a school when supplying a CV for a job application. The reason why she made this suggestion was, coming from South Africa, she perceived she was expected to struggle when speaking English and meeting a school representative dispelled that misconception. She said:

I would advise them to meet someone at the school. Make an appointment to see the person who does the relief coordination, otherwise you are just a foreigner on a piece of paper and that's not attractive, as far as I can tell.

The fact that you show you are able to conduct yourself in English helps. I was expected to stumble by in English but it's my teaching subject. It was as though people just didn't think I would cope with basic conversation.

Emily would have appreciated being informed that she was unlikely to be awarded a permanent teaching post by a school, unless she had done relief teaching at that school for six months or a year, and so she suggested looking for temporary positions:

I would tell people to forget about getting permanent work at a place but look for temporary work. 
Another idea Emily had about temporary teaching was that OTTs spend a day in a school before relief teaching in order to orientate themselves. She had the following to say:

Some useful advice would be to try and spend some time in a school. I think that would actually help to contextualise things. That way when you do end up relieving, you have some sense of the way people communicate. For some of the relief work I did, it would have been helpful if I'd had time in a classroom in that school before going in on my own.

Emily advised OTTs think about whether they really would like to teach in New Zealand. She said:

Decide if you really want to be a teacher. I don't think it's very easy, depending on where you come from. Some of the schools are quite tough. So decide if it's worth it - the slog of a year of some pretty difficult teaching experiences before you can get into a school where it's great to teach.

The steps that Emily followed on her pathway into teaching in New Zealand are depicted in Figure 5: Emily"s Pathway on the next page. Her supports, challenges, and suggestions for others are provided in short lists. 
Figure 5: Emily's pathway

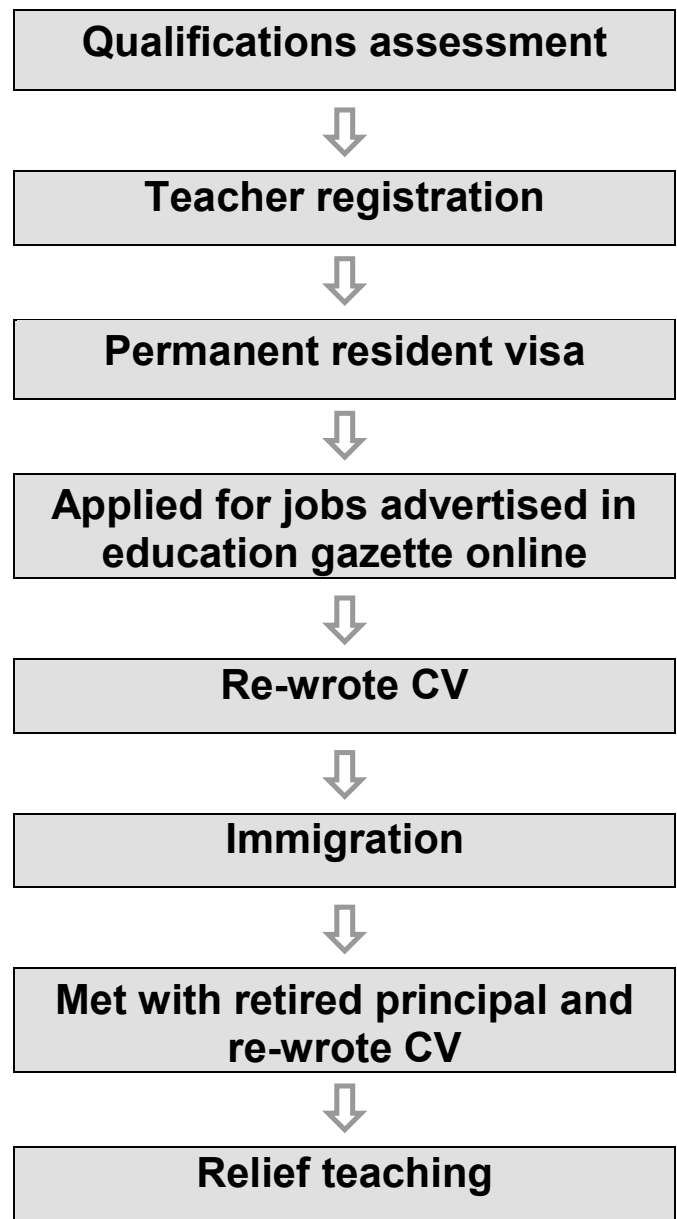

\begin{tabular}{|l|}
\hline \multicolumn{1}{|c|}{ Supports } \\
\hline - Luck \\
- Network \\
- Preparation \\
\hline
\end{tabular}

\begin{tabular}{|l|}
\hline \multicolumn{1}{|c|}{ Challenges } \\
\hline - Bureaucracy \\
- Culture shock \\
\hline
\end{tabular}

II

\begin{tabular}{|c|}
\hline $\begin{array}{c}\text { Applied for job advertised in } \\
\text { education gazette online }\end{array}$ \\
\hline$\square$ \\
\hline Face-to-face interview \\
\hline
\end{tabular}

『

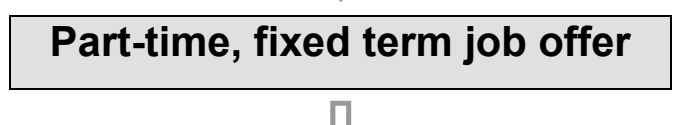

$\sqrt{5}$

Salary assessment

?

Full-time job offer 


\subsection{Alabama's journey}

Alabama was a teacher from the United Kingdom who had completed a Bachelor of Science and a Postgraduate Certificate in Education. She had been teaching for twoand-a-half years and her teaching subject was Science. Her first language was English and her second language French. She came to New Zealand on a Work Visa and had Provisional Teacher Registration.

A friend teaching with Alabama in the United Kingdom had taught in New Zealand and she felt lucky to know someone who had been through the process. Her friend advised that she make certain applications before leaving the United Kingdom. She said that:

I was very lucky because I have a very good friend who was teaching with me in England who had taught in New Zealand. She said to me, "Make sure you get your qualifications assessed by the New Zealand Qualifications Authority and get your teacher registration before you leave," and so I did. That's how I was able to get a job so quickly because I had done all of that before I left the UK. I know from talking to other people that those can be a hassle to sort out.

Through the Education Gazette online Alabama applied for positions before emigrating and those applications received no response. She had the following to say:

I think I applied for ten jobs online before we left, which would have been prior to the end of October in 2006. We travelled for three months before we got to New Zealand and I put it down to that that I didn't hear back from a single school.

Upon arrival in New Zealand, Alabama registered with a Wellington-based teacher recruitment company that advised her to apply for the single teaching job they had on their books for the Wellington Region at that time. She was encouraged to apply in spite of her limited experience teaching Physics and Electronics, which were two of the subjects that the role required. She had the following to say: 
The school wanted a Physics and Electronics teacher and I had been through the recruitment company, and they said, "Well, why don't you just go for it. You've got a little bit of Physics and Electronics in what you taught in England." So I thought I had nothing to lose and I went for an interview and got the job!

Due to Alabama"s limited prior teaching experience in Physics and Electronics, she faced challenges teaching these subjects. She described her experience saying:

There were huge challenges with teaching. The Science was fine. The Science curriculum is very similar to the English one, but I had to teach Electronics and Physics, none of which I had any prior experience of and with the new curriculum as well. It was still quite a big hurdle and also the fact that I was the only Electronics teacher at the school.

In order to overcome these challenges Alabama made a point of networking. She said that:

There was this really good, little community of Electronics teachers in the city. So, I joined in with that and got a lot of advice, tips and resources; and I got a Physics tutor.

Alabama had been teaching for a couple of years before immigrating and said that her first year of teaching in New Zealand felt as challenging as her first year of teaching after graduating from university.

The school supported Alabama and she described this support by saying:

The school actually really gave me one class less than I should have had, so I did have extra time for that first year and they were really supportive. For example, they let me go on a lot of professional development courses and up- 
skill and gave me time off when I needed it and my classes were all really nice as well.

Getting to know the indigenous culture and teaching in a culturally responsive way were challenges that Alabama spoke about, saying:

I experienced cultural challenges like working with a lot more ethnic groups than I was used to. The challenge was getting to know the local culture and trying to teach in a culturally responsive way.

In order to overcome these challenges Alabama enrolled in courses and took advantage of professional development opportunities. She said these courses informed her of what to say and do, and also what she said and did that could cause offence to students of different cultures. She said:

You know what to say and what not to say and you know a Eurocentric way of doing things and saying things. It just makes you realise there's a lot of things you do without noticing, like pointing and making eye contact. It's just about respecting other people's cultures. You know that just because students don't do those things it doesn't mean that it's wrong or they're disrespecting you and vice versa.

Alabama perceived having recently qualified as an advantage and she said:

I guess being quite a newly qualified teacher I was a bit more aware about finding out about students, their backgrounds and their lives.

Alabama spoke about locally trained teachers going overseas to teach in order to gain higher salaries than are paid in New Zealand. She indicated that the school she worked at had a practice of employing the best candidate for the position, irrespective of whether they had come from overseas or been trained locally. She stated: 
There isn't a policy of a preference for Kiwi teachers but just the best teacher for the role.

According to Alabama, OTTs with the teaching subjects of Maths and Science would find work with ease and the content of these subjects was fairly universal but teachers of subjects such as Physical Education would struggle to find work in New Zealand. She surmised that teachers of Geography and History might have a greater challenge with the different subject content of their more place-based subjects and said:

I think the English system, particularly in Science, is so similar but I imagine being a History teacher or a Geography teacher might be a bit more challenging.

I imagine you will find, in a lot of countries, that if people teach Maths and Science they don't have a problem finding teaching work.

Alabama would advise OTTs to have their qualifications assessed and their teacher registration complete well in advance of arriving. She said:

I think I started the process about six months before we left, so it was all done before we flew out. Get your qualifications assessed and your teacher registration application done and dusted well in advance of leaving the country because this really helps with applying for and getting jobs.

When talking about advice for OTTs, Alabama suggested reading everything available about the area they were moving to and about the school they were applying to. This was because teachers might become despondent if they ended up teaching at a challenging school, and consequently thinking all schools in New Zealand were difficult and deciding to return to their country of origin. She suggested: 
Make sure you know what area you are going to and read up a lot about the school because I was very fortunate, I ended up at a really nice school but I didn't have a clue.

In Alabama"s experience, professional development activities received greater support from schools in New Zealand than in the United Kingdom and she advised OTTs ask to attend any courses that might support their teaching. She said:

Just ask for support, particularly with any professional development that you want. I think most schools in New Zealand are really good at supporting professional development needs. I really noticed a difference. We barely ever got support for professional development in England and here you just get tons of it and I think that's great.

Alabama perceived that these opportunities were also immensely helpful because teachers could constantly learn through them and not forget what it was like to be a student; and consequently have greater understanding of their students. She encouraged OTTs to be persistent and indicated that the process of immigrating and finding work would be really difficult at times but they should not become despondent saying:

When it gets hard just keep on going. Don't give up.

Alabama"s pathway is documented in steps in a diagram, Figure 6: Alabama"s Pathway, on the next page. Those things that she found supportive and challenging are listed and her suggestions for others are provided. 
Figure 6: Alabama's pathway

Qualifications assessment

$\sqrt{2}$

Teacher registration

II

Work visa

II

\section{Applied for jobs advertised in the education gazette online}

II

Three month holiday

II

\section{Immigration}

II

\section{Registered with recruiter}

$\sqrt{5}$

Alerted to job by recruiter

$\sqrt{5}$

Face-to-face interview

$\sqrt{2}$

Offer of employment

I

Started work

II

Salary assessment

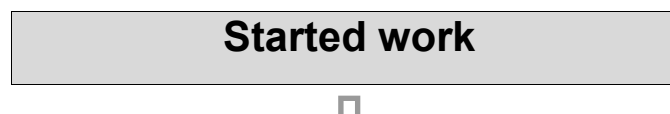

\section{Supports}

- Luck

- Professional development

- Network

\begin{tabular}{|l|}
\hline \multicolumn{1}{|c|}{ Challenges } \\
\hline - Bureaucracy \\
- Culture shock \\
\hline
\end{tabular}

Suggestions

- Positive attitude

- Preparation

- Professional development 


\subsection{Josh's journey}

After completing a Bachelor of Science majoring in Mathematics and a Post Graduate Certificate in Education, Josh had been teaching Mathematics at a school in London for seven years. He had been promoted to the position of Assistant Head of Department and was later offered the Head of Department position, which he turned down in order to move to New Zealand. He arrived in New Zealand on a Permanent Resident Visa (PRV) with Teacher Registration in the category, Subject to Confirmation.

Josh"s partner was from New Zealand and they wanted to bring their children up here. Josh attended an Australia and New Zealand immigration fair and was provided with information about the Education Gazette online and the name of an Auckland-based teacher recruitment company. He started looking for jobs in the Education Gazette online but was hesitant to apply for any posts due to the difference in the start and end dates for school terms in New Zealand and the United Kingdom. He said:

I was looking but not massively actively because of the difference in the years. In the UK the school years run from September to July, which meant that there was no point in me applying when all the UK jobs come up at Easter time but nobody in New Zealand would have handed their notice in until the end of the year so, you wouldn't know whether any jobs were available. It was all a little bit up in the air.

After attending an information evening run by a recruitment company, Josh submitted his CV to that recruiter. He applied to the NZQA to have his qualifications assessed and to the NZTC for Teacher Registration. He was granted a PRV and notes that these applications were expensive stating:

I got my visa and I knew I then had to get my qualifications assessed by the $N Z Q A$, and all of these processes were financially consuming. 
Josh questioned the need for sending the same information firstly to the NZQA and subsequently to the NZTC and wondered whether interagency co-operation could negate this duplication. He suggested that the report the NZQA provides, assessing OTTs" qualifications, could be provided to the NZTC saying:

Once l've got my NZQA application done, and l've been registered, that information should go directly to the MoE. If you state, which I had in my NZQA application, that it's to be assessed to be able to teach then that information should go directly to the NZTC and directly to the MoE. I shouldn't have to provide anything extra because it's all been provided to one place first.

This requirement for the same documentation to be supplied to three institutions caused frustration, particularly because the duration it took for the NZQA to assess Josh"s qualifications meant his Police Clearance Certificate (PCC) was out of date by the time it was sent to the NZTC and he had to apply for another one. Application for a new PCC cost money and delayed his application for Teacher Registration. He had the following to say:

I got a letter back from the NZTC saying that my PCC was no longer current. It was eight months old and, out of those eight months, it had spent four months with the NZQA. It wasn't as though I had held onto it. And each time you have to get a PCC, it costs another hundred pounds in the UK.

At the time of our interview, Josh still was not being paid at an accurate rate because his qualifications were again required, this time by the $\mathrm{MoE}$, in order to complete a Salary Assessment but he could not provide these because they were in storage. $\mathrm{He}$ explained the situation saying that:

All of my stuff is still in storage, because we don't have a house yet, including the filing cabinet with the original certificates in and therefore I'm still not on full pay. I'm on unqualified teacher pay. 
Josh felt lucky that he and his partner were house sitting which saved money during a time when he was not being paid the salary he was entitled to. He said:

Luckily, just because of the coincidence of the situation, we haven't had a house up till now. So we've actually been moving around and house sitting for people. I've been living out of a suitcase and coming into work. It's not really ideal but because of not having to pay rent, because friends and family have been putting us up, the financial aspect of not being paid in full is not as bad as it could be. If we'd moved into a furnished house, l'd have the place but not the actual filing cupboard with my certificate saying that I am qualified to teach.

The Auckland-based recruitment company which Josh had initially dealt with was not aware of teaching positions that were being advertised in the Education Gazette online for the Wellington region, the area of New Zealand Josh and his partner wanted to move to in order to be close to extended family. He realised that, although the manager of this company had stated during that meeting that his company would find him a job, he was going to have to find a teaching position without that recruiter"s assistance. He described the situation saying:

At a meeting at New Zealand House I had been given the impression that, "Yes, we'll find you a job. Your CV is brilliant. You've been teaching in a North London Comprehensive. People will want to hire you." I thought that they would find me a job, and that would be it. Then a few jobs had come up, and l'd not heard anything. So, I started asking questions and was told that they weren't aware of those positions and I should be contacting schools myself. I've got no issue with that but it wasn't really the way the thing was sold to me and that was a concern. So, I decided to take the bull by the horns and find a job myself.

Taking control of the situation, Josh wrote a covering letter for his CV detailing his experience, the kind of roles he was interested in, and how he saw his future. He sent 
this information to eight schools in the Wellington Region and was contacted by one, requesting an interview via Skype. He researched all of the information he could find online about that school and had the following to say:

I had looked on the website. I looked at loads of the school reports and information. I was happy with some of the questions I had asked back about the number of scholarships that were coming out of the school. As I say, I wasn't fully conversant with it all but knew the scholarships that came out and what proportion of those were Maths related. During the interview, I thought that was a good question and it showed I had a really strong interest in the school. It showed that l'd not just gone in blank to the interview, l'd done as much research as I could possibly do, and I had some relevant questions about the school.

The interview proved challenging because the video feed from the school in New Zealand ceased to relay video but continued to send video from him to the five interviewers. This meant he had no nonverbal feedback to inform him of how the interview might be progressing. He received a letter of offer a few days after this interview and noted that he had received no feedback from other schools to which he had applied. He said:

And the other jobs that l'd applied for I didn't get any of them, didn't get interviewed, didn't get mention to any of it and I just got this thing from one school that the field was really strong and I didn't make the shortlist this time and l'd still had no feedback, which I thought was a little bit disappointing.

When asked about those things Josh found most supportive he indicated that family, friends and colleagues in New Zealand had been incredibly supportive, explaining that:

I had been in contact, basically, as a background to this role. My nephews go to the school, their dad used to coach rugby here. He contacted the Head of Maths at the school to say I was interested. The Head of Maths put me onto the 
Assistant Head of Maths and he gave me a bit of an insight into the role. I had some e-mail contact and that was really useful.

The school had also been very supportive and he described the situation as follows:

We have laptops here, and mine didn't have the software I needed on it, so I couldn't access and display lessons. Seven years of resources gone! The school was great saying, "Yeah, we can install that programme on a laptop. You can get that." So, I put it on a laptop and now I can access lessons and convert them slowly to Power Point and teach off all this work. Things like that have been really nice.

Initially he found the term Restorative Practice, in terms of managing student behaviour, foreign but spending time with the Restorative Practice Coordinator, a fellow OTT from the same country of origin, was both informative and supportive. He perceived Restorative Practice would be implemented in some form in the United Kingdom in future.

Josh"s pathway is presented in the form of a diagram on the next page, Figure 7: Josh"s Pathway. Those supports and challenges he encountered, as well as his suggestions for agencies, are documented. 
Figure 7: Josh's pathway

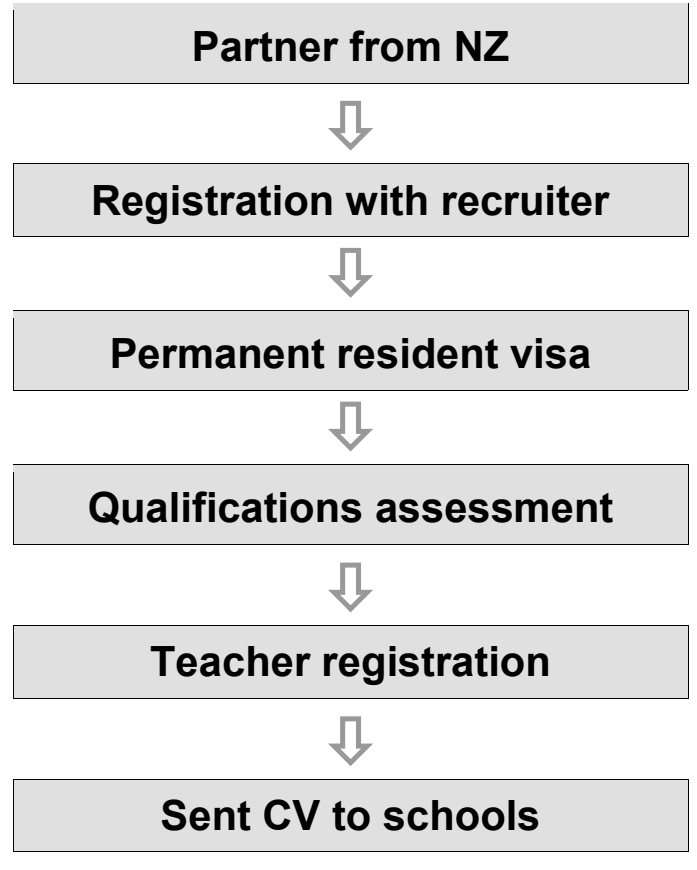

Applied for job advertised in education gazette online

I

Skype interview

II

Offer of employment

I

Immigration

I

Started teaching

II

Salary assessment pending further evidence of qualifications

\begin{tabular}{|l|}
\hline \multicolumn{1}{|c|}{ Supports } \\
\hline - Luck \\
- Network \\
- Preparation \\
\hline
\end{tabular}

\begin{tabular}{|l|}
\hline \multicolumn{1}{|c|}{ Challenges } \\
\hline - Bureaucracy \\
- Finance \\
\hline
\end{tabular}

\begin{tabular}{|c|}
\hline Suggestions \\
\hline - Interagency co-operation \\
\hline
\end{tabular}




\subsection{Leonard's journey}

Leonard was a teacher from the United Kingdom who had completed a Bachelor of Science with Honours and a Postgraduate Certificate in Education. English was his first language and his teaching subjects were Electronics, Mathematics, Physics and Science. He had been teaching for four years in the United Kingdom before coming to New Zealand with a Permanent Resident Visa and Provisional Teacher Registration.

Leonard"s partner had visited New Zealand twice and they had decided to immigrate here. He started looking for teaching positions and saw a post advertised in the Education Gazette online and applied for it. He was living in the United Kingdom at that time and was interviewed via Skype and subsequently offered a post. He perceived being a Physics teacher had helped and he explained:

Obviously being a Physics teacher means that there is less competition for roles because there are fewer so, it was all a relatively painless experience up until that point.

The job offer he received was subject to his gaining a Visa from INZ and Teacher Registration from the NZTC. He and his partner applied for PRVs and these were awarded prior to their arrival.

The difference in dates of the school terms in New Zealand and the United Kingdom caused a challenge for Leonard because by the time the offering school had obtained references there was insufficient time for him to resign from his job for the stipulated start date. He explained the situation saying:

I interviewed towards the end of May and, in the UK, the final half term break starts about then. So, the problem we had was that by the time the school had got my references from my previous employers, I was actually no longer able to resign in time for the originally intended start date. 
After some deliberation on the school's part they decided to hold the role for me until January when I started.

Leonard perceived the Teacher Registration process to be unnecessarily bureaucratic and felt concerned sending the only copy of his university degree certificate to the NZTC for verification. He suggested that the NZTC could communicate directly with the awarding university to verify overseas qualifications, which would be quicker than waiting on couriered qualifications. He also suggested an alternative of the NZTC accepting certified copies of qualifications to guard against possible loss or damage.

Leonard found delays in the salary assessment process a challenge. He believed salary assessment could have been started as soon as his qualifications had been assessed by the NZQA. At the time of our interview he was to be paid for the third time at the minimum rate which he estimated was half of the salary he was entitled to.

At times during the applications Leonard thought about abandoning the process because it appeared designed for inaccessibility. He explained the situation saying:

I really think more could be done to entice and make the whole process a lot easier because there were a lot of stages along the way where we thought, "It's just not worth the bother." I understand the need for rigorous medical checks and all that sort of thing but again, considering the skills that myself and my partner are bringing to New Zealand, I thought the immigration services were doing their absolute best to make it as difficult as it could be. I just think the whole process is extremely bureaucratic and unnecessarily so.

Leonard indicated that with Physics teachers being on INZ"s Skills Shortage List, the process should be less cumbersome so OTTs could immigrate and be employed with ease in order to address this shortage. He said: 
There's a Long Term Skills Shortage list. Our visas are under the Skilled Migrant Category and the skills of teachers, particularly those able to teach Science, Mathematics and Physics, this country has a long term shortage of people with those skills and it says so upfront on the website. So it seems like they're saying, "Yeah, come on in. We need people like you," and then you go through the process and it's very, very difficult to get through.

Having secured a job before arriving, Leonard questioned why he had been required to wait until he arrived in the country before he could apply for an IRD number because this delayed his receiving a salary and applying for a Salary Assessment. He suggested interagency co-operation could streamline these processes saying:

The NZQA could talk directly to the MoE. Presumably they have to work together periodically, why not under these circumstances? Why do I have to wait until I get to New Zealand and then wait ten working days to get my IRD number? Why can't that be set up before I land? I clearly have a job to come to and I am going to be resident in this country. Basically, that delayed me getting any pay for some time and any pay I would get would be taxed at 45 or $50 \%$.

Leonard had PTR and could gain Full Registration after one year of teaching, as opposed to the usual two-year timeframe, because he had all the required documentation from the United Kingdom, but the various applications and bureaucracy in general had pushed him to the point where he was not motivated to make an application for Full Teacher Registration. He stated that:

Teacher Registration stays provisional for two years. Although I do believe that I could have that reduced to one year because I do have all my induction documents from the United Kingdom, although I haven't bothered looking into that because I'm kind of bored with bureaucracy now and so I'm going to leave that for a while. 
The entire process of immigrating to New Zealand had cost Leonard and his partner $\$ 18000.00$ and he indicated that if they had not had savings they would not have been able to afford this move. Some OTTs are eligible to apply for an International Relocation Grant (IRG) after a period of teaching has been completed (MoE, 2013) and the IRG seemed insufficient to him, when contrasting it to the cost of immigrating. He said:

We're fortunate that we had significant savings. We could not have made this move if we did not have savings and that probably shouldn't be the case. If New Zealand wants teachers to come in, not all of them are going to have savings in order to do it. I would estimate that it's cost us in the region of $\$ 18000.00$ all told. The IRG is $\$ 4000.00$, of which you get $\$ 2000.00$ after about six weeks of the process, and a second $\$ 2000.00$ after 20 weeks.

When asked how Leonard had overcome challenges that he had faced he said that being honest, being particular and going back to people repeatedly for documentation and clarification had led to his successful immigration and employment.

Leonard"s suggestions to other OTTs were to be persistent and to allow a lot of time for all of the required applications before leaving their country of origin. He advised:

Just be very patient and make sure you have plenty of time.

Phoning and talking to staff at INZ and the NZTC had helped Leonard and he suggested other OTTs do the same saying:

The actual staff at INZ are really good, really helpful. Talk to them a great deal if you do have any issues.

Having a job to come to was a real advantage and Leonard recommended securing a job before arriving in New Zealand if at all possible. He said: 
Definitely try and secure a position before you arrive. That way you do know that there is going to be income when you get here.

Finally, he encouraged future applicants to remain calm because the bureaucracy could become frustrating. He had the following to say:

Be patient, is the most important thing. Just try not to lose your temper. It can be extremely easy to lose your temper. It gets very frustrating at times.

Leonard"s personal journey is depicted in Figure 8: Leonard"s Pathway on the following page and his supports, challenges and suggestions are presented in lists. 
Figure 8: Leonard's pathway

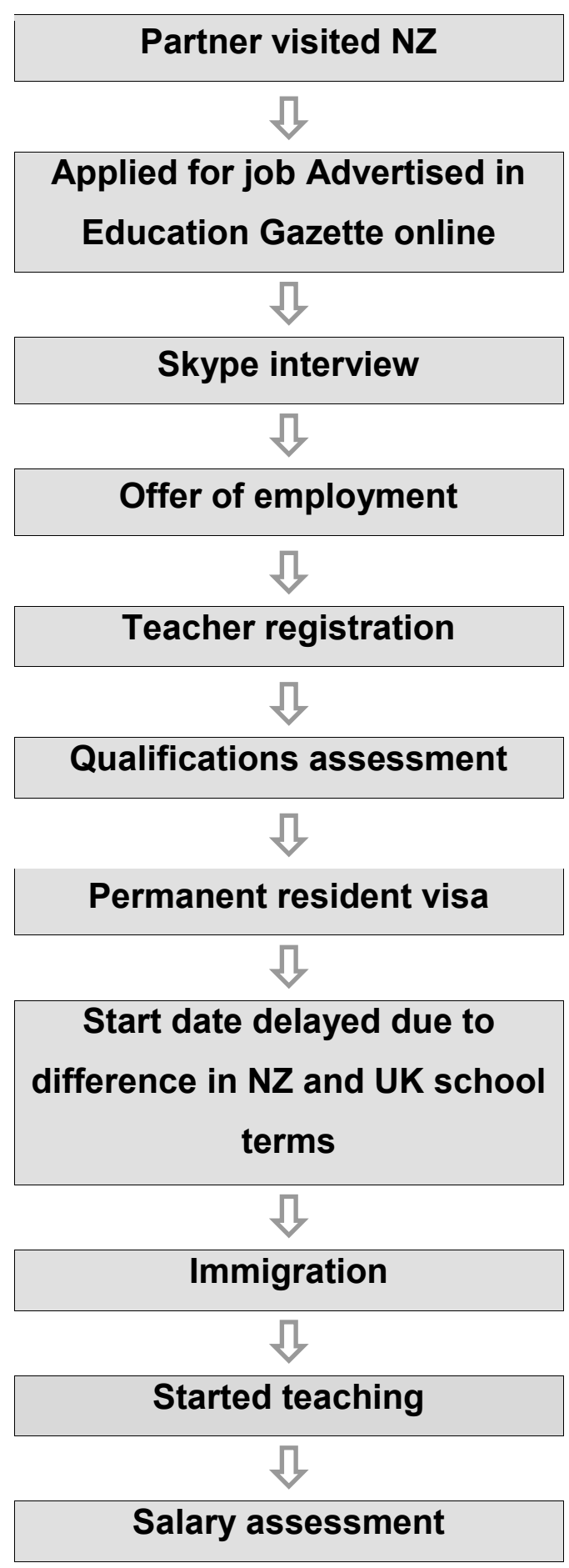

\begin{tabular}{|l|}
\hline \multicolumn{1}{|c|}{ Supports } \\
\hline - Network \\
- Preparation \\
- Teaching subject \\
\hline
\end{tabular}

\begin{tabular}{|l|}
\hline \multicolumn{1}{|c|}{ Challenges } \\
\hline - Bureaucracy \\
- Finance \\
\hline
\end{tabular}

\begin{tabular}{|l|}
\hline \multicolumn{1}{|c|}{ Suggestions } \\
\hline - Interagency co-operation \\
- Network \\
- Positive attitude \\
- Preparation \\
\hline
\end{tabular}




\subsection{Doug's journey}

Doug was a Music teacher and deputy principal from the United Kingdom who had been teaching for 18 years. His first language was English and he had completed a Bachelor of Arts with Honours, a Postgraduate Certificate in Education, a Licentiate of Trinity College of London and a National Professional Qualification for Headship. He had Teacher Registration in the category Subject to Confirmation and a Permanent Resident Visa when he arrived in New Zealand.

In 2007, Doug and his family visited his sister-in-law in Wellington. While visiting he took the opportunity to see some schools and meet with principals. He asked what it would take for him to make a successful move to New Zealand. He also took the time to register with a Wellington-based teacher recruitment company and to meet with one of its representatives.

Doug and his family returned to the United Kingdom in September 2007, having made the decision to immigrate, and applied for PRVs. He also applied to have his qualifications assessed for Teacher Registration and a Salary Assessment. He was grateful the recruiter advised him to make all of the applications that he could while he was still in the United Kingdom because this left less for him to do upon arrival in New Zealand. He explained the situation saying:

You see, having the recruitment company advising me through the whole process, one thing they said was to get the Salary Assessment sorted before coming to New Zealand. "Get it all done before you're here. Don't wait till you're here." So, a lot of things l'd got done.

The recruiter phoned in March 2008 to inform Doug that there was a Head of Department position open for application at a school in the Wellington Region. This post would be a step down from his position as Deputy Principal but he perceived it might permit him an opportunity to learn about the New Zealand curriculum and assessment 
methods. He was interviewed via telephone and received a letter of offer subsequently. Upon arrival in New Zealand he started teaching almost immediately.

Doug found that acquiring documentation for various applications involved in the immigration process was challenging. An example of this was the difficulty in acquiring transcripts from the university that he had studied at due to their records from that time being paper based. A university staff member had to locate the physical documents from archives to supply these to him. He said:

Probably the biggest challenge was getting things like transcripts off my old university that I left in 1990. These were archived in a filing cabinet somewhere because in those days, of course, they wouldn't have been computerised.

Finding a job was described by Doug as a challenge because it was important to him to have secured work before arriving so that he could provide for his family.

When asked about advice for others, Doug recommended visiting New Zealand before making a decision to immigrate here and going to see schools during that visit. He said:

Well, there are several critical points that led us here on the positive side, and one was visiting and knowing that it was the right thing for us. I think the first bit of advice is - do pay a visit to New Zealand. Spend a month here, go and see some schools, make sure you know you're comfortable with your own values around the kind of school where you want to teach.

The financial implications of moving from the United Kingdom to New Zealand were negative and Doug advised that OTTs do extensive research about what salary they might be eligible for and the cost of living in New Zealand. He explained: 
I believe that if you come to New Zealand you come for other reasons, you don't come for money because you won't earn as much in New Zealand as you do in the UK, pound for pound, and the cost of living is higher here.

Doug indicated that teachers were paid less in New Zealand and the cost of living was higher here; he advised that OTTs be fully informed about the financial implications so they were in a position to make an informed decision about whether they could afford the compromised financial situation of life as a teacher in New Zealand. He explained:

Do your homework on the financial side of things. I learned very quickly that you can't keep converting from pounds to dollars and back again because, actually, you just earn in dollars and you spend in dollars. So just get used to what dollars look and feel like. Don't keep converting back because otherwise you'll never immigrate because it's never going to be as good.

Doug advised that OTTs find out what type of school they would like to work for by researching schools and understanding the decile system used in New Zealand. The decile scale runs from 1-10, with 1 being the lowest and 10 being the highest, and is a socio-economic status indicator for schools (MoE, 2011). He suggested they also understood and were able to talk about the National Certificates of Educational Achievement (NCEA) during interviews. NCEA are national, standards-based qualifications in New Zealand for senior secondary school students (Shulruf et al., 2008). Doug said:

Just make sure you've done your homework on what NCEA is. What's the difference between the NCEA and the General Certificate in Secondary Education? How does the assessment differ?

It had been incredibly helpful to Doug to have many of the necessary applications complete prior to departing the United Kingdom and he suggested others might benefit from doing the same, saying: 
Get as much done before you leave the UK, like your NZQA, Salary Assessment and Teacher Registration.

Signing up with a teacher recruitment agency had benefited Doug and he suggested others do the same. He recommended signing up with the Education Gazette online too and explained not all jobs were on the recruiters" books but that all teaching jobs were advertised in the Education Gazette online, making it best to sign up to both. $\mathrm{He}$ explained the situation as follows:

Sign up with an agency, if you can. Also get onto the mailing list of the Education Gazette and maybe think about which bit of New Zealand you want to live in and you can just get the Education Gazette to e-mail you jobs within that area. Some schools don't use agencies because those charge a finder's fee.

Securing a teaching post before arriving in New Zealand was another suggestion Doug made saying:

Try and find a job, if you can.

The last suggestion that Doug made was to find an OTT who had been through the process of immigrating and ask them what was required. He stated:

I guess the final thing is, find someone that's done it and is here and just find out as much as you can.

The pathway that Doug followed, his supports, challenges and suggestions are detailed on the next page in Figure 9: Doug"s Pathway. 
Figure 9: Doug's pathway

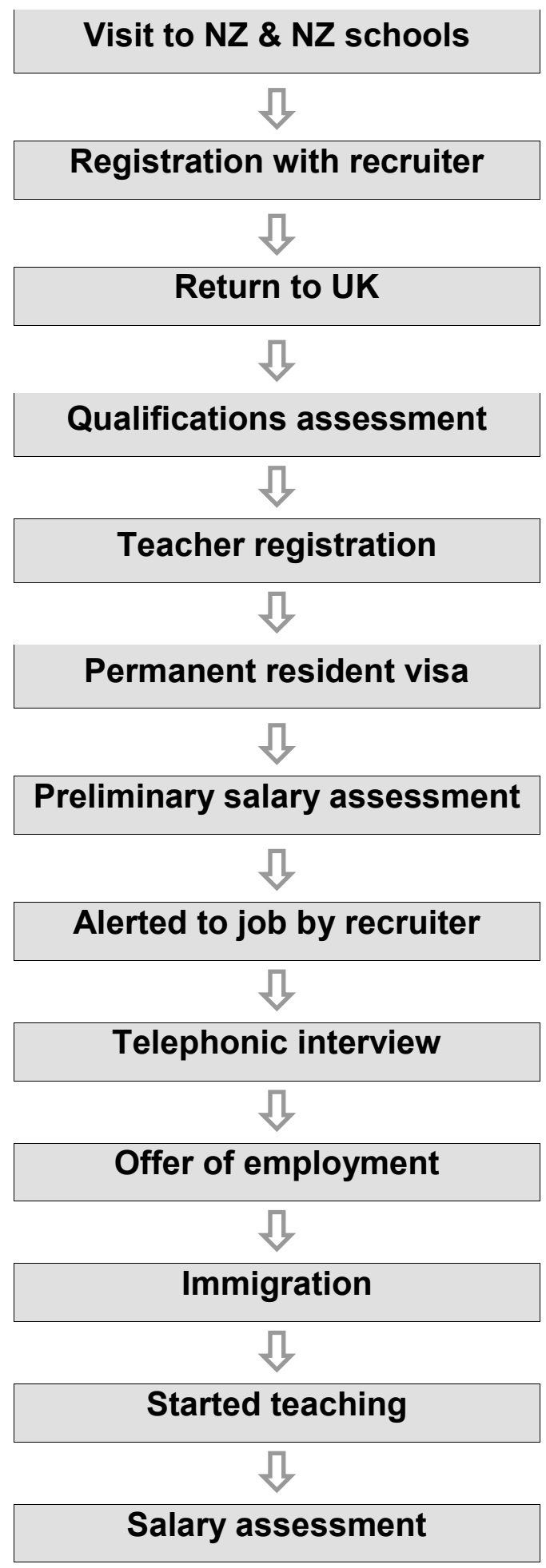

\begin{tabular}{|l|}
\hline \multicolumn{1}{|c|}{ Supports } \\
\hline - Networks \\
- Preparation \\
\hline
\end{tabular}

\begin{tabular}{|l|}
\hline \multicolumn{1}{|c|}{ Challenges } \\
\hline - Bureaucracy \\
- Finance
\end{tabular}

\begin{tabular}{|l|}
\hline \multicolumn{1}{|c|}{ Suggestions } \\
\hline - Networks \\
- Preparation \\
\hline
\end{tabular}




\subsection{Pathways}

The six journeys began for different reasons and there were some steps in each that were necessarily the same. These included applying for a teaching position, visa, Qualifications Assessment, Teacher Registration and Salary Assessment. The order in which these occurred was different. The difference in order was by design in some instances, for example, Alabama and Doug were advised to make visa and Teacher Registration applications prior to seeking work. In other cases the order unfolded as OTTs made applications and were directed to complete further applications.

Apart from Tom, who was in the unique position of being informally offered a job without having applied for one, all participants applied for positions while they were still resident in their country of origin. Only Tom and Leonard were offered work before they had made their visa and other applications, and their offers of employment were made subject to successful completion of those applications required for immigration. Josh and Doug had done the required applications and were offered work subsequently, and these offers of employment were made while they were still resident in the United Kingdom. The two female participants, Emily and Alabama, were the two participants who had successfully made the required applications but had not secured work prior to their arrival in New Zealand.

All of the participants, except Tom, were aware of and had made use of the Education Gazette online to look for vacancies before leaving their country of origin. Emily, Leonard and Josh found their teaching positions through the Education Gazette online. Although they used the same method to find work, Emily found a post after arriving in New Zealand while Leonard and Josh had secured their positions before arriving.

Alabama, Josh and Doug registered with a teacher recruitment company. Alabama and Doug found teaching positions through a recruitment company but Josh found a post independently through the Education Gazette online. Josh had signed up with an 
Auckland-based recruitment company, while Alabama and Doug had registered with a Wellington-based recruiter.

Tom, Emily and Alabama had face-to-face interviews. Tom"s interview was unique from the perspective that it was conducted by an associate of the school, and not by an employee, and it took place prior to Tom"s arrival in New Zealand. Employment interviews for Emily and Alabama were conducted face-to-face at the two schools subsequent to their arrival in New Zealand. Doug was the only applicant to be interviewed via telephone. Josh and Leonard were interviewed via Skype.

Emily, the only South African, was the single participant to have done relief teaching prior to securing a permanent teaching position. She was the only participant to have sought work outside of teaching. She was also the single participant to have been employed in a part-time, fixed-term role before being offered a full-time, permanent post.

Tom and Alabama were granted Work Visas and later applied for Permanent Resident Visas (PRV). Tom made his application for a PRV after his application for renewal of his Work Visa was declined. All other participants applied for, and were awarded, PRVs prior to their arrival in New Zealand.

Josh who had been an assistant head of department and Doug who had been an assistant head of school in the United Kingdom received Teacher Registration in the category, Subject to Confirmation. All of the other participants received Provisional Teacher Registration.

The six pathways navigated by participants are represented in a single figure over the page. The differences in the individual pathways are readily evident when viewed alongside each other in diagram format. 
Figure 10: Pathways

\begin{tabular}{|c|c|c|c|c|c|}
\hline Tom & Emily & Alabama & Josh & Leonard & Doug \\
\hline Partner from NZ & $\begin{array}{l}\text { Qualifications } \\
\text { assessment }\end{array}$ & $\begin{array}{l}\text { Qualifications } \\
\text { assessment }\end{array}$ & Partner from NZ & $\begin{array}{c}\text { Partner visited } \\
\text { NZ }\end{array}$ & $\begin{array}{c}\text { Visit to NZ \& NZ } \\
\text { schools }\end{array}$ \\
\hline$\sqrt{2}$ & $\sqrt{1}$ & $\sqrt{n}$ & $\sqrt{2}$ & $\sqrt{n}$ & $\sqrt{2}$ \\
\hline Informal job offer & $\begin{array}{l}\text { Teacher } \\
\text { registration }\end{array}$ & $\begin{array}{l}\text { Teacher } \\
\text { registration }\end{array}$ & $\begin{array}{l}\text { Registration with } \\
\text { recruiter }\end{array}$ & $\begin{array}{l}\text { Applied for jobs } \\
\text { in Education } \\
\text { Gazette online }\end{array}$ & $\begin{array}{l}\text { Registration with } \\
\text { recruiter }\end{array}$ \\
\hline$\sqrt{n}$ & $\sqrt{n}$ & $\sqrt{n}$ & $\sqrt{n}$ & $\sqrt{n}$ & $\sqrt{n}$ \\
\hline $\begin{array}{c}\text { Face-to-face } \\
\text { interview }\end{array}$ & $\begin{array}{l}\text { Permanent } \\
\text { resident visa }\end{array}$ & Work visa & $\begin{array}{l}\text { Permanent } \\
\text { resident visa }\end{array}$ & Skype interview & Return to UK \\
\hline$\sqrt{3}$ & $\sqrt{n}$ & $\sqrt{n}$ & $\sqrt{2}$ & $\sqrt{2}$ & $\sqrt{3}$ \\
\hline Formal job offer & $\begin{array}{l}\text { Applied for jobs } \\
\text { in education } \\
\text { Gazette Online }\end{array}$ & $\begin{array}{l}\text { Applied for jobs } \\
\text { in Education } \\
\text { Gazette online }\end{array}$ & $\begin{array}{l}\text { Qualifications } \\
\text { assessment }\end{array}$ & $\begin{array}{c}\text { Offer of } \\
\text { employment }\end{array}$ & $\begin{array}{l}\text { Qualifications } \\
\text { assessment }\end{array}$ \\
\hline$\sqrt{n}$ & $\sqrt{1}$ & $\sqrt{5}$ & $\sqrt{n}$ & $\sqrt{7}$ & $\sqrt{n}$ \\
\hline $\begin{array}{l}\text { Qualifications } \\
\text { assessment }\end{array}$ & Re-wrote CV & $\begin{array}{c}\text { Three month } \\
\text { holiday }\end{array}$ & $\begin{array}{l}\text { Teacher } \\
\text { registration }\end{array}$ & $\begin{array}{l}\text { Teacher } \\
\text { registration }\end{array}$ & $\begin{array}{l}\text { Teacher } \\
\text { registration }\end{array}$ \\
\hline$\sqrt{5}$ & $\sqrt{n}$ & $\sqrt{\eta}$ & $\sqrt{n}$ & $\sqrt{3}$ & $\sqrt{3}$ \\
\hline $\begin{array}{l}\text { Teacher } \\
\text { registration }\end{array}$ & Immigration & Immigration & $\begin{array}{l}\text { Sent CV to } \\
\text { schools }\end{array}$ & $\begin{array}{c}\text { Qualifications } \\
\text { assessment }\end{array}$ & $\begin{array}{l}\text { Permanent } \\
\text { resident visa }\end{array}$ \\
\hline$\sqrt{\sqrt{2}}$ & $\sqrt{n}$ & $\sqrt{2}$ & $\sqrt{\sqrt{2}}$ & $\sqrt{n}$ & $\sqrt{n}$ \\
\hline Work visa & $\begin{array}{l}\text { Met with retired } \\
\text { principal and re- } \\
\text { wrote } \mathrm{CV}\end{array}$ & $\begin{array}{l}\text { Registered with } \\
\text { recruiter }\end{array}$ & $\begin{array}{l}\text { Applied for job in } \\
\text { Education } \\
\text { Gazette online }\end{array}$ & $\begin{array}{l}\text { Permanent } \\
\text { resident visa }\end{array}$ & $\begin{array}{l}\text { Preliminary } \\
\text { salary } \\
\text { assessment }\end{array}$ \\
\hline$\sqrt{7}$ & $\sqrt{n}$ & $\sqrt{7}$ & $\sqrt{n}$ & $\sqrt{n}$ & $\sqrt{2}$ \\
\hline Immigration & Relief teaching & $\begin{array}{l}\text { Alerted to job by } \\
\text { recruiter }\end{array}$ & Skype interview & $\begin{array}{c}\text { Start date } \\
\text { delayed due to } \\
\text { different school } \\
\text { terms }\end{array}$ & $\begin{array}{l}\text { Alerted to job by } \\
\text { recruiter }\end{array}$ \\
\hline$\sqrt{n}$ & $\sqrt{n}$ & $\sqrt{n}$ & $\sqrt{7}$ & $\sqrt{n}$ & $\sqrt{n}$ \\
\hline Started teaching & $\begin{array}{l}\text { Applied for job in } \\
\text { Education } \\
\text { Gazette online }\end{array}$ & $\begin{array}{c}\text { Face-to-face } \\
\text { interview }\end{array}$ & $\begin{array}{c}\text { Offer of } \\
\text { employment }\end{array}$ & Immigration & $\begin{array}{l}\text { Telephonic } \\
\text { interview }\end{array}$ \\
\hline$\sqrt{n}$ & $\sqrt{n}$ & $\sqrt{2}$ & $\sqrt{2}$ & $\sqrt{2}$ & $\sqrt{2}$ \\
\hline $\begin{array}{l}\text { Permanent } \\
\text { resident visa }\end{array}$ & $\begin{array}{c}\text { Face-to-face } \\
\text { interview }\end{array}$ & $\begin{array}{c}\text { Offer of } \\
\text { employment }\end{array}$ & Immigration & Started teaching & $\begin{array}{c}\text { Offer of } \\
\text { employment }\end{array}$ \\
\hline$\sqrt{n}$ & $\sqrt{n}$ & $\sqrt{n}$ & $\sqrt{n}$ & $\sqrt{n}$ & $\sqrt{2}$ \\
\hline \multirow[t]{5}{*}{$\begin{array}{c}\text { Salary } \\
\text { assessment } \\
\text { pending }\end{array}$} & $\begin{array}{l}\text { Part-time, fixed } \\
\text { term job offer }\end{array}$ & Started work & Started teaching & $\begin{array}{c}\text { Salary } \\
\text { assessment }\end{array}$ & Immigration \\
\hline & $\sqrt{n}$ & $\sqrt{7}$ & $\sqrt{7}$ & & $\sqrt{\sqrt{2}}$ \\
\hline & $\begin{array}{c}\text { Salary } \\
\text { assessment }\end{array}$ & $\begin{array}{c}\text { Salary } \\
\text { assessment }\end{array}$ & $\begin{array}{c}\text { Salary } \\
\text { assessment } \\
\text { pending }\end{array}$ & & Started teaching \\
\hline & $\sqrt{n}$ & & & & $\sqrt{n}$ \\
\hline & Full-time job offer & & & & $\begin{array}{c}\text { Salary } \\
\text { assessment }\end{array}$ \\
\hline
\end{tabular}




\subsection{Themes}

The themes of bureaucracy, culture shock, professional development and networks were identified in the literature review. Themes emerged from interviews and these were entered into the categories challenges, supports and suggestions. Additional themes that emerged from this study were preparation, teaching subjects, positive attitude and interagency co-operation. These are documented below in Table 4.10: Themes.

\section{Table 2: Themes}

\begin{tabular}{|c|c|c|c|}
\hline Participant & Challenges & Supports & Suggestions \\
\hline Tom & $\begin{array}{l}\text { Bureaucracy } \\
\text { Culture shock }\end{array}$ & $\begin{array}{l}\text { Luck } \\
\text { Natural environment } \\
\text { Networks }\end{array}$ & $\begin{array}{l}\text { Preparation } \\
\text { Professional development }\end{array}$ \\
\hline Emily & $\begin{array}{l}\text { Bureaucracy } \\
\text { Culture shock }\end{array}$ & $\begin{array}{l}\text { Luck } \\
\text { Networks } \\
\text { Preparation }\end{array}$ & $\begin{array}{l}\text { Preparation } \\
\text { Networks } \\
\text { Relief teach }\end{array}$ \\
\hline Alabama & $\begin{array}{l}\text { Bureaucracy } \\
\text { Culture shock } \\
\text { Lack of subject experience }\end{array}$ & $\begin{array}{l}\text { Luck } \\
\text { Networks } \\
\text { Professional development } \\
\text { Teaching subjects }\end{array}$ & $\begin{array}{l}\text { Positive attitude } \\
\text { Preparation } \\
\text { Professional development }\end{array}$ \\
\hline Josh & $\begin{array}{l}\text { Bureaucracy } \\
\text { Finance }\end{array}$ & $\begin{array}{l}\text { Luck } \\
\text { Networks } \\
\text { Preparation }\end{array}$ & Interagency co-operation \\
\hline Leonard & $\begin{array}{l}\text { Bureaucracy } \\
\text { Finance }\end{array}$ & $\begin{array}{l}\text { Networks } \\
\text { Preparation } \\
\text { Teaching subjects }\end{array}$ & $\begin{array}{l}\text { Interagency co-operation } \\
\text { Positive attitude } \\
\text { Preparation }\end{array}$ \\
\hline Doug & $\begin{array}{l}\text { Bureaucracy } \\
\text { Finance }\end{array}$ & $\begin{array}{l}\text { Networks } \\
\text { Preparation }\end{array}$ & $\begin{array}{l}\text { Networks } \\
\text { Preparation }\end{array}$ \\
\hline
\end{tabular}




\subsection{Challenges}

In this section themes that emerged in the category challenges are documented. Table 4.11 sets out challenges in two lists, one indicating those commonly experienced and the other an individual challenge. These are then described in turn with those most frequently reported by participants appearing first.

Table 3: Challenges

\begin{tabular}{|l|}
\hline \multicolumn{1}{|c|}{ Common challenges } \\
\hline - Bureaucracy \\
- Culture Shock \\
- Finance \\
\hline
\end{tabular}

\begin{tabular}{|c|}
\hline Individual challenge \\
\hline - Lack of subject experience \\
\hline
\end{tabular}

\section{Bureaucracy}

Challenges resulting from bureaucracy were faced when making applications, and this was due to receiving misinformation or not receiving feedback. Challenges due to bureaucracy were experienced when acquiring documentation and also as a consequence of the volume of paperwork. These challenges will be described using information provided by participants during interviews.

Tom and Leonard faced challenges associated with their applications for Salary Assessment. Tom"s difficulty was gaining detailed proof of previous employment from employers based in the United Kingdom while he was located in New Zealand and also because those industries in which he had worked were transitory in nature. Leonard's struggle was because he had to wait until he had started work to apply for a Salary Assessment and would have preferred to make that application upon securing a job. These delayed salary assessments had negative financial implications for participants at a time when they had many expenses having recently moved to a new country. 
Another application that proved problematic was the application for Teacher Registration. This was a difficult application process for Emily, Josh and Leonard. Emily found the complicated paperwork requirements of the NZTC a challenge and Leonard found the Teacher Registration process unnecessarily bureaucratic. He found it so frustrating that he considered abandoning the idea of immigrating to New Zealand entirely. Josh"s difficulty was that his Police Clearance Certificate (PCC) was outdated after it had been supplied firstly to the NZQA, which took some time to process his application for Qualifications Assessment and, secondly, to the NZTC.

Making applications was difficult and being provided with misinformation was also problematic. During their interviews four of the participants referred to being given misinformation and they were: Tom, Emily, Leonard and Josh.

Emily and Leonard perceived they had been misinformed when they were investigating emigration to New Zealand. The Skills Shortage List on INZ"s website indicated a need for secondary school English and Physics teachers. Emily, an English teacher, perceived that information from INZ and the large number of vacancies in the Education Gazette online indicated a shortage of teachers. However, her experience contradicted this because she made multiple job applications and was not invited to an interview for several months. Leonard thought information provided by INZ online indicating a need for Physics teachers was contradicted by the difficult process of applying to teach in New Zealand.

Josh was given misinformation when he signed up with a recruitment company. The manager of that company stated it would find him work but it did not provide him any assistance in finding a teaching position. He eventually found a position without the help of that recruiter.

Tom was the only participant to have applied for renewal of a Work Visa. He had been misinformed about the ease of renewing a Work Visa and this visa was not renewed but was extended, giving him time to apply for a PRV. Tom found the process of applying 
for a PRV while starting life in New Zealand difficult due to the time, effort and funds this application demanded.

Emily, Alabama and Josh applied for work through the Education Gazette online while they were resident in their countries of origin and received no feedback. They found it unpleasant gaining no response to applications for posts they had both the qualifications and experience to fill.

The acquisition of documents was difficult for Tom and Doug. Tom had collected letters of reference from each of his previous employers but those were not useful in New Zealand and he faced difficulty obtaining suitable work references from the United Kingdom while located in this country. He was still facing the challenge of gaining proof of employment from several employers in support of his application for Salary Assessment at the time of our interview. Doug had difficulty gaining the required proof of his qualifications to supply in support of his application due to the pre-digital archiving at the university he had attended.

Josh and Leonard found the difference in school term dates in New Zealand and the United Kingdom a challenge. Josh held off on applying for posts due to this difference and the start date of Leonard"s contract was delayed due to it.

Subsequent to completing a multitude of required applications, Tom and Leonard found themselves unmotivated to complete further applications. In the case of Tom, it was an application for Salary Assessment that he was not motivated to complete. For Leonard, it was his application for Full Teacher Registration.

\section{Culture shock}

Three participants referred to experiences that can be described as culture shock based on the definition used for the purposes of this thesis. Culture shock refers to difficulties 
an OTT faces as a consequence of a move to their country of choice. Tom, Emily and Alabama all experienced culture shock.

Emily experienced culture shock outside of the classroom in interactions with school management and thought employers had an aversion to employing OTTs because it was perceived they might have difficulty settling. She perceived an institutional view that her overseas qualifications and experience were not valued in New Zealand. She also faced the challenge of proving her ability to converse fluently in English, which was unexpected because English is her first language and her teaching subject.

Tom and Emily experienced culture shock in the classroom because student behaviour in New Zealand was challenging. Tom perceived that students were either passive or aggressive. Emily found it difficult to ascertain what behaviour was simply different from what she had come across before, but was acceptable in the context of a New Zealand classroom, and what behaviour was different and unacceptable. Alabama referred to the challenge of teaching children of indigenous cultures in a culturally responsive way.

\section{Finance}

Moving to a new country is expensive and Josh, Leonard and Doug referred to the financial challenges associated with immigrating to New Zealand. Josh referred to the entire application process as "financially consuming". Leonard compared the cost of immigrating to the Relocation Grant and indicated that without the savings he and his partner had, they could not have afforded to immigrate to this country. Doug stressed the high cost of living and low remuneration for teaching compared to the United Kingdom. 


\section{Lack of subject experience}

There was a challenge unique to one participant and that was a lack of experience teaching two subjects. A recruiter had encouraged Alabama to apply for a post she did not have the experience to fill and she found her lack of teaching experience in Electronics and Physics a challenge. She was challenged further by the situation of being the only Electronics teacher at school; because this meant she had to learn both the subject content and how to teach it without input from colleagues.

\subsection{Supports}

There were supports that many of the participants benefited from and others that were experienced by a particular individual only. The following table lists supports commonly experienced and individual supports. This table is followed by examples of each of these supports.

\section{Table 4: Supports}

\begin{tabular}{|l|}
\hline \multicolumn{1}{|c|}{ Common supports } \\
\hline - Networks \\
- Preparation \\
- Luck \\
- Teaching subjects \\
\hline
\end{tabular}

\begin{tabular}{|l|}
\hline \multicolumn{1}{|c|}{ Individual supports } \\
\hline - Natural environment \\
- Professional development \\
\hline
\end{tabular}

\section{Networks}

The type of support that was most often spoken about during interviews was support gained through networks: family networks, networks of friends and formal networks. Tom, Josh, Emily and Alabama felt strongly supported by networks. Tom and Josh"s family networks had supported them in their efforts to find posts. Tom"s partner received a job offer and he received an offer of employment at the same time. Josh"s brother-inlaw furnished him with contact details of the Head of the Mathematics Department at 
that school. Information about the immigration process that was supplied by friends was helpful to Emily and Alabama. Emily was helped with rewriting her CV for the New Zealand context by a friend and by a retired school principal. Alabama was given information about the application process by a friend who had taught in New Zealand.

Two participants found the formal network of a recruitment agency helpful. Doug was greatly assisted by a recruiter in his decision about when to submit paperwork. Alabama was encouraged by a recruiter to apply for a position that required teaching subjects she did not have knowledge of, or experience teaching, and she secured that post.

Some school networks were supportive of participants. School management"s willingness to employ OTTs was an advantage for Emily and Alabama when applying for posts. Emily found that her school"s high percentage of students with immigrant parents made that school"s management more open to employing OTTs. Alabama perceived her school to have a practice of hiring the best candidate for the post, irrespective of whether that candidate was New Zealand-trained or an OTT.

The difference in school term dates in New Zealand and the United Kingdom meant that Leonard was not able to resign in time for the start date of his teaching contract. The school in New Zealand was supportive, choosing to hold a position open for him.

Participants received further support from schools after they had started working in New Zealand. Alabama found professional development courses she attended helpful and was grateful to school management for supporting her to attend those courses. Josh experienced supportive school management when computer software was purchased to enable him to access the teaching resources he had brought with him. Alabama and Josh found their colleagues supportive. 


\section{Preparation}

All participants took time to prepare before their move. They reported how helpful preparation is and advised how important it is for OTTs to prepare. Making use of online resources was a great support when OTTs were preparing to teach in New Zealand. The Education Gazette online was used by most of the participants and Emily, Josh and Leonard found their posts through that gazette. Extensive online research prior to an interview supported Josh to secure his post. He conducted online research about the school, including reports on the school, scholarships coming out of that school and the percentage of those scholarships that were related to his teaching subject.

The timing at which applications were submitted was helpful to some participants. Alabama and Doug found it advantageous to have completed many of their applications prior to their departure from the United Kingdom. A friend advised Alabama to complete as many applications as possible before leaving the United Kingdom and Doug was advised by a recruiter to do the same.

Visiting New Zealand before choosing to immigrate was a deciding factor for Doug and his family. They were certain they were making the right move after visiting, and during that visit he went to schools and met with school management. He also registered with a teacher recruitment company at that time and was able to meet that recruiter in person.

\section{Luck}

Luck was important to many of the participants. Tom perceived his luck having received work through his partner"s network while offshore. Emily described it as luck finding a post teaching senior students. Alabama perceived herself as lucky having a friend in the United Kingdom who had taught in New Zealand and could advise her about the application process. Josh felt lucky to have had an opportunity to house sit while his Salary Assessment was being processed; because this meant that he did not have to pay rent during a time when he was being paid a beginning teacher"s salary. 


\section{Teaching subjects}

At the time of seeking work particular teaching subjects were seen to be of greater value in the New Zealand context than others. Leonard believed his teaching subject, Physics, to be a key to his success; because of a demand for Physics teachers indicated in INZ"s Skills Shortage List. Alabama surmised that Physics and Mathematics were easier to teach in a new country than more place-based subjects such as Geography and History.

\section{Natural environment}

The natural environment was of significance to Tom. He found access to nature to be both a great support when teaching Geography classes and an advantage of living in New Zealand. He viewed access to nature as a benefit for students that could be publicised to OTTs and international students.

\section{Professional development}

Completing various courses and meeting with groups of teachers were of value to Alabama. She found her recent graduation from teaching to be an advantage because she had been taught to find out about students and their backgrounds; and that assisted when supporting students from different cultures. She also found it informative to attend courses about indigenous culture at a university and those presented by her school. Joining a group of Electronics teachers who met and shared resources was a great support to her, as was finding a Physics tutor.

\subsection{Suggestions}

Participants had useful suggestions for others in a similar situation. These are listed in the table below with those most often described appearing on the left. Suggestions are detailed in turn, starting with those most frequently indicated during interviews. 
Table 5: Suggestions

\begin{tabular}{|l|}
\hline \multicolumn{1}{|c|}{ Common suggestions } \\
\hline - Preparation \\
- Networks \\
- Interagency co-operation \\
- Positive attitude \\
\hline
\end{tabular}

\begin{tabular}{|l|}
\hline Individual suggestion \\
\hline - Relief teach \\
\hline
\end{tabular}

\section{Preparation}

Participants had prepared in different ways and had various suggestions about how best to prepare to teach in New Zealand.

Doug had found a visit to this country helpful and advised that others visit before making a decision to live here. Although Tom and Emily did not suggest coming here before emigrating they encouraged OTTs to engage in careful thought before decision-making. Tom stated that OTTs should be certain that outdoor activities and a contemplative lifestyle were things they would like before making a move here; and Emily warned that OTTs should consider carefully whether they would like to teach in New Zealand.

Research had assisted OTTs and Alabama advised reading about a preferred geographical location and schools in that area prior to immigrating. Doug recommended careful consideration of the financial implications of moving to New Zealand and investigation about assessment methods, the decile system, and the differences between NCEA and GCSE.

Completing required applications prior to arrival was a great advantage to Alabama and Doug. They both thought it worthwhile to apply ahead of arriving in New Zealand. Alabama suggested OTTs get their qualifications assessed and gain Teacher Registration before arrival. Doug encouraged OTTs to get as many of the mandatory applications completed prior to departure as was possible. Leonard also referred to 
applications, warning that OTTs should allow a lot of time for these to be processed. He suggested that they should phone and ask questions, be persistent and remain calm throughout the process.

Prior to their arrival in New Zealand, both Leonard and Doug had secured teaching positions. Leonard advised securing work prior to arrival so that OTTs were guaranteed an income upon arrival and Doug also recommended gaining work before immigrating. He had done so to be sure that he could provide for his family when they arrived.

Another way that Doug suggested OTTs could prepare was by registering both with a recruitment company and the Education Gazette online. He suggested both avenues as a way of gaining information about a greater number of vacancies; explaining that all jobs were advertised in the Education Gazette online and only some by recruiters.

Professional development was suggested by Tom and had been helpful to Alabama. He recommended that OTTs attend courses in order to gain information about the bicultural New Zealand environment. She indicated that professional development courses were informative and encouraged OTTs to request such opportunities.

\section{Networks}

Networks had assisted every participant and Doug suggested finding an OTT who had been through the immigration process and obtaining information from them. Leonard found staff at INZ and the NZTC friendly and helpful when he contacted them. He also found it helpful to be honest and particular when completing paperwork, and to ask questions when making applications.

Emily suggested that OTTs meet with someone working in Education to gain editing advice about their $\mathrm{CV}$; in order that it could be rewritten with relevance to the New Zealand market. She suggested meeting with a representative of a school when submitting a $\mathrm{CV}$ to have a conversation and prove language ability. She indicated that spending a day in a school, prior to working there, would be helpful. 


\section{Interagency co-operation}

Josh and Leonard made suggestions for interagency co-operation. Josh suggested that the report the NZQA provides could be submitted to NZTC in support of OTTs" applications for Teacher Registration and Leonard proposed that NZTC communicate directly with the awarding university to gain confirmation of qualifications as opposed to requesting original degree certificates from OTTs or, alternatively, that NZTC accept certified copies of degree certificates. He indicated that interagency co-operation could streamline the process of application for Salary Assessment.

\section{Positive attitude}

Maintaining a positive attitude throughout the immigration, registration and recruitment process was encouraged by both Leonard and Alabama. He indicated that patience during this process was invaluable because the bureaucracy was frustrating at times. She advocated persistence at those times when the process became difficult.

\section{Relief teach}

Finding a temporary teaching position had led to permanent work for Emily. She advised that looking for temporary teaching posts could help to secure a permanent position; because it would allow OTTs to gain New Zealand teaching experience and this would make their CV more attractive to school-hiring staff. 


\subsection{Conclusion}

Chapter four has provided demographic information and presented a narrative about each OTT"s experience separately, as an individual case. Data was sorted within the categories of challenges, supports and suggestions. The challenges of bureaucracy, culture shock and finance were found to be common, whereas, the challenge of lack of subject-specific teaching experience was not. Recurring supports were luck, preparation and networks. Supports that were referred to in a single case only were the natural environment and professional development. Suggestions regarding interagency cooperation, positive attitude, preparation and securing work prior to arriving in this country were most often mentioned; while the suggestion that OTTs relief teach was mentioned by a single participant. These findings will be discussed and analysed in the next chapter. 


\section{Chapter 5: Discussion}

\subsection{Introduction}

The aim of this study was to formulate a pathway by learning from the multiple, individual pathways navigated by OTTs into a career teaching in New Zealand and addressing the challenges and supports they encountered. This chapter compares and contrasts the findings of this research with existing literature on OTTs. The findings of this study were that; bureaucracy created challenges; some OTTs experienced culture shock; and others faced financial difficulties due to their move to New Zealand. Support was found in networks to which the participants belonged and as a function of how much preparation they had done before relocating. Some were supported by virtue of the subject that they taught and due to their access to professional development. They were further assisted by the positive attitude they chose to adopt, because of luck and due to enjoyment of the natural environment in New Zealand. The findings are used to suggest a pathway.

\subsection{Challenges}

Participants commonly faced difficulty due to the bureaucracy involved in the immigration and teacher registration processes. Many had experiences that resulted in culture shock; and finance created challenges for some of the participants.

\section{Bureaucracy}

Challenges associated with bureaucracy included a disconnection between information and experience, a lack of interagency co-operation, excessive paperwork requirements, and difficulty in obtaining documentation from previous employers.

Emily and Leonard spoke about having been provided with misinformation. Emily perceived there to be a disconnection between information provided by INZ, which had 
teachers listed on the long-term skills shortage list, and the lack of shortage that she experienced. Leonard also perceived he had been misinformed. This was because INZ stated Physics teachers were needed but he experienced the immigration process as being difficult. He thought that OTTs with skills New Zealand needed should have had an easier time immigrating.

Emily and Leonard"s experiences echo the findings of international research which indicates OTTs receive misinformation about teacher shortages and access to the teaching profession (De Villiers \& Books, 2009; Guo \& Singh, 2009; Pollock, 2010; Vohra, 2005). In some cases misinformation has led to disillusionment for both OTTs and schools because their expectations were not met (De Villiers \& Books, 2009).

The disconnection between information provided and the reality experienced by OTTs could be due to different perspectives among OTTs, immigration authorities and recruiters. OTTs go through an individual experience and each will vary; some OTTs do not perceive a disconnection while others, as Emily and Leonard, do. The perspective of immigration authorities is different from the individual perspective of Emily and Leonard. This is because it includes feedback from the education sector, extends over the long term and encompasses many OTTs over a wider geographical spread. This wider perspective over a greater duration indicates that there is a long-term shortage of teachers. This ongoing teacher shortage is thus accurately reported by immigration authorities, in spite of differing from the individual experiences of some OTTs. The perspective of recruiters is different again; and their focus is solely on the employment of OTTs, including relief and permanent placements. It is possible that which Emily and Leonard perceive as misinformation may be described as a difference in perspective among some OTTs, who experience difficulty immigrating and securing work, immigration authorities and recruiters.

Josh and Leonard were concerned about a different aspect of information; which was information sharing among the agencies involved in the immigration, registration and recruitment of OTTs. They both suggested that interagency co-operation would be of 
benefit to all parties. Their concerns about a lack of interagency co-operation were similar to those of South Auckland principals interviewed by Biggs (2010). That study found school principals were concerned by a lack of efficient communication among agencies and the delays this caused. Efficiencies could be gained for OTTs, schools, NZQA, NZTC and MoE through improved interagency co-operation and communication. Josh suggested efficiency could be increased if the NZTC accepted a Qualifications Assessment from NZQA without requiring proof of past employment, qualifications and a Police Clearance Certificate; all of which NZQA had already received, checked and accepted. This suggestion could also serve to minimise the challenge that Emily referred to when she indicated that the paperwork requirements of the NZTC were long and complicated.

Internationally teacher registration has been identified as a barrier for OTTs (Beynon et al., 2004; Chow, 2011; Guo \& Singh, 2009). Participants"descriptions of the immigration and registration process as excessive and unnecessarily bureaucratic are aligned with descriptions of the Canadian teacher registration process which Walsh, Brigham and Wang (2011) refer to as, "a maze of regulations and bureaucracy" (p. 662).

Bureaucracy is part of the immigration and employment process and, although authorities could possibly streamline some of the paperwork requirements, there will always be a requirement to prove OTTs have the necessary qualifications and experience required to teach. Doug and Leonard provided possible supports to help OTTs navigate this challenge. Doug suggested speaking to someone who had successfully been through the process; and Leonard indicated that allowing time for applications and speaking to authorities to gain clarity about applications could be helpful. If OTTs were in a position to follow these three suggestions this could assist in reducing the complexity of the situation; because they would know what to expect having spoken to a peer, understanding the requirements due to contacting authorities and having sufficient time to obtain documentation. Authorities could also assist in supporting OTTs to overcome this challenge according to a study conducted by 
Sutherland and Rees (1995) in the United Kingdom that found an orientation programme designed to inform OTTs about the paperwork requirements was beneficial.

Paperwork requirements were a particular challenge for Tom who had difficulty acquiring documentation from the United Kingdom to prove work experience. A participant in Guo and Singh"s (2009) study shared this problem; and stated that, "It was an absolute nightmare trying to prove that I had done any supply work so I just gave up trying to prove that" (p. 4). Tom had given up trying to gain proof of work he had done for NGOs and, because of this, was not receiving the salary he estimated he could. This situation would be difficult to address because it is important for evidence of previous work experience to be submitted and there is no alternate way for the MoE to obtain this information. A solution would be for OTTs to obtain letters at the end of each employment contract. The problem that would remain would be that individuals do not always know many years in advance that they are going to emigrate and should collect reference letters in preparation.

\section{Culture shock}

Culture shock is a recurrent theme in the literature and can be experienced at many points in the migration process. It can be experienced before OTTs secure work due to the devaluing of their qualifications and experience. It can arise when seeking work, as a function of perceptions about language difficulties. Upon securing work and entering the new teaching environment culture shock can be experienced based on varied expectations about acceptable behaviour for teachers and students.

In this study only Emily, from South Africa, reported that her qualifications were not valued but the reasons for this are not clear. It could be speculated that schools perceived her qualifications to be awarded by a university in a developing country, and held a misconception that those qualifications are inferior. This is clearly a misconception because NZQA had assessed her qualifications as comparable to those awarded in New Zealand. In contrast to the experiences of other participants, she was not invited to interviews prior to arriving in New Zealand nor for three months after her 
arrival. All other participants were from the United Kingdom and most were offered positions before their arrival in this country.

Although Emily"s experience of a lack of value placed on her qualifications differed from all other participants in this study, it intersects with the findings of other New Zealandbased and international research (Beynon et al., 2004; Guo \& Singh, 2009; Miller, 2008; Miller, 2009; Ryan, et al., 2009; Stewart, 2010). Internationally, OTTs struggle to gain access to the teaching profession in their country of choice (Cho, 2010; Mawhinney \& Xu, 1997; Miller, 2008; Pollock, 2010; Sharplin, 2009) because of perceived language difficulties (Mawhinney \& Xu, 1997; Sharplin, 2009), problems applying for teacher registration (Cho, 2010) and marginalization by school-hiring staff (Pollock, 2010). In particular OTTs from developing countries are not provided easy access into the workforce (Miller, 2008; Ryan et al., 2009). In the New Zealand context, Nayar (2009) found the situation to be the same because Indian OTTs had trouble accessing the teaching profession due to difficulty securing interviews, undervalued qualifications and experience, and discrimination because of accent.

People born overseas make up $22.9 \%$ of the New Zealand population and England was the most common overseas birthplace of immigrants from 1956 to 2006 (Statistics New Zealand, 2006). The 2006 Census documented that $28.6 \%$ of immigrants had been born in England (Statistics New Zealand, 2006) and, Anand and Dewar (2004), in their research on OTTs, found that $41.4 \%$ respondents were English. Due to the English being the largest immigrant group school-hiring staff may have greater familiarity with immigrants from that country. The findings from this study concur in that the participants from the United Kingdom had relatively easy access to the profession compared with Emily from South Africa.

A common theme in literature is problems that arise due to language. All participants in this study are native speakers of English, albeit English as spoken in their own countries. Emily was the only South African participant and the only one who faced challenges due to language. She stated that potential employers expected her to 
struggle when speaking English in spite of it being her first language, a language in which she holds a Masters" degree and is her teaching subject. A number of studies have found that language leads to challenges for OTTs (Guo \& Singh, 2009; Mawhinney and Xu, 1997; Schmidt, 2010; Sharplin, 2009; Subedi, 2008; Walsh, 2008; Walsh, Brigham and Wang, 2011). Ordinarily those challenges are faced by OTTs for whom English is not a first language. It appears that school-hiring staff expected Emily"s language proficiency to be that of a second language speaker of English. This false assumption is possibly because she is South African and there is an incorrect assumption that English is not spoken as a first language in that country. This is inaccurate, as Setati, Adler, Reed and Bapoo (2002) explain, "the majority of South Africa"s teachers work in classrooms and schools where English is officially the language of learning" (p. 129).

Emily perceived that without meeting school-hiring staff she was perceived as a foreign teacher who was expected to struggle using English. She suggested OTTs meet prospective employers to have a conversation and through that prove English language ability. Staff would want students to be able to understand their teachers and hesitate to employ non-native English speakers for that reason. International literature challenges this notion; indicating that students may struggle to understand non-native English speakers in the first few lessons but not later on, once they had become familiar with a different accent (Walsh, 2008) or new vocabulary (Sharplin, 2009).

Different expectations about classroom behaviour can be a cause of culture shock. This was something that concerned both Tom and Emily. Tom found the bicultural, New Zealand environment different from the multicultural context of the United Kingdom. He had a particular expectation about how students would interact with him and each other, but found New Zealand students either passive or aggressive. Behaviour between these two extremes was not evident to him. Tom"s perception could be due to differences in student behaviour in New Zealand and the United Kingdom; because expected and acceptable student behaviour in New Zealand might not be the same as 
in his country of origin. A possible alternative explanation could be that Tom"s different teaching methods may have elicited passive or aggressive responses from students.

Emily referred to her experience of the differences among student behaviour in New Zealand, South Africa and Ireland. New Zealand students behaved differently from what she had experienced previously; they spoke to her and with each other more frequently and asked her personal questions. Consequently, she had to recalibrate her expectations about what behaviour was acceptable in this new teaching context. She was unaccustomed to the frequency and the topics of conversation in New Zealand classrooms; and this could be because the South African context she came from was one in which students spoke less. In Ireland she had taught foreign language students who did not speak English as a first language; and possibly would not have spoken to her as frequently because of this.

Tom and Emily expected students to behave differently based on past experience and this finding supports international literature (Florence, 2010; Inglis \& Philps, 1995; Sharplin, 2009). Research suggests OTTs acknowledge difference (Florence, 2010; Sharplin, 2009) and find ways to create positive change (Florence, 2010; Okumara, 2008); and Emily did this by noticing the differences in student behaviour and changing her expectations. It might be helpful for OTTs to expect to make some alterations to their expectations about behaviour when teaching in a new country. It could be difficult to prepare for this and talking to an OTT from the same country of origin, who is teaching in New Zealand, could provide insight into the differences between student behaviour in that particular country of origin and in this new teaching context.

Classroom management can lead to the experience of culture shock. Alabama expressed concerns about teaching in a culturally responsive way and attended professional development courses to learn how to do so. Similarly to Tom, she had taught in a multicultural context previously but had not been exposed to Pacific and Māori cultures and she wanted to learn how to teach responsively. Her concerns about classroom management are supported by previous studies (Seah \& Bishop, 2002; 
Sharplin, 2009; Warner, 2010). Warner (2010) indicated that classroom management was a professional difficulty faced by OTTs in the United Kingdom; and Sharplin (2009) identified that OTTs in Australia were concerned about the difference in their own and their students" beliefs and values about classroom management.

Emily suggested during her interview that it might be helpful for OTTs to spend some time in a classroom in order to ascertain how people communicate with each other in the new teaching context. This finding concurs with other New Zealand-based research (Biggs, 2010; Okumara, 2008). Biggs (2010) recommended that, "OTTs, before beginning to teach in a school, may consider asking principals if they may observe teachers working with classes to gain an understanding of the way New Zealand classrooms function" (p. 113). This is advisable because observing some of the differences before teaching a class could help to lessen OTTs" experience of culture shock due to varied expectations about classroom management.

Alabama"s aim to provide culturally responsive teaching to students is encouraged by Mitchell"s (2010) research, which found some teachers who could not master cultural responsiveness left the profession. Engaging in professional development opportunities, as Alabama did, could assist in acquiring knowledge and skills in order to teach with cultural responsiveness.

Expectations about behaviour may need to be adjusted, as may expectations about subject content. Seah (2005) looked at the difference between expectations about the subject of Mathematics in OTTs" country of origin and in Australia and found these created difficulties when, for example, an OTT valued the accurate answer to a mathematical problem but in Australia marks could be awarded if the correct process had been followed even if the resulting answer was incorrect. Alabama"s experience contradicts this because she found that teaching the subject content of Science in New Zealand was not problematic because the curriculum content was similar to that which she had taught in the United Kingdom. She encountered no difference in her expectations about Science from those of her students. However, she assumed that 
teaching place-based subjects, such as History and Geography, could be difficult. Tom disagreed with her about teaching Geography; and conveyed that a greater access to nature in New Zealand would be advantageous to teachers. He did not express concern about the difference in the subject content of Geography here and in the United Kingdom; it was freedom from the textbook and access to the environment that he saw as beneficial. Doug suggested investigating NCEA and assessments; and this could help OTTs align their expectations about subject content with those of their students. Information about NCEA and assessments is readily available online via NZQA"s website; and OTTs could include an exploration of these in their preparation before coming to New Zealand.

\section{Finances}

Josh, Leonard and Doug found finances to be an issue but for different reasons. Josh and Leonard"s financial challenge was the expense of applications required for immigration. Leonard indicated he could not have immigrated without savings and the Relocation Grant was minimal in comparison to the cost of immigration. Doug"s concern was the lower remuneration and higher cost of living in New Zealand compared with the United Kingdom.

Previous studies concur with the finding that finance causes difficulty for OTTs (Beynon et al., 2004; Miller, 2006; Sharplin, 2009; Walsh et al., 2011). Difficulties arise due to the expense of the teacher registration process (Beynon et al., 2004; Walsh et al., 2011) and because OTTs can find themselves worse off financially as a result of their move (Miller, 2006).

Immigration is expensive and OTTs can prepare by making sure they are well informed. Biggs (2010) research states, "Prior to moving to New Zealand it is essential that OTTs complete the salary assessment process and ensure that they have accurate information on the salary they can expect to receive before immigrating to New Zealand" (p. 112). Relocating is an expensive exercise when moving within a city or across a country and emigration is even more expensive. It is a move between 
countries and requires international travel, including the expense of moving belongings between countries, and upon arrival there are set-up costs. If OTTs are in a position to obtain information about the salary they can expect and save before moving these strategies will help to adjust expectations and lessen the financial burden.

\subsection{Supports}

This study found that participants gained from networking with others, both socially and professionally. They derived benefit from making preparations before coming to New Zealand and from the nature of the teaching subject they were qualified to teach. Luck played a part in their success, as did maintaining a positive attitude throughout the immigration process. Professional development assisted in the transition process and the natural environment was found to be a benefit of living in New Zealand.

\section{Networking}

Networking assisted all participants to secure their first position. These included social networks consisting of their family and friends, and more formal networks of recruitment agencies and hiring schools.

Tom"s family network secured him his role because both he and his partner were offered a position at the high school she had attended. Josh"s brother-in-law gave him the Head of Department"s contact details and then provided him with information about the school that subsequently hired him. Emily gained assistance through her social network because her husband"s colleague put her in contact with a retired principal who met with her and edited her CV. Alabama"s social network provided her with help because a friend of hers had taught in New Zealand and advised her about the application process. This concurs with Okumara (2008) who also found that social and professional networking helped secure teaching positions in New Zealand. Networking can give access to knowledge and experience not otherwise accessible; and OTTs can secure a position and have support from family, friends and colleagues through the transition of moving to New Zealand. 
The recruitment agency through which Alabama found work had suggested that she apply for a position teaching subjects for which she had little previous experience; and this was effective because she was offered a position. However, she struggled because of her lack of experience and due to being the only Electronics teacher on staff. That situation is similar to the findings of De Villiers and Books (2009) who researched recruitment websites and found that they promised OTTs and schools they would match staff and roles perfectly. However, that was not the case. The suggestion that Alabama"s recruiter made turned out well because she secured a post but it also created stress for her; because she struggled to teach subjects she had not taught before. However, she and her employer were not disappointed by a mismatch between teaching position and OTT the way that teachers and schools in De Villiers and Books study were. OTTs can benefit from registering with a recruiter and could keep in mind that the ultimate responsibility for finding an appropriate post lies with the individual. OTTs should be mindful of their personal requirements (regarding location, teaching subject and school) and avoid being encouraged by recruiters to apply for unsuitable roles.

The school that hired Emily had many students whose parents were immigrants to New Zealand and she thought that was a reason why it was more open to hiring OTTs. The school that hired Alabama had a practice of selecting the best candidate for the role, be they from New Zealand or OTTs. Schmidt and Block (2010) explored Manitoba Education"s Action Plan for Ethnocultural Equity and that plan had extensive content to support employment equity and diversity. However, employment equity was not included in all Canadian divisional employment policy. Emily and Alabama stated schools were open to hiring OTTs but the employment policy of those schools was not investigated as was the case in Schmidt and Block"s study. Hiring local teachers is important and so is hiring the best teacher for the role. Schools are in a position of responsibility because they are tasked with making an appointment that is mindful of students, staff, the school and the community. Added to this responsibility is the requirement that public sector employers implement equal employment opportunity 
policies (Mintrom \& True, 2004) meaning appointment of teachers should be made with consideration for diversity.

\section{Preparation}

Doug could be described as the most prepared participant because he visited New Zealand before deciding to emigrate, met with a recruiter and school principals and had made many of the required applications before arriving here. His transition appeared the easiest and that may be attributed in part to his preparation. All of the participants had prepared before coming to New Zealand and they suggested ways for others to prepare and the importance of such preparation is indicated by other studies (Biggs, 2010; Hutchinson, 2005; Phillion, 2003; Sutherland \& Rees, 1995). The difficulty in preparing is that OTTs are doing so for a context they are not familiar with yet the most useful strategy is to prepare as much as possible.

\section{Teaching subject}

Alabama and Leonard spoke about the ease of securing work in New Zealand based on OTTs" teaching subjects; because there are fewer teachers of subjects such as Physics and these teachers are in demand. This concurs with Subedi"s (2008) finding that teachers in specialist subject areas were granted easy access to the teaching profession in Australia. It would seem logical to assume, as Alabama and Leonard have, that less competition would lead to ease finding jobs. However, OTTs who teach subjects in high demand in New Zealand still face the rigours of applications for visas, Qualifications Assessment and Teacher Registration. These teachers are required to complete the same application process as all OTTs and should thus not expect the process to be simplified based on a need for their specialist skills. 


\section{Luck and a positive attitude}

The word luck was used by each participant and was an unexpected element of success. This finding intersects with Butcher"s (2012) New Zealand-based study which found that participants frequently referred to luck when explaining their progress toward professional socialisation. It is possible that luck is aligned with a positive personal attitude and participants view themselves as lucky as a function of that attitude.

Alabama and Leonard prescribed a positive attitude as an ingredient for success. Alabama encouraged persistence and Leonard advised that patience was important when the process of immigration became difficult. The findings of Warner"s (2010) study conducted in the United Kingdom support this notion because those included a positive personal attitude as a reason for OTTs" success. A positive attitude could be seen as an ingredient for success in many endeavours and immigration is no different. Maintaining a positive attitude could be useful because it could help OTTs maintain motivation when the immigration process becomes difficult.

\section{Natural environment}

Tom"s indication that New Zealand is about outdoor living is supported by the findings of Anand and Dewar (2004) that indicated $71.8 \%$ of the 539 teachers in their study were attracted to New Zealand by the lifestyle. Those who had arrived in New Zealand for a non-permanent stay had decided to stay longer than they had originally intended because of the lifestyle and outdoor opportunities.

\section{Professional development}

Several participants reported that receiving professional development was supportive. For example, Josh appreciated his time with the Restorative Practice Coordinator and Alabama found subject specific professional development very valuable.

Teacher training programmes for OTTs have been investigated both internationally (Cruickshank, 2004; Walsh \& Brigham, 2007) and in New Zealand (Biggs, 2010). Warner (2010) found professional support at school, through teacher training 
programmes, was a reason for professional success in the United Kingdom. New Zealand has no reported programmes specifically for OTTs and that is problematic. OTTs to New Zealand could be supported toward success if given access to customized training programmes.

Mentorship programmes have likewise been found to support OTTs (Deters, 2006; Peeler \& Jane, 2005; Warner, 2010). Peeler and Jane (2005) found mentorship helped OTTs to settle into teaching in Australia; and Deters (2006) indicated mentorship and support were key components for OTTs" success in Canada. Deters (2006) found acceptance by the school community to be an important element for success and Vohra"s (2005) New Zealand-based research concurred; indicating that recognition by schools and associated professional institutions of OTTs" efforts to integrate would support that integration. Similarly, a study conducted by Abramova (2011) in the United States of America recommended that the community could support OTTs by recognising their needs.

Training and mentorship programmes are supportive of OTTs and these could be integrated into an orientation programme. Alabama did not have access to a bespoke orientation programme and created her own by asking a friend for advice about the mandatory applications involved in the immigration process, attending courses about culture, joining a group of Electronics teachers and finding a Physics tutor.

The finding from this study that there was no tailored orientation programme available is supported by Biggs (2010). Researchers propose that authorities understand the needs of OTTs and, using that understanding, create programmes to appropriately facilitate their entry into teaching in their new country (Biggs, 2010; Cross et al., 2011; Phillion, 2003). OTTs to New Zealand could benefit from a needs-based orientation programme and the development of such a programme could be informed by research about those needs. 
OTTs can create supports for themselves by networking, being prepared and remaining positive through the immigration process. They can be supported through this process by being given access to tailored professional development opportunities.

\subsection{Suggested pathway}

The findings from this study suggest that those contemplating emigration should start by researching the country and deciding on an area to live. Once an area has been selected, a search for schools in that area and research about those schools can begin, with the aim of choosing several schools that might be suitable. A visit to that area and those schools could help to support decision-making process and would also create an opportunity to start networking and provide an introduction to the local culture.

Returning to the country of origin having made the decision to emigrate, and having the context of a visit as a framework, means that detailed research about the education system can begin. Investigating National Certificates of Educational Achievement, assessment methods and the decile system will support further decision-making about whether teaching would be the most suitable profession to pursue after emigrating. It would also serve as useful preparation for interviews.

To further support decision-making and preparation, networking is suggested. OTTs who have been through the process and people working in education could offer advice and information.

CV requirements may differ between different countries and exploring what those differences are and re-writing accordingly could ensure applications are not dismissed because they do not contain necessary information. Subsequently, registration with a New Zealand-based recruiter and the Education Gazette online could occur. This could come earlier in the process but might be better placed after the CV is rewritten so that, if a suitable position is available, an application can be made easily with a CV that is ready to send. 
Applications take a long time and that should be expected and allowed for. An Expression of Interest in applying for a Permanent Resident Visa is best done first because that outcome will indicate eligibility to apply. Subsequently, a Qualifications Assessment should be applied for because the result of this is required for submission, along with other documentation, to obtain Teacher Registration. After positive results are received from those submissions a preliminary Salary Assessment can be applied for and having this application done before emigrating can save time during a later application for Salary Assessment.

One can gain access to more employment opportunities by searching for both full and part-time positions so that, upon immigration, a job is available and income is certain. An application for an IRD number and subsequent full Salary Assessment are best made as soon as possible after beginning work. This is so that pay is received at the appropriate salary level sooner rather than later, making it easier to cope with the high cost of setting up in a new country. Asking for professional development opportunities could assist in gaining knowledge and information about the new cultural and educational context thus supporting a successful transition.

This suggested pathway is documented on the next page in Figure 11: Suggested Pathway. 
Figure 11: Suggested pathway

Select an area and research schools in that area Л

Visit NZ \& NZ schools

Investigate NCEA, assessment methods, decile system

I

\begin{tabular}{|c|}
\hline Network \\
\hline$\sqrt{l}$ \\
\hline Rewrite CV \\
\hline$\sqrt{l}$ \\
\hline Register with a recruiter \& the Education Gazette online
\end{tabular}

$\sqrt{2}$

Qualifications assessment

Teacher registration

Permanent resident visa

$\sqrt{2}$

Preliminary salary assessment

त

Search for part and full-time teaching positions

II

Secure a post

Immigrate

Start teaching

II

Apply for an Inland Revenue Department number

Salary assessment

Request professional development 


\subsection{Conclusion}

This chapter has compared the findings of this thesis to those of other studies. The findings from this research concur with the literature in that culture shock, bureaucracy and finance caused challenges for OTTs. Also concurring with the literature were the findings that professional development, preparation, networking, teaching subject, luck and a positive attitude were supports for OTTs. These findings were used to formulate a suggested pathway and this pathway is an addition to the body of New Zealand literature about OTTs. A further addition to the literature is the finding that Emily, a first language speaker of English, was expected to face the same language difficulties as second language speakers because she immigrated from a developing country. 


\section{Chapter 6: Conclusion}

\subsection{Summary}

New Zealand-trained teachers leave to teach abroad, change careers or retire and OTTs immigrate to teach in New Zealand. For OTTs, the process of securing work in a new country can be difficult and it is useful to facilitate this as a way of filling vacancies.

This thesis reported how six OTTs immigrated to, and found work in, New Zealand. The research question asked what individual pathways OTTs had navigated into teaching and there were three sub-questions. The first asked what challenges had been faced, the second what supports had been experienced, and the third enquired about participants" suggestions for other OTTs.

The theoretical framework for this study was interpretive; it used words as data and placed importance on subjective experience. To answer the research questions a qualitative design was used and this design employed semi-structured interviews to gather data. The six participants were overseas trained secondary school teachers from the Wellington Region of New Zealand; five of them had emigrated from the United Kingdom and one from South Africa. All had been tertiary educated and gained teaching experience overseas. Data were analysed thematically using the following three themes: challenges, supports and suggestions. Each interview was analysed individually and treated as a single case. Subsequently, all six cases were compared and contrasted and this method can be described as a collective, case study.

Findings related to the first theme, challenges, were that all of the participants experienced bureaucracy as a hindrance, most experienced culture shock and some faced financial difficulty. These findings concur with previous research that similarly found bureaucracy, culture shock and finances were challenging to OTTs in New 
Zealand and abroad. One participant in this study faced the unique obstacle of a lack of teaching experience in a subject she was hired to teach.

Findings related to the second theme, supports, were that all participants were assisted by networks, most found preparation helpful, some felt luck had played a part in their success, two perceived their teaching subjects to be useful, one thought the natural environment was of value, and one placed importance on professional development. In other literature cited, professional development was most often mentioned as a support to OTTs. Luck, a positive attitude, networking and the natural environment were also found by other researchers to be supportive.

Under the theme, suggestions, findings were that most participants advised preparation, some proposed networking, two advocated interagency co-operation, two encouraged a positive attitude, and one recommended relief teaching. Networking, preparation, interagency co-operation and a positive attitude were found useful by other studies. Relief teaching was not investigated as an element involved in OTTs" success by other researchers and is thus an addition to the literature.

\subsection{Recommendations}

The primary recommendation for OTTs is to make use of the pathway suggested by this thesis. Further recommendations for prospective OTTs include visiting New Zealand, and going to schools to meet with principals, before making a decision to emigrate. Preparation through extensive research should further assist in decision-making. Networking is encouraged as a way of gathering information and making connections that assist OTTs toward their goal of moving to, and working in, their country of choice. Starting mandatory applications as soon as possible is advised because all of those applications take several months to acquire. It is useful for OTTs to search for both part and full-time work, thus maximising employment opportunities. Once a position has been secured, it is recommended that an IRD number and a Salary Assessment are applied for as soon as possible. This is to minimise the time period of salary payment at 
minimum rate because immigrating is expensive and receiving full pay quickly is desirable. OTTs are encouraged to request professional development opportunities in order to make their transition easier.

Schools are recommended to promote cultural responsiveness by valuing the cultural, linguistic and professional capital OTTs bring with them. Permitting OTTs to observe lessons prior to teaching is recommended to allow them to gain understanding about appropriate classroom management in New Zealand. Schools can support the transition of OTTs by allowing them to make use of professional development opportunities, including courses about curriculum and those with a focus on culture, and providing a mentor.

A recommendation for immigration and education authorities is to work toward interagency co-operation because that could create efficiencies thus saving the time of both agencies and OTTs. For example, the NZQA requires original qualifications and a Police Clearance Certificate (PCC) in order to complete a Qualifications Assessment. NZTC requires original qualifications, a PCC and an NZQA Qualifications Assessment. Applicants courier documents to NZQA; await the return of these documents and their Qualifications Assessment; and then courier these to NZTC. It is suggested that providing an NZQA Qualifications Assessment to NZTC negates the NZTC requirement for original qualifications and a PCC.

A further recommendation is for verification of qualifications to be sought from the awarding institution rather than waiting on couriered original degree certificates. This would reduce application-processing time for authorities. It would also negate the possibility of original degree certificates going missing. 


\subsection{Limitations of the research}

This research was limited partly due to demographics of the participants and partly due to aspects of its methodology.

In terms of demographics, six OTTs were interviewed and the findings of this study were not generalisable due to this small number of participants (Myers, 2000). Participants volunteered and their willingness to volunteer set them apart from teachers who received information about this study and decided not to take part (Katzer, Cook \& Crough, 1998; Terre Blanche \& Durrheim, 2002). Those who were interviewed were also different from others because they can be viewed as the successes, having emigrated and secured teaching jobs. Additionally, participants were from a limited geographical spread and most had emigrated from a single country of origin and these factors may have influenced their experiences.

The methodology limited this research because it employed the interpretive paradigm that focuses on subjective experience that cannot be generalised. Participants selfreported and were interviewed only once. More interviews and multiple methods of data gathering such as questionnaires and observation could have provided a more detailed account of this situation. A lack of data triangulation is a further limitation; data triangulation involves gathering information from many different sources (Terre Blanche \& Durrheim, 2002). Engaging with other stakeholders such as principals, staff at INZ and the NZTC could have strengthened findings but this was beyond the scope of the present study.

In spite of these limitations it is perceived that this research presents some useful information for potential OTTs about a topic that is relatively unexplored in academic literature in New Zealand to date. 


\subsection{Future research}

Future research may address the demographic and methodological limitations of this study. This could be achieved if studies were done with a variety of participants including OTTs from a greater geographical spread and from a wider number of source countries. It could also be achieved by including respondents from different areas within the education sector and by making use of diverse tools to gather data.

Research conducted in future could explore whether the experiences of these six OTTS reflect the experiences of OTTs across New Zealand. It is possible that OTTs in different locations could share similar, and also have some unique experiences, particular to a geographic location. Including respondents from other areas could establish whether that is the case.

Future research could ascertain whether OTTs from countries other than the United Kingdom and South Africa have similar experiences. There may be influences on the experiences of these six participants that are due to their country of origin. OTTs who emigrate from other countries might face different challenges and receive support in ways not found by this study.

In order to gain more extensive information about the situation, future studies could expand the diversity of the pool of participants. This expansion could include participants such as: school-hiring staff, locally trained teachers, immigration officials, and staff at the NZTC, the NZQA and the MoE. A more holistic picture of the situation could be obtained with information from this wide cross spectrum of participants from the Education sector.

Other research could aim at data triangulation by obtaining data from varied tools. These tools could be both quantitative and qualitative in nature, gathering different types of data. Data-gathering tools could include questionnaires, surveys, videos and focus groups. 


\subsection{Conclusion}

People have always moved around the world and the digital and technological age has led to more convenient and quicker means of travel being available. Resulting globalisation has had the consequence of a diverse student body. In New Zealand, where immigrants make up more than $20 \%$ of the general population, this diversity is relatively great. Filling teaching vacancies and allowing local students exposure to qualified and experienced teachers from other countries can be beneficial; and the suggested pathway resulting from this thesis can assist future OTTs to secure work in New Zealand. 


\section{References}

Abramova, I. (2011). Making meaning of work: uncovering the complexity of immigrant experience in a multicultural landscape. Multicultural perspectives, 13(4), 209214.

American Federation of Teachers. (2009). Importing educators: causes and consequences of international teacher recruitment. Washington, DC: Author.

Anand, V., \& Dewar, S. (2004). Survey of overseas teachers 2003. Wellington: Ministry of Education.

Anderton, J., Maharey, S., Wilson, M., Dalziel, L. \& Hobbs, M. (2003). Population and sustainable development 2003. Wellington: Ministry of Economic Development, Ministry of Social Development \& Department of Labour.

Appleton, S. Sives, A. \& Morgan, W. (2006). The impact of international teacher migration on schooling in developing countries - the case of Southern Africa. Globalisation, Societies and Education, 4(1), 121-142.

Arva, V., \& Medgyes, P. (2000). Native and non-native teachers in the classroom. Systems, 28, 355-372.

Atieno, O. (2009). An analysis of the strengths and limitations of qualitative and quantitative research paradigms. Problems of Education in the $21^{\text {st }}$ Century, 13, 13-18.

Barback, J. (2013, April). Feast or famine: The supply of new teachers. Postgrad Schools of Education, 2-6.

Barbour, R. (2008). Introducing qualitative research: a student guide to the craft of doing qualitative research. London, UK: Sage Publications.

Barnes, G., Crowe, E., \& Schaefer, B. (2007). The cost of teacher turnover in five school districts: a pilot study. Washington, DC: National Commission on Teaching and America"s Future. Retrieved from http://nctaf.org/wp-content/uploads/2012/01/NCTAF-Cost-of-Teacher-Turnover2007-full-report.pdf

Bedford, C. (2003). Skill shortages in New Zealand: public and private sector responses. New Zealand Population Review, 29(2), 63-88.

Beynon, J., llieva, R., \& Dichupa, M. (2004). Re-credentialling experiences of immigrant teachers: Negotiating institutional structures, professional identities and pedagogy. Teachers and Teaching: Theory and Practice, 10 (4), $431-444$.

Biggs, K. (2010). The induction of overseas trained teachers in South Auckland secondary schools (Unpublished master"s thesis). Unitec Institute of Technology, New Zealand.

Boeije, H. (2009). Analysis in qualitative research. London: Sage.

Books, S. \& De Villiers, R. (2013). Importing educators and redefining what it means to be a teacher in the U.S. Journal for Critical Education Policy, 11(2), 82-122.

Branch, R. M., \& Kritsonis, W. A. (2006). National agenda: minority teacher recruitment, development and retention. Doctoral Forum National Journal for Publishing and Mentoring Doctoral Student Research, 3(1), 1-4. Retrieved from http://www.nationalforum.com/Electronic\%20Journal\%20Volumes/Branch, 
\%20Robert\%20M\%20\%20National\%20Agenda\%20Minority\%20Teacher

$\% 20$ Recruitment.pdf

Brooker, M. (2004, January 16). Schools search overseas. The Press.

Bunniss, S., \& Kelly, D. (2010). Research paradigms in medical educational research. Medical Education, 44, 358-366.

Burns, R., \& Hornel, A. (1989). Gender division of tasks by parents and their children. Psychology of Women Quarterly, 13(1), 113-125.

Butcher, J. (2012). Overseas trained teachers' experiences of professional socialisation in New Zealand (Unpublished master"s thesis). University of Waikato, New Zealand.

Cameron, M., \& Baker, R. (2004). Research on Initial Teacher Education in New Zealand: 1993-2004. Wellington: Ministry of Education.

Cameron, M., Baker, R., \& Lovett, S. (2006). Teachers of promise: getting started in teaching. Wellington: New Zealand Council for Educational Research.

Cho, C. (2010) "Qualifying" as teacher: Immigrant teacher candidates" counterstories. Canadian Journal of Educational Administration and Policy, (100), 1-22.

Retrieved from http://umanitoba.ca/publications/cjeap/pdf_files/cho-eit.pdf

Chow, L. (2011). Being and becoming public school teachers: career mobility of Chinese overseas-trained teachers in the San Francisco Bay Area (Unpublished doctoral dissertation). University of San Francisco, California.

Cranton, P. (2001). Interpretive and critical evaluation. New Directions for Teaching and Learning 88, 11-18.

Creedy, J., Enright, J., Gemmell, N., \& Mellish, A. (2009, July). Population ageing and taxation in New Zealand. [Research Paper Number 1078]. Melbourne: University of Melbourne. Retrieved from http://www.economics.unimelb.edu.au/downloads/wp/wp09/1078.pdf

Creswell, J. (2003). Research design: qualitative, quantitative, and mixed methods approaches $\left(2^{\text {nd }}\right.$ ed. $)$. Thousand Oaks, CA: Sage.

Cross, D., Hong, J., \& Williams-Johnson, M. (2011). It"s not better or worse, it"s just different: examining Jamaican teachers" pedagogical and emotional experiences. Teacher Development, 15(4), 499-515.

Cruickshank, K. (2004). Towards diversity in teacher education: teacher preparation of immigrant teachers. European Journal of Teacher Education 27(2), 125-138.

Cushner, K. \& Mahon, J. (2002). Overseas student teaching: Affecting personal, professional and global competencies in an age of globalization. Journal of Studies in International Education, 6(1), 44-58.

Dei, S. (2002). Beyond the rhetoric: moving from exclusion, reaching for inclusion in Canadian schools. The Alberta Journal of Educational Research, 48(1), 61-87.

Department for Education. (2013). Information for teachers qualified in Australia, Canada, New Zealand and the United States of America. Retrieved from http://www.education.gov.uk/schools/careers/careeropportunities/overseastrainedteachers/a00205926/australia-canada-nz-usa

Deters, P. (2006, September). Immigrant teachers in Canada: learning the language and culture of a new professional community. Paper presented at the AELFE Conference, Zarago, Spain. Retrieved from http://www.unizar.es/aelfe2006/ALEFE06/2.\%20didactics/53.pdf 
De Villiers, R. \& Books, S. (2009). Recruiting teachers online: marketing strategies and information dissemination practices of UK-based agencies. Educational Review, 61(3), 315-325.

De Wit, B., Loman, K. Faithfull, K., \& Hinckson, E. (2012). Reliability and validity of the hands-up survey in assessing commuting to school in New Zealand elementary school children. Health Promotion Practice, 13(3), 349-354.

Double Figures. (2003). Education Journal, 70, 11.

Education Counts. (2010). How does New Zealand's education system compare? OECD's Education at a Glance 2010. Retrieved from http://www.educationcounts.govt.nz/publications/ECE/81180/9.-staffingresources

Education Counts. (2011). OECD Review on Evaluation and Assessment Frameworks for Improving School Outcomes. Retrieved from http://www.educationcounts.govt.nz/publications/schooling/oecd-review-onevaluation-and-assessment-frameworks-for-improving-school-outcomes/chapter1-the-school-system

Eisenhardt, K. (1989). Building theories from case study research. The Academy of Management Review, 14(4), 532-550.

Faez, F. (2010). Linguistic and cultural adaptation of internationally educated teacher candidates. Canadian Journal of Educational Administration and Policy, (100), 1-20. Retrieved from http://umanitoba.ca/publications/cjeap/pdf_files/ragnarsdottir-iet.pdf

Fenwick, L.T. (2001). Patterns of excellences: policy perspectives on diversity in teaching and school leadership. Atlanta, GA: Southern Education Foundation.

Firkin, P., Dupuis, A., \& Meares, C. (2004). New Zealand experience(s): biographical narratives of professional migrants on working in New Zealand (Research Report Series 2004/2). Auckland: Massey University.

Fisher, A. (2011, January 26). Shortage warning as teaching stars leave NZ. Dominion Post. Retrieved from

http://www.stuff.co.nz/dominion-post/news/4580578/Shortage-warning-asteaching-stars-leave-NZ

Florence, N. (2010). Immigrant teachers, American students: cultural differences, cultural disconnections. New York, USA: Palgrave Macmillan.

Gallagher, D. (2006). If not absolute objectivity, then what? A reply to Kauffman and Sasso. Exceptionality, 14(2), 91-107.

Gao, Y. (2010). Tale of two teachers: Chinese immigrant teachers' professional identity in US foreign language classrooms (Published doctoral dissertation). University of Minnesota, USA.

Gifford, J. (2007). Building better bridges: toward more effective strategies for promoting teacher diversity in California secondary Social Science classrooms at the pre-service level (Unpublished master"s thesis). Dominican University of California, USA.

Gilpin, L. (2005). Storying and de-storying black teacher identities. Teacher Education and Practice, 18(2), 215-230.

Grenfell, M. (2009). Applying Bourdieu"s field theory: the case of social capital and education. Education, Knowledge \& economy, 3(1), 17-34. 
Guest, R., Bryant, J., \& Scobie, G. (2003). Population ageing in New Zealand Implications for living standards and the optimal rate of saving [Working Paper 03/10]. Wellington: New Zealand Treasury. Retrieved from http://www.treasury.govt.nz/publications/research-policy/wp/2003/03-10

Guo, W., \& Singh, M. (2009, November). Overseas trained teachers in Australia: a study of barriers, skills and qualifications. Paper presented at the AARE International Education Research Conference, Canberra, Australia. Retrieved from http://www.aare.edu.au/09pap/guo091408.pdf

Halcon, F. (2011, November). The case study strategy: a research type in studying innovations in women's business education. Paper presented at the $6^{\text {th }}$ Qualitative Research Convention, Putrajaya, Malaysia. Retrieved from http://myqra.org/convention2011/node/121

Hall, D., \& Langton, B. (2006). Perceptions of the status of teachers. Wellington: Ministry of Education.

Harker, R., \& Chapman, J. (2006). Teacher numbers in New Zealand: attrition and replacement. New Zealand Journal of Teachers' Work. 3(1), 42-55.

Hartsuyker, L. (2007). Top of the class: report on the inquiry into teacher education. Canberra: The Parliament of the Commonwealth of Australia.

Hawthorne, L. (2007). Labour market outcomes for migrant professionals: Canada and Australia compared. Ottowa: Statistics Canada.

Hess, F. (2009). Revitalizing teacher education by revisiting our assumptions about teaching. Journal of teacher education, 60(5), 450-457.

Hirsch, E. (2006). Recruiting and retaining teachers in Alabama: educators on what it will take to staff all classrooms with quality teachers. Alabama: Center for Teaching Quality.

Howard, J. (2009). Pride and prejudice and other barriers to teaching for Asian New Zealanders. Asia Pacific Journal of Education. 29(2), 143-157.

Huddleston, R., \& Pullum, G. (2002). The Cambridge Grammar of the English Language. Cambridge, United Kingdom: Cambridge University Press.

Hutchinson, C. (2005). Cross-cultural issues arising for four science teachers during their international migration to teach in U.S. high schools. School Science and Mathematics, 106(2), 74-83.

Hwang, Y., Baek, E., \& Vrongistinos, K. (2005). Immigrant Hispanic/Latino teachers' perception of education. Paper presented at the Annual Meeting of the American Educational Research Association, Montreal, Canada.

Immigration New Zealand. (n.d.a). Work visa guide. Retrieved from http://www.immigration.govt.nz/NR/rdonlyres/371C5E08-3AAE-4F62-A2838430B1716E70/0/INZ1016.pdf

Immigration New Zealand. (n.d.b). Guide for resident and former resident visa holders. Retrieved from http://www.immigration.govt.nz/NR/rdonlyres/CAF71A48-28D3-40B8-9D765C663CCA17FA/0/INZ1176July2011.pdf

Immigration New Zealand. (2012a). Self-assessment guide for residence in New Zealand [INZ1003]. Retrieved from http://www.immigration.govt.nz/NR/rdonlyres/4DAD508D-CC26-425A-A57BD2AF557C8510/0/NZIS1003.pdf 
Immigration New Zealand. (2012b). Skilled migrant category: expression of interest guide [1101]. Retrieved from

http://www.immigration.govt.nz/NR/rdonlyres/E741D6F6-7670-48E1-B824-

69B3959461D4/0/INZ110130July2012.pdf

Immigration New Zealand. (2012c). Qualifications. Retrieved from

http://www.immigration.govt.nz/migrant/general/formsandfees/formsandguides/lor q/default.htm

Inglis, C., \& Philps, R. (1995). Teachers in the sun: the impact of immigrant teachers on the labour force. Canberra: Australian Government Publishing Service.

Inland Revenue Department. (2013). IRD number applications. Retrieved from http://www.ird.govt.nz/how-to/irdnumbers/\#01

Jack, M., \& Wevers, M. (2013). Report of the Ministerial Inquiry into the Novopay Project. Wellington: New Zealand Government.

Johnson, B. \& Christensen, L. (2008). Educational research: Quantitative, qualitative and mixed approaches ( $3^{\text {rd }}$ ed.). Thousand Oaks, California: Sage Publications.

Johnson, L. (2003). The diversity imperative: building a culturally responsive school ethos. Intercultural Education, 14(1), 17-30.

Jones, M. (2009). New Zealand: electoral politics in times of crisis. In P. Hart \& K. Tindall (Eds.), Framing the global economic downturn: crisis rhetoric and the politics of recessions (pp. 243-266). Canberra: ANU E Press.

Kaboub, F. (2008). Positivist paradigm. In F.T. Leong (Ed.), Encyclopedia of counseling psychology, volume two: Personal and emotional counselling (p. 343). Thousand Oaks, CA: Sage.

Kane, R., \& Mallon, M. (2006). Perceptions of teachers and teaching. Wellington: Ministry of Education.

Kain, E. (2011, August 3). High Teacher Turnover Rates are a Big Problem for America"s Public Schools. Forbes. Retrieved from

http://www.forbes.com/sites/erikkain/2011/03/08/high-teacher-turnover-rates-area-big-problem-for-americas-public-schools/

Katzer, J., Cook, K., \& Cough, W. (1998). Evaluating information: a guide for users of social science research $\left(4^{\text {th }}\right.$ ed.). Boston, MA: McGraw-Hill.

Kersaint, G., Lewis, J., Potter, R., \& Meisels, G. (2005). Why teachers leave: factors that influence retention and resignation. Teaching and Teacher Education (23), 775-794.

Kitonga, N. (2010). Postcolonial construction of self: two immigrant secondary Science teachers from Nigeria and Kenya explore the role of cultural and indigenous beliefs in their teaching (Unpublished doctoral dissertation, Chapman University, California). Retrieved from http://gradworks.umi.com/3440233.pdf

Laxon, A. (2012, May 26). The OC school of hard knocks. The New Zealand Herald. Retrieved from http://www.nzherald.co.nz/nz/news/article.cfm?c_id=1\&objectid=10808505

Lee, M. (2011). Monitoring teacher supply: survey of staffing in New Zealand schools at the beginning of the 2011 school year. Wellington: Ministry of Education.

Lewis, J. (2010, May 12). Warning of possible teacher shortage. Otago Daily Times. Retrieved from http://www.odt.co.nz/news/dunedin/105596/warning-possible-teacher-shortages 
Lonsdale, M., \& Ingvarson, L. (2003). Initiatives to address teacher shortage. Victoria: Australian Council for Educational Research.

Lunenburg, F. (2011). The generation and verification of theory: a bridge to the continuing quest for a knowledge base. National Forum of Applied Educational Research Journal, 25(1\&2), 2-11.

Mawhinney, H., \& Xu, F. (1997). Reconstructing the professional identity of foreigntrained teachers in Ontario schools. TESOL Quarterly, 31, 632-639.

McNamara, O., Lewis, S. \& Howson, J. (2004). The recruitment of overseas trained teachers. Birmingham, United Kingdom: National Association of Schoolmasters Union of Women Teachers.

McNamara, O., Lewis, S., \& Howson, J. (2007). "Turning the tap on and off": the recruitment of overseas trained teachers to the United Kingdom. Perspectives in Education, 25(2), 40-54.

Miller, P. (2006). Professional lives in transition: overseas trained teachers in England. Caribbean Journal of Education, 28(2), 187-215.

Miller, P. (2007). "Brain gain" in England: how overseas trained teachers have enriched and sustained English education. Perspectives in Education, 25(2), 25-37.

Miller, P. (2008). Downgrading and discounting the qualifications of migrant professionals in England: the case of overseas-trained teachers. Education, Knowledge \& Economy: A Journal for Education and Social Enterprise, 2(1), 1525.

Miller, P. (2009). Reconstructing teacher identities: shock turbulence, resistance and adaptation in Caribbean teacher migration to England. Education, Knowledge \& Economy: A Journal for Education and Social Enterprise, 3(2), 97-105.

Miller, P., Ochs, K., \& Mulvaney, G. (2008). International teacher migration and the Commonwealth Teacher Recruitment Protocol. European Education, 40(3), 89101.

Ministry of Education. (2005). Report on the Findings of the 2004 Teacher Census. Wellington: Ministry of Education. Retrieved from http://www.educationcounts.govt.nz/publications/schooling/teacher_census

Ministry of Education. (2011). Decile Ratings. Retrieved from http://www.minedu.govt.nz/NZEducation/EducationPolicies/Schools/SchoolOpera tions/Resourcing/ResourcingHandbook/Chapter1/DecileRatings.aspx

Ministry of Education. (2012, February 20). Overseas teacher recruitment. Board and Principal Alert. Wellington: Ministry of Education.

Ministry of Education. (2013). International Relocation Grant for overseas trained teachers/principals. Retrieved from

http://www.minedu.govt.nz/NZEducation/EducationPolicies/Schools/SchoolOpera tions/Resourcing/RelocatingTeachingStaff/RelocationGrants/InternationalRelocat ionGrant/OverseasTrained.aspx

Mintrom, M., \& True, J. (2004). Framework for the future: Equal employment opportunities in New Zealand [Summary publication]. Wellington: Human Rights Commission.

Mitchell, I. (2010). The importance of culture in a New Zealand high school context: an exploration of whether the culture of overseas teachers is seen by students, in 
Years 12 and 13, to impact on the quality of their learning experiences. (Unpublished master"s thesis). University of Waikato: Hamilton.

Myers, M. (2000). Qualitative research and the generalizability question: standing firm with proteus. The Qualitative Report, 4(3\&4).

Nayar, S. (2009). Immigrant teachers" experiences of racial discrimination. Pacific-Asian Education 21(1), 7-18.

New Zealand Teachers Council. (n.d.a). Overseas teachers. Retrieved from http://www.teacherscouncil.govt.nz/content/overseas-teachers

New Zealand Teachers Council. (n.d.b). Information for teachers from outside New Zealand. Retrieved from http://www.teacherscouncil.govt.nz/os/

$\mathrm{Ng}$, L. (2006). Monitoring teacher supply survey of staffing in New Zealand schools at the beginning of the 2006 school year. Wellington: Ministry of Education, Research Division.

Novopay. (n.d.). Request a salary assessment. Retrieved from http://www.novopay.govt.nz/Site/Service_Desk/Request_a_Salary_Assessment. aspx

Oberg, K. (1960). Cultural shock: adjustment to new cultural environments. Practical Anthropology, 7, 177 - 182.

Okumara, Y. (2008). Clearing cultural clutter: Experiences of Japanese native speaker teachers teaching Japanese in New Zealand (Unpublished doctoral thesis). University of Canterbury: New Zealand.

Olmedo, I. \& Harbon, L. (2010). Broadening our sights: internationalizing teacher education for a global arena. Teaching Education, 21(1), 75-88.

Patton, M. Q. (2002). Qualitative research and evaluation methods ( $3^{\text {rd }}$ ed.). Thousand Oaks, California: Sage Publications.

Peeler, E. \& Jane, B. (2005). Mentoring: Immigrant teachers bridging professional practices. Teaching Education, 16(4), 325-336.

Phillion, J. (2003). Obstacles to accessing the teaching profession for immigrant women. Multicultural Education, 11(1), 41-45.

Pollock, K. (2010). Marginalization and the occasional teacher workforce in Ontario: the case of internationally educated teachers (IETs). Canadian Journal of Educational Administration and Policy, (100), 1-21. Retrieved from http://umanitoba.ca/publications/cjeap/pdf_files/pollock-iet.pdf

Reimers, F. (2006). Citizenship, identity and education: examining the public purposes of schools in an age of globalization. Prospects, 36(3), 275-294.

Reitz, J. (2005). Tapping immigrants" skills: new directions for Canadian immigration policy in the knowledge economy. IRPP Choices, 11(1).

Richards, L. \& Morse, J. M. (2007). Read me first for a user's guide to qualitative methods $\left(2^{\text {nd }}\right.$ ed. $)$. Thousand Oaks, USA: Sage Publications.

Ross, A., \& Hutchings, M. (2003). Attracting, developing and retaining effective teachers in the United Kingdom of Great Britain and Northern Ireland [OECD country background report]. London: London Metropolitan University, Institute for Policy Studies in Education.

Ryan, J., Pollock, K., \& Anonelli, F. (2009). Teacher diversity in Canada: leaky pipelines, bottlenecks, and glass ceilings. Canadian Journal of education, 32(3), 591-617. 
Saha, L. (1985). The legitimacy of early school leaving: Occupational orientations, vocational training plans, and educational attainment among urban Australian youth. Sociology of Education, 58(4), 228-240.

Sarney, E. (1996, June 23). Crisis in our schools. Sunday Star Times, p. 5.

Santoro, N. (2000, April). Cultural diversity in the teaching profession: a case study. Paper presented at the Annual Meeting of the American Education Research Association: New Orleans.

Santoro, N. (2007). "Outsiders" and "others": "different" teachers teaching in culturally diverse classrooms. Teachers and Teaching: Theory and Practice, 13(1), 81-97.

Schalm, P. \& Guan, J. (2009). Integrating internationally educated professionals: documenting university bridging programmes in Ontario. Ontario: Ryerson University, The G. Raymond Chang School for Continuing Education.

Schmidt, C. (2010). Systemic discrimination as a barrier for immigrant teachers. Diaspora, Indigenous, and Minority Education, 4(4), 235-252.

Schmidt, C., \& Block, L. (2010). Without and within: the implications of employment and ethnocultural equity policies for internationally educated teachers. Canadian Journal of Educational Administration and Policy, (100), 1-23. Retrieved from http://umanitoba.ca/publications/cjeap/pdf_files/schmidt_block-iet.pdf

Scott, D., \& Gini, P. (2010). How does New Z̄ealand's education system compare? OECD's Education at a Glance 2010. Wellington: Ministry of Education.

Seah, W. (2005). Negotiating about perceived value differences in Mathematics teaching: the case of immigrant teachers in Australia. Paper presented at the Conference of the International Group for the Psychology of Mathematics Education, Melbourne, Australia.

Seah, W., \& Bishop, A. (2002). Researching for validity and value: the negotiation of cultural value conflicts by immigrant teachers in Australia. Paper presented at the $83^{\text {rd }}$ Annual Meeting of the American Educational Research Association, New Orleans. Retrieved from http://www.education.monash.edu.au/research/groups/smte/projects/vamp/aera2 002.pdf

Setati, M., Adler, J., Reed, Y., \& Bapoo, A. (2002). Incomplete journeys: code-switching and other language practices in Mathematics, Science and English language classrooms in South Africa. Language and Education, 16(2), 128-149.

Sharplin, E. (2009). Bringing them in: The experiences of imported and overseasqualified teachers. Australian Journal of Education, 53(2), 192-206.

Shenton, A. K. (2004). Strategies for ensuring trustworthiness in qualitative research. Education for Information 22(2), 63-75.

Shulruf, B., Hattie, J., \& Tumen, S. (2008). The predictability of enrolment and first year university results from secondary school performance: the New Zealand National Certificate of Educational Achievement. Studies in Higher Education, 33(6), 685698.

Silverman, D. (2000). Doing qualitative research: A practical handbook. London: Sage.

Stake, R. (1995). The art of case study research. Thousand Oaks, CA: Sage.

Statistics New Zealand (2002). Census snapshot: Cultural diversity. Retrieved from http://www.stats.govt.nz/browse_for_stats/population/census_counts/censussnapshot-cultural-diversity.aspx 
Statistics New Zealand (2006a). Birthplace and people born overseas. Retrieved from http://www.stats.govt.nz/Census/2006CensusHomePage/QuickStats/quickstatsabout-a-subject/culture-and-identity/birthplace-and-people-born-overseas.aspx

Statistics New Zealand (2006b). Languages spoken. Retrieved from http://www.stats.govt.nz/Census/2006CensusHomePage/QuickStats/quickstatsabout-a-subject/culture-and-identity/languages-spoken.aspx

Stewart, R. (2010). Being an inclusive faculty in New Zealand schools. New Zealand Journal of Teachers' Work, 7(4), 47-52.

Stinebrickner, T. (2002). An analysis of occupational change and departure from the labour force: evidence of the reasons that teachers quit. The Journal of Human Resources (37)1, 192-216.

Subedi, B. (2008). Contesting racialization: Asian immigrant teachers" critiques and claims of teacher authenticity. Race, Ethnicity and Education, 11(1), 57-70.

Sutherland, H. \& Rees, S. (1995). Wasted lives? Access to the profession for overseas trained teachers. Adults Learning (England), 7(1), 17-19.

TeachNZ. (n.d.). Teaching in New Zealand: Finding a job. Retrieved from http://www.teachnz.govt.nz/teaching-in-new-zealand/finding-a-job/

Tellis, W. (1997). Application of a Case Study Methodology. The Qualitative Report, 3 (3), 1. Retrieved from http://www.nova.edu

Terre Blanche, M., \& Durrheim, K. (2002). Research in practice: Applied methods for the social sciences. Cape Town, South Africa: UCT Press.

United Nations Development Programme. (2013). Human development report 2013 The rise of the South: human progress in a diverse world. New York: United Nations Development Programme.

Vohra, V. (2005). From transition to professional integration: Indian immigrant teachers in New Zealand primary schools. (Unpublished master's thesis). University of Auckland: Auckland.

Voigt Graf, C., Iredale, R., \& Khoo, S. (2009). Teacher mobility in the Pacific region: Cook Islands, Fiji \& Vanuatu \& Australia and New Zealand. (Final project report, funded by the Australian Research Council, 2004-2006, ARC discovery grant DP 0450085). Canberra, ACT: Australian Research Council.

Walsh, S. (2008). Listening to difference in the teaching of English: insights from internationally educated teachers. Changing English, 15(4), 397-405.

Walsh, S., \& Brigham, S. (2007). Internationally educated teachers and teacher education programs in Canada: current practices [Report prepared for the Atlantic Metropolis Centre for Excellence]. Nova Scotia: Mount Saint Vincent University.

Walsh, S., Brigham, S., \& Wang, Y. (2011). Internationally educated female teachers in the neoliberal context: their labour market and teacher certification experiences in Canada. Teaching and Teacher Education, 27, 657-665.

Ward, C., \& Masgoret, A. (2008). Attitudes toward immigrants, immigration, and multiculturalism in New Zealand: A Social Psychological analysis. International Migration Review, 42(1), 227-248.

Warner, L. (2010). Overseas trained teachers: part of a problem or part of a solution? Tean Journal 1(2), 1-19. Retrieved from 
http://www.cumbria.ac.uk/AboutUs/Subjects/Education/Research/TEAN/TEANJo urnal.aspx

Wotherspoon, T. (1989). Immigration and the Production of a Teaching Force: Policy Implications for Education and Labour. International Migration, 27(4), 543-562.

Woulfe, C. (2008, June 29). Surge in foreign teachers fills gap but worries schools. Sunday Star Times.

Zhao, Y. (2009). Catching up or leading the way: American education in the age of globalization. Alexandria: Association for Supervision \& Curriculum Development. 


\section{Appendix A: Information sheet for participants}

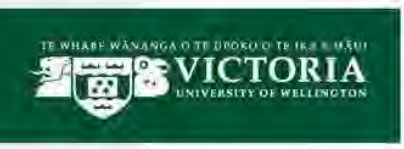

FACULTY OF EDUCATION

TE WHANAUU D AKO PAI

VICTORIA UNIVERSITY OF WELLINGTON, PO Box 71.310, Do ohald St, Karon, Wellington 6147, New Zealand

Phone + 64-4-4639500 Fax +64-4-463 9649 Email pgeducation Ovuw ac. nz

Web www victoria. ac.nzleducation

\section{INFORMATION SHEET FOR PARTICIPANTS}

Research Title: Journeys into teaching: The pathways followed by immigrant teachers into a career secondary school teaching in New Zealand

Researcher: Celia Stanyon, School of Psychology and Pedagogy, Victoria University of Wellington

Supervisors: Anne Yates anne.yates@vuw.ac.nz and Professor Dugald Scott

dugald.scott@vuw.ac.nz

Dear Fellow Teacher

Thank you for your interest in being interviewed. You have been contacted because you are an overseas-trained teacher who has immigrated to New Zealand between 2006 and 2011 and successfully found teaching employment in your new country of residence. I would like to interview you regarding the pathway that you followed to gain full-time, permanent work as a secondary school teacher in New Zealand.

I would like to take this opportunity to describe the study so that you might decide whether it is something that you would feel comfortable being a part of. If you choose to complete the attached consent form then your interview, along with the interviews of up to ten other overseas-trained teachers who have immigrated to New Zealand and been successful at gaining employment in New Zealand, will provide information on some of the possible pathways to gaining teaching employment in New Zealand. This information could assist teachers who have arrived in the country with the legal right to live and work in New Zealand to navigate their way into teaching posts. The pathways presented could further assist in supporting immigrant teachers from a diversity of cultures to find teaching positions in order to reflect the diversity of the student population. The information could also help with the efficient filling of those teaching posts vacated by New Zealand trained teachers who choose to teach abroad and those vacancies created by retiring teachers.

If you choose to sign the enclosed informed consent form then I will contact you to make an appointment to meet with you at a time and place convenient to you. At that meeting I would like to interview you for approximately one hour and to record the interview so that the information that you share is not misunderstood or misconstrued by me. A copy of the questions that will be asked at the interview is enclosed with this letter. I will transcribe the interview and identifying details such as your name, place of work and location will be altered to ensure confidentiality. A copy of the interview transcript will be provided to you in February 2012 and I will meet with you in order to give 
you the opportunity to provide clarification and feedback. You will be welcome to withdraw from the study or to refrain from answering any question at any fime prior to the write up of the findings. Write up will commence in May 2012

Information collected during the course of this study will only be viewed by me and my two supervisors. Information will be saved securely on my personal computer at home and destroyed upon completion of the project.

It is important to note that parts of the interview transcript might be quoted in the thesis resulting from this research study, and that the thesis will be entered into the Victoria University library. From there it will be accessible to staff, students and other stakeholders. Quotations from the interview transcripts may also be published in journals and presented at conferences

The VUW Faculty of Education Ethics Committee has approved the ethical application (Reference Number SEPP/2011/66 RM 18810). Any concerns about the project are to be addressed to Dr. Allison Kirkman, Chair of the VUW Human Elhics Committee at allison kirkman@vuw ac nz

Please complete the enclosed Informed Consent form and return it to celia.stanyon@vuw.ac.nz or P. B Box 7451, Newtown, Wellington, 6242.

Thank you for your assistance

Kind regards

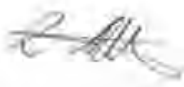

Celia Stanyon 


\section{Appendix B: Interview questions}

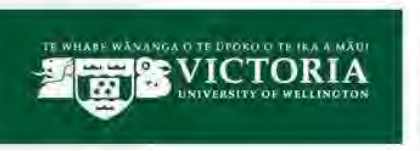

FACULTY OF EDUCÁTION

TEWHANAU O AKO PAI

VICTORIA UNIVERSITY OF WELLINGTON, POO Box 71 .310, Donald St, Karoni, Wellington 6147 , New Zealand

Phone + 64-4-4639500 Fax +64-4-4639648 Email pgeducation @vuw.ac.nz

Web www.victoria.ac.nzleducation

Interview Questions

Section 1: Demographics

Name:

Female $\square \quad$ Male $\square$

1.) Country of Origin:

2.) First Language:

3.) Other Language(s):

4.) Qualification(s):

5.) Visa Type:

6.) Initial NZTC registration type granted:

7.) Current NZTC registration type:

8.) Years of teaching experience prior to arrival in New Zealand:

9.) Teaching subjects: 


\section{Section 2: Interview Questions}

1) Could you please tell me your story of coming to New Zealand and getting a job in a secondary school?

2.) What were the challenges for you in the process?

3.) How did you overcome them?

4) Were there critical points for you in the process?

5. What advice would you give to someone going through this process?

Thank you! 


\section{Appendix C: Consent form}

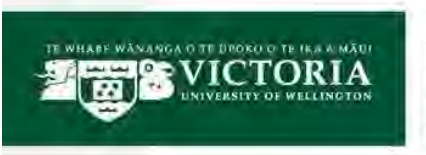

FACULTY OF EDUCÁTION

TE MHAMNAU D AKO PAI

VICTORIA UNIVERSITY OF WELLINGTON, PO Box 71-310, Donald St, Karon, Wellingten 6147, New Zealanid

Phone + 64-4-4639500 Fax +64-4-463 9649 Email pgeducation @vuw ac $n z$

Web www. victoria.ac.nz/education

\section{Consent Form}

Research Title: Journeys into teaching: The pathways followed by immigrant teachers into a career secondary school teaching in New Zealand

Researcher: Celia Stanyon, School of Psychology and Pedagogy, Victoria University of Wellington

Supervisors: Anne Yates and Professor Dugald Scott

\begin{tabular}{|l|l|}
\hline Name: & \\
\hline Surname: & \\
\hline E-mail: & \\
\hline Telephone: & \\
\hline I would like to receive a copy of the completed Masters thesis: $\mathrm{Y} \square \quad \mathrm{N} \square$ \\
\hline
\end{tabular}

I have read and understood the enclosed covering letter and interview questions. $Y_{\square} \mathrm{N} \square$

I consent to:
a.) being contacted to arrange an interview. $\mathrm{Y} \square \mathrm{N} \square$
b.) being interviewed and having the interview recorded. $Y_{\square} N \square$
c.) the recording being transcribed. $Y_{\square} N \square$
d.) meet to discuss the interview transcript. $Y_{\square} \quad \mathrm{N} \square$
e.) relevant quotations from the transcription being included in the completed Masters thesis. $\mathrm{Y} \square \mathrm{N} \square$
f.) having my name and other identifying details changed to protect confidentiality. $\mathrm{Y} \square \mathrm{N} \square$
g.) the publication of material in journal articles. $\mathrm{Y} \square \mathrm{N} \square$
h.) the publication of material in conference papers. $Y \square \quad N \square$ 
I understand that the thesis will be entered into the Victoria University library and will be accessible to staff, students and other stakeholders. $Y_{\square} \mathrm{Na}$

I am aware that I am able to withdraw from or refuse to answer any question at any time prior to the write up of the findings in April 2012. Y $\square \mathrm{N} \square$

If you have any questions or would like any further information regarding the study please contact Celia Stanyon at celia stanyon@vuw.ac.nz

Your signature below means that you voluntarily agree to participate in this study.

Name:

Signature: Date: 


\section{Appendix D: Data collection calendar}

\begin{tabular}{|c|c|}
\hline Month & Collection \\
\hline 25 November 2011 & Interviewed Tom \\
\hline 26 November 2011 & Interviewed Emily \\
\hline $4-15$ January 2012 & Transcribed Tom"s interview \\
\hline $16-26$ January 2012 & Transcribed Emily"s interview \\
\hline 7 February 2012 & Transcript to Tom for review \\
\hline 8 February 2012 & Tom verified transcript \\
\hline 8 February 2012 & Transcript to Emily for review \\
\hline 8 February 2012 & Interviewed Alabama \\
\hline 12 February 2012 & Emily verified transcript \\
\hline $11-20$ February 2012 & Transcribed Alabama"s interview \\
\hline 24 February 2012 & Interviewed Josh \\
\hline 25 February - 4 March 2012 & Transcribed Josh"s interview \\
\hline 25 February 2012 & Transcript to Alabama for review \\
\hline 26 February 2012 & Alabama verified transcript subject to minor changes \\
\hline 1 March 2012 & Interviewed Leonard \\
\hline 1 - 3 March 2012 & Transcribed Leonard"s interview \\
\hline 3 March 2012 & Transcript to Leonard for review \\
\hline 4 March 2012 & Transcript to Josh for review \\
\hline 20 March 2012 & Josh verified transcript \\
\hline 5 April 2012 & Leonard verified transcript \\
\hline 19 April 2012 & Interviewed Doug \\
\hline 20 April 2012 & Transcribed Doug"s interview \\
\hline 29 April 2012 & Transcript to Doug for review \\
\hline 29 April 2012 & Doug verified transcript \\
\hline 22 August 2012 & Tom verified draft of „Tom"s Journey" \\
\hline 23 August 2012 & Doug verified draft of „Doug"s Journey" \\
\hline 23 August 2012 & Emily verified draft of „Emily"s Journey" \\
\hline 23 August 2012 & Alabama verified draft of "Alabama"s Journey" \\
\hline 26 August 2012 & Leonard verified draft of „Leonard"s Journey" \\
\hline 27 August 2012 & Josh verified draft of „Josh"s Journey" \\
\hline
\end{tabular}


Appendix E: Research journal - entry 1

Section 1: Demographics

Name:

Celia Elaine Stanyon

Female

1.) Country of origin: South Africa

2.) First language: English

3.) Other language(s): $\quad$ Afrikaans

4.) Qualification(s): Bachelor of Arts (Honours)

Postgraduate Certificate in Education

Honours Degree in Psychology

5.) Visa type: Permanent Resident Visa

6.) Initial NZTC registration type: Provisional Teacher Registration

7.) Current NZTC registration: Not currently registered

8.) Years of teaching experience prior to arrival in New Zealand: Five

9.) Teaching Subjects: English

Social Studies 


\section{Section 2: Interview questions}

1.) Could you please tell me your story of coming to New Zealand and getting a job in a secondary school?

I had five years of teaching experience, a Permanent Resident Visa, comparable qualifications (assessed by NZQA), and Provisional Teacher Registration. I applied for and did not secure work as a teacher in New Zealand. After three months in New Zealand without an interview at a school I applied for work outside of teaching and, oddly, was awarded the first job I applied for which, interestingly, happened to be more lucrative than teaching.

2.) What were the challenges for you in the process?

a.) Applying for positions I was qualified and experienced to fill and not receiving invitations to interview was challenging.

b.) Being interviewed and told I had done well but couldn"t be hired as I had no New Zealand teaching experience was challenging.

3.) How did you overcome them?

a.) I enrolled in a Master of Education and was given information by a fellow student about how to write a CV for the New Zealand context. I rewrote my CV, applied for jobs and was invited to two interviews.

b.) I realised that without New Zealand teaching experience I could not get a job and I could not gain New Zealand experience without a job. This situation was an effective catalyst for a career change. 
4.) Were there critical points for you in the process?

A critical point was the day I decided to look for work outside of teaching. To analyse the situation and make the decision to turn away from a career I had chosen, with a view to being part of preparing the next generation for adult life, was difficult. Being a teacher had significance to me. Being in the privileged position to have involvement in the education of young people had great value to me.

5.) What advice would you give to someone going through this process?

The experiences of the wonderful people who shared their stories with me are really interesting and some might resonate with you. Read those stories or chat to anyone who is willing to speak to you about what they have learned through immigrating. You might find someone you talk to will have that key bit of information that will open up teaching in New Zealand for you. 